\title{
WestVirginiaUniversity
}

THE RESEARCH REPOSITORY @ WVU

Graduate Theses, Dissertations, and Problem Reports

2006

\section{Chemotherapy disrupts bone marrow stromal cell function}

\author{
Suzanne Davis Clutter \\ West Virginia University
}

Follow this and additional works at: https://researchrepository.wvu.edu/etd

\section{Recommended Citation}

Clutter, Suzanne Davis, "Chemotherapy disrupts bone marrow stromal cell function" (2006). Graduate Theses, Dissertations, and Problem Reports. 2397.

https://researchrepository.wvu.edu/etd/2397

This Dissertation is protected by copyright and/or related rights. It has been brought to you by the The Research Repository @ WVU with permission from the rights-holder(s). You are free to use this Dissertation in any way that is permitted by the copyright and related rights legislation that applies to your use. For other uses you must obtain permission from the rights-holder(s) directly, unless additional rights are indicated by a Creative Commons license in the record and/ or on the work itself. This Dissertation has been accepted for inclusion in WVU Graduate Theses, Dissertations, and Problem Reports collection by an authorized administrator of The Research Repository @ WVU.

For more information, please contact researchrepository@mail.wvu.edu. 


\title{
Chemotherapy Disrupts Bone Marrow Stromal Cell Function
}

\author{
Suzanne Davis Clutter \\ Dissertation submitted to the School of Medicine at West Virginia University in partial \\ fulfillment of the requirements for the degree of
}

\author{
Doctor of Philosophy \\ In \\ Microbiology and Immunology \\ Laura F. Gibson, Ph.D., Chair \\ Solveig G. Ericson, M.D., Ph.D. \\ Bing Hua-Jiang, Ph.D \\ Kenneth S. Landreth, Ph.D. \\ William Petros, Pharm.D. \\ Department of Microbiology and Immunology \\ Morgantown, West Virginia \\ 2006
}

Key Words: Microenvironment, CXCL12, chemotherapy, bone marrow, hematopoiesis, stromal cell, transplant, MMP-2 


\title{
Abstract
}

\section{Chemotherapy Disrupts Bone Marrow Stromal Cell Function}

\author{
Suzanne Davis Clutter \\ Advisor: Laura F. Gibson, Ph.D. Associate Professor Department of Pediatrics
}

A variety of bone marrow microenvironment derived signals influence steady state hematopoiesis as well as hematopoietic recovery following bone marrow transplantation. Bone marrow stromal cells found in this unique anatomical niche influence hematopoiesis, in part, through production of soluble cytokines and chemokines. Developmental signals are also initiated by physical interaction of hematopoietic progenitor cells with stromal cells which are mediated by binding of their integrins to receptors on the stromal cell surface. Finally, the extracellular matrix, including may components produced by stromal cells, provides structure as well as a scaffold on which hematopoietic growth factors can be concentrated and stabilized in the marrow. Efficient hematopoietic recovery following transplantation of stem or immature progenitor cells requires sustained function of these components of the bone marrow during dose escalated chemotherapy.

In the current study we investigated the effects of the chemotherapeutic agent etoposide (VP-16) on bone marrow stromal cell function. We have previously demonstrated that stromal cells chronically exposed to VP-16 display diminished extra-cellular levels of SDF-1 resulting in disrupted support of pro-B cell chemotaxis. We have also determined that bone marrow stromal cell MMP-2 protein is diminished following exposure to VP-16. Regulation of MMP-2 is required for release of SDF-1 from stromal cell surfaces and ultimately required for optimal support of chemotaxis. Additionally, VP-16 treatment results in alterations of pathways that regulate protein translation, consistent with diminished translation of MMP-2 protein in treated stromal cells. We also determined that following acute VP-16 exposure, MMP-2 activation was transiently increased. Increased MMP-2 activity resulted in activation of TGF- $\beta$, which resulted in diminished stromal cell support of pro-B cell adhesion and survival. Collectively, these data contribute to our understanding of the global impact of chemotherapy on the bone marrow microenvironment. 


\section{Dedication}

I dedicate this dissertation to my parents, Charles and Elizabeth Davis, who have always encouraged my dreams and believed in my ability to achieve them and to my husband, Chad Clutter, whose sacrifices have made my dreams come true. 


\section{Acknowledgments}

I am forever indebted to my advisor, Laura Gibson, for her unwavering dedication and support throughout my graduate education. My experiences with Dr. Gibson have enriched my life on both a professional and personal level. I hold her in the highest esteem and deeply appreciate the opportunity of working under her supervision.

I am grateful to the members of my committee, Dr. Kenneth Landreth, Dr. Solveig Ericson, Dr. Bing Hua-Jiang, and Dr. William Petros for their support throughout the course of my graduate studies. They have provided much insight and encouragement that aided in the completion of these studies.

Finally I would like to thank all the members of the Gibson laboratory, both past and present, for their help and support. I am especially thankful for the interactions with Jim Fortney, Heather O’Leary, and Brett Hall which have resulted in valuable friendships. 


\section{Table of Contents}

Chemotherapy Disrupts Bone Marrow Stromal Cell Function...................... i

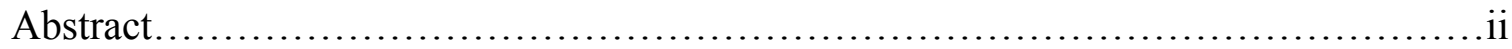

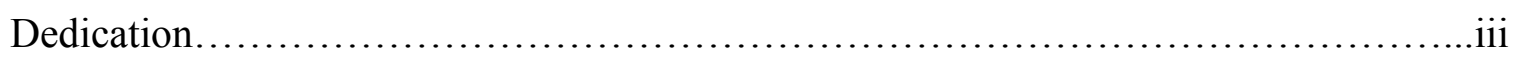

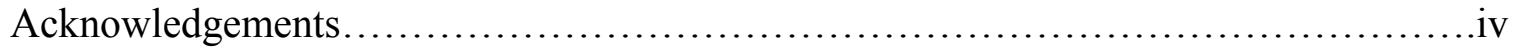

Table of Contents.............................................................

Abbreviations ............................................................. viii

\section{Chapter I}

Introduction and Review of Literature.......................................

I. Hematopoiesis....................................................

II. Bone Marrow Microenvironment..........................................

III. Extracellular Matrix................................................20

IV. Hematopoietic Cell Trafficking........................................29

V. $\quad$ References....................................................... 34

\section{Chapter II}

MMP-2 Is Required for Bone Marrow Stromal Cell Support of Chemotaxis........59

Abstract......................................................................60

Introduction.............................................................61

Materials and Methods.....................................................63 
Results................................................................. 70

Discussion............................................................. 73

Acknowledgements.................................................... 77

References............................................................. 78

Figure Legends........................................................ 83

Figures.............................................................. 86

\section{Chapter III}

Activation of TGF- $\beta 1 / p 38 /$ Smad3 Signaling in Stromal Cells Requires ROS-Mediated MMP-2 Activity During Bone Marrow Damage............................ 91

Abstract.............................................................. 92

Introduction.......................................................... 93

Materials and Methods...................................................95

Results..............................................................103

Discussion.............................................................. 110

Acknowledgements..................................................... 115

References............................................................ 116

Figure Legends....................................................... 124

Figures............................................................ 129

\section{Chapter IV}

Etoposide Disrupts Activity of Translational Regulatory Proteins in Bone Marrow Stromal

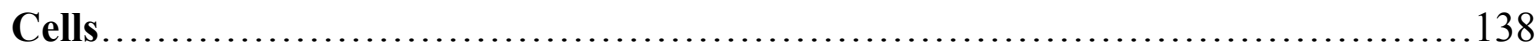


Abstract................................................................. 139

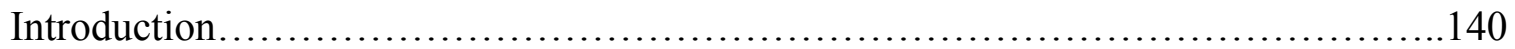

Materials and Methods....................................................... 143

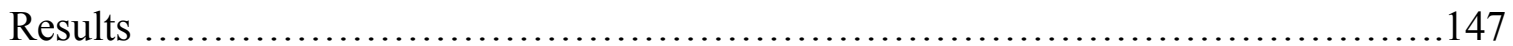

Discussion.............................................................. 150

References............................................................... 153

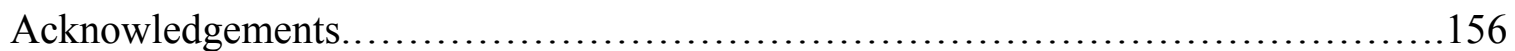

Figure Legends...................................................... 157

Figures.......................................................................

\section{Chapter V}

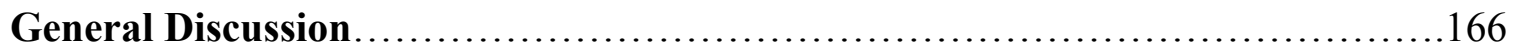

References............................................................. 176

Curriculum Vitae......................................................... 179 


\section{Abbreviations}

$\begin{array}{ll}\text { 4EBP-1 } & \text { 4E-Binding Protein-1 } \\ \text { 4-HC } & \text { 4-hydroperoxycyclophosphamide } \\ \text { 5'TOP } & \text { 5' Tract of Pyrimidines } \\ & \\ \text { a-MEM } & \text { Alpha Modification of Eagles Medium } \\ \text { AGM } & \text { Aorta-Gonads-Mesonephros } \\ \text { AML/RUNX1 } & \text { Runt-Related Transcription Factor } \\ \text { BCA } & \text { Bicinchoninic acid } \\ \text { bFGF } & \text { basic Fibroblast Growth Factor } \\ \text { BMP } & \text { Bone Morphogenic Protein } \\ \text { BMT } & \text { Bone Marrow Transplant } \\ & \\ \text { CBP } & \text { Creb-Binding Protein } \\ \text { CCL11 } & \text { Eotaxin Chemokine } \\ \text { CGT } & \text { Ceremide Galactosyltransferase } \\ \text { CXCR4 } & \text { CXC Receptor-4 } \\ \text { CCLB } & \text { Complete Cell Lysis Buffer } \\ & \\ \text { DBH } & \text { Dopamine } \beta \text {-Hydroxylase } \\ \text { DMSO } & \text { Dimethyl Sulfoxide } \\ \text { DNR } & \text { Daunorubicin } \\ \text { Dox } & \text { Doxorubicin } \\ \text { DPP-IV } & \text { Dipeptidyl Peptidase-IV } \\ \text { dsRNA } & \text { double stranded RNA } \\ \text { EAE } & \text { Experimental Autoimmune Encephalomyelitis } \\ \text { ECM } & \text { Extra-cellular Matrix } \\ \text { eIF4A } & \text { Eukaryotic Initiation Factor-4A } \\ \text { eIF-4E } & \text { Eukaryotic Initiation Fctor-4E } \\ \text { eIF4G } & \text { Eukaryotic Initiation Factor-4G } \\ \text { ELISA } & \text { Enzyme Linked Immunosorbent Assay } \\ \text { EPO } & \text { Erythropoietin } \\ \text { EPOR } & \text { Erythropoietin Receptor } \\ \text { FGF } & \text { Fibroblast Growth Factor } \\ \text { FLK1 } & \text { Fetal Liver Kinase-1 } \\ \text { FLK-2 } & \text { Fetal Liver Kinase-2 } \\ \text { GAG } & \text { Glycosaminoglycan } \\ \text { GAPDH } & \text { Glyceraldehyde-3-Phosphate Dehydrogenase } \\ \text { GATA1 } & \text { Globin Transcription Factor-1 } \\ & \end{array}$


G-CSF

GM-CSF

GRO- $\alpha$

$\mathrm{H}_{2} \mathrm{O}_{2}$

HIM

HSC

HSCT

ICAM-1

IGF-1

IL-1

IL-3

IL-4

IL-5

IL-6

IL-7

IL-7R

IL-9

IL-11

IL-12

INF- $\gamma$

JAK2

LAP

LFA-3

LIF

$\mathrm{LMO} 2$

LTBP

LTMC

MAPK

M-CSF

Mel

MHC-II

MIP-1 $\alpha$

MMP

MMP-2/-/MMP-2KO

mRNA

NAC

N-CoR

$\mathrm{NE}$

NPII
Granulocyte Stimulating Factor

Granulocyte-Macrophage Colony Stimulating Factor

Growth-Related Activity- $\alpha$

Hydorgen Peroxide

Hematopoietic Inductive Microenvironment

Hematopoietic Stem Cell

Hematopoietic Stem Cell Transplant

Intracellular Adhesion Molecule-1

Insulin-like Growth Factor-1

Interleukin-1

Interleukin-3

Interleukin-4

Interleukin-5

Interleukin-6

Interleukin-7

Interleukin-7 Receptor

Interleukin-9

Interleukin-11

Interleukin-12

Interferon- $\gamma$

Janus Kinase-2

Latency Associated Protein

Leukocyte Functional Antigen-3

Leukemia Inhibitory Factor

T-cell Leukemia LIM Protein

Latent TGF- $\beta$ Binding Protein

Long-Term Marrow Culture

Mitogen-Activated Protein Kinase

Macrophage Colony Stimulating Factor

Melphalan

Major Histocompatibility Complex Type-II

Macrophage Inflammatory Protein- $1 \alpha$

Matrix Metalloproteinase

Matrix Metalloproteinase-2 Knockout

messenger RNA

N-Acetyl-Cysteine

Nuclear Receptor Co-Repressor

Norepinephrine

Neomycin Phosphotransferase II 


$\begin{array}{ll}\text { OA } & \begin{array}{l}\text { Okadiac Acid } \\ \text { cis-9-octadecenoyl-N-hydroxylamide }\end{array} \\ \text { PI } & \text { Propidium Iodide } \\ \text { PP1 } & \text { Protein Phosphatase-1 } \\ \text { PP2A } & \text { Protein Phosphatase-2A } \\ \text { PP2A/c } & \text { Protein Phosphatase-2A catalytic subunit } \\ \text { PP2B } & \text { Protein Phosphatase-2B } \\ \text { RAG1 } & \text { Recombinase-Activating Enzyme-1 } \\ \text { ROS } & \text { Reactive Oxygen Species } \\ \text { SCF } & \text { Stem Cell Factor } \\ \text { SDF-1 } & \text { Stromal Cell Derived Factor-1/CXCL12 } \\ \text { SDS-PAGE } & \text { Sodium Dodecyl Sulfate-Polyacrylamide Gel Electrophoresis } \\ \text { siRNA } & \text { short interfering RNA } \\ \text { TAL1/SCL } & \text { T-cell Acute Leukemia-1/Stem Cell Leukemia } \\ \text { TDT } & \text { Terminal Deoxynucleotidyl Transferase } \\ \text { TGF- } \beta & \text { Transforming Growth Factor- } \beta \\ \text { TGM } & \text { Transfection Growth Medium } \\ \text { TIMP } & \text { Tissue Inhibitor of Matrix Metalloproteinase } \\ \text { TNF } \alpha & \text { Tumor Necrosis Factor- } \alpha \\ \text { VCAM-1 } & \text { Vascular Cell Adhesion Molecule-1 } \\ \text { VCR } & \text { Vincristine } \\ \text { XLA } & \text { X-Linked Agammaglobinemia }\end{array}$




\section{CHAPTER I}

INTRODUCTION AND REVIEW OF LITERATURE 


\section{Hematopoiesis}

\section{Prenatal Hematopoiesis}

Hematopoiesis, defined as the development of blood cells, initiates in the embryo and development is characterized by migration of immature immune cells from one supportive niche to the next (1). The first sites of hematopoiesis in the developing embryo of both human and mouse are the extra-embryonic yolk sac and the intraembryonic aorta-gonads-mesonephros (AGM) region. The extra-embryonic yolk sac is the site of blood island formation which is where hematopoiesis originates. In mice, primitive hematopoiesis occurs in the blood islands of the yolk sac at embryonic day 7.5 and in humans this process begins at embryonic day 15 and continues for 6 weeks (2). In the yolk sac the only blood lineage cells which develop are nucleated erythrocytes containing fetal hemoglobin and macrophages (3), therefore the yolk sac is referred to as a primitive hematopoietic organ.

The AGM is the site of definitive hematopoiesis, with the process initiating in mice at embryonic day 10.5 and in humans at embryonic day 30. It is in the AGM that development of the first hematopoietic stem cell occurs $(4 ; 5)$. Because all hematopoietic cell types can differentiate from this pluripotent stem cell, the AGM is considered the site of initiating definitive hematopoiesis.

Hematopoiesis shifts to the fetal liver at embryonic day 12.5 in mice and at approximately 6 weeks in humans. The fetal liver is the site where constitution of the immune system occurs and hematopoiesis primarily resides during embryogenesis (6). Embryonic HSC migration to the fetal liver is regulated by integrin and chemokine expression. $\beta 1$ integrin expression is required for HSC colonization of fetal liver (7) and $\alpha 4$ is necessary for fetal T-cell 
development (8). In addition, deletion of the chemokine stromal cell derived factor-1 (SDF1/CXCL12) or its receptor CXCR4 blocks fetal liver B-cell hematopoiesis (9-11). The fetal liver provides a microenvironment in which expansive proliferation of HSCs occurs $(6 ; 12)$. In humans hematopoiesis shifts during the second and third trimesters of gestation to the bone marrow and thymus (13).

\section{Postnatal Hematopoiesis}

The primary site of postnatal hematopoiesis is the bone marrow. Blood cells are short lived and therefore need to be continuously replenished throughout life. In addition, following infection or blood loss, production of all blood cell types is essential. The bone marrow microenvironment provides all of the necessary requirements for hematopoiesis including growth factors and adhesive interactions for blood cell development, which originates from the HSC. Specific components of the microenvironment are described in more detail in section II.

The existence of a HSC was first suggested in 1909 by Alexander Maximow (14), with more convincing evidence for a HSC provided in 1960. At that time, Till and McCulloch transplanted bone marrow cells into irradiated mice and observed colony forming units in the spleen (15). However, the term hematopoietic stem cell wasn't coined until 1962 by Goodman and Hodgson (16). The phenotype of human HSCs is CD34 ${ }^{+}$, Lineage $\mathrm{S}^{-}$Sca- $1^{+}, \mathrm{c}^{-k i t^{+}}$. These pluripotent cells are found primarily adherent to osteoblasts in the "HSC niche" $(17 ; 18)$ as a noncycling population (19). Plasticity of HSC allows the differentiation into immune cells of the lymphoid and myeloid lineages, including B-cells, T-cells, neutrophils, basophils, dendritic cells, mast cells, macrophages, eosinophils, erythrocytes, and platelets, while maintaining the potential to self-renew (Figure 1). Differentiation into lineage specific cells is regulated by stimulatory 
and inhibitory cytokines, and thymic or bone marrow stromal cells. In a healthy human, following maturation, lineage specific hematopoietic cells exit the bone marrow into the peripheral blood as functional mature cells.

Steady-state hematopoiesis requires a balance of proliferation, differentiation, and survival. Numerous factors regulate hematopoiesis, with pronounced redundancy. For example, as many as seven different growth factors can stimulate the proliferation of megakaryocytes colonies in culture (20). IL-3 can differentially regulate stem cells, erythrocytes, macrophages, eosinophils, megakaryocytes, mast cells, and B-lymphocyte precursors $(20 ; 21)$. Like other necessary biological functions, redundancy within the system underscores the importance of balanced, sustained hematopoiesis.

In contrast to evidence of redundancy, knockout mouse models have identified hematopoietic defects that suggest several critical factors are both required and unique. Several essential genes have been identified in primitive and definitive hematopoiesis including T-cell acute leukemia-1/stem cell leukemia (TAL1/SCL) (22), T-cell leukemia LIM protein LMO2 (23), globin transcription factor-1 (GATA1) (24), fetal liver kinase-1 (FLK1) (25), the protein tyrosine kinase, Tie2 (26), and creb-binding protein (CBP) (27). Mice in which these genes have been knocked out die embryonically and exhibit a marked reduction in yolk sac hematopoiesis and absence of fetal liver hematopoiesis. Many other genes including runt-related transcription factor (AML/RUNX1) (28), GATA2 (29), c-MYB (30), c-kit (31) erythropoietin (EPO) (32) or erythropoietin receptor (EPOR)(32;33), janus kinase-2 (JAK2) (34), the transcription factor, Pu.1 (35), Ikaros (36), Lim homeodomain (LHX) (37), nuclear receptor co-repressor (N-CoR) (38), and RELA (39) are also imperative for definitive hematopoiesis. Mice lacking these genes are also, for the most part, embryonic lethals. The exception is c-kit knockout mice which die at 
birth and Ikaros knockout mice which remain viable, but which have diminished HSC generation and proliferation. Mice lacking the genes required for definitive hematopoiesis typically display normal yolk sac hematopoiesis, but reduced or blocked fetal liver hematopoiesis. Mutation of genes including $\beta-1$ integrin (7), $\alpha-4$ integrin (8), and SDF-1 (9) or its receptor CXCR4 (10;11), which regulate migration of hematopoietic cells and colonization of hematopoietic organs, also result in embryonic lethality. Most of these genes listed which influence hematopoiesis encode transcription factors, receptor tyrosine kinases, and adhesion molecules. Mice lacking the genes described above, display ablation of hematopoiesis, however loss of additional proteins, not discussed, are capable of disrupting lineage-specific hematopoiesis. 


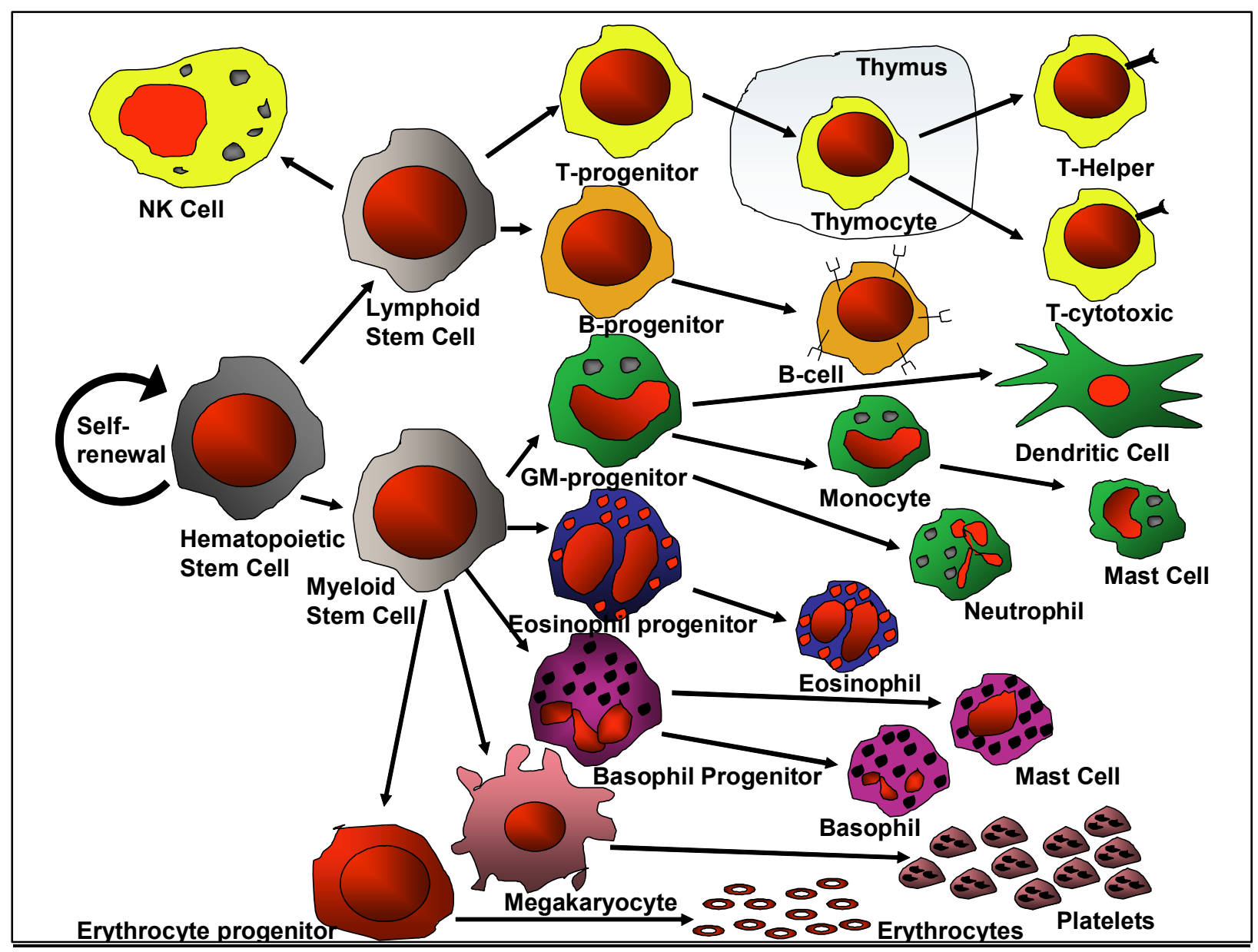

Figure 1: Postnatal Hematopoiesis originates in the bone marrow and thymus from HSCs. 


\section{Bone Marrow Microenvironment}

\section{Anatomy of the Bone Marrow}

The bone marrow microenvironment or hematopoietic microenvironment is defined as the local network of stromal cells including fibroblasts, macrophages, endothelial cells and adipocytes, accessory cells such as T-lymphocytes and monocytes, and their products including extra-cellular matrix and cytokines. All of these factors are capable of influencing self-renewal, proliferation and differentiation of hematopoietic stem and progenitor cells (40). The hematopoietic microenvironment was first described in 1966 from studies by Curry and Trenton who called it the "hematopoietic inductive microenvironment" (HIM). Their work suggested the HIM is radioresistant, since hematopoiesis was supported in irradiated mice transplanted with bone marrow cells (41). In addition to the bone marrow which supports more than $95 \%$ of adult hematopoietic activity (40), the spleen can also act as a hematopoietic organ (42) under certain conditions, such as stress. Till and McCulloch also observed that hematopoiesis was established in the bone marrow and to a lesser extent in the spleen (15), providing further evidence for specific microenvironments in which hematopoiesis is accomplished.

As defined above, the hematopoietic microenvironment is a network of cells and extracellular matrix which physically supports and influences the proliferation, differentiation, and survival of hematopoietic cells (40). It has been suggested that hematopoiesis occurs in localized microgeographical regions within the bone marrow and that the spatial distribution of lineage specific hematopoiesis is not random (43). The specific hematopoietic "niche" will be discussed in detail later, however, it is thought that in mammals hematopoiesis occurs in the extra-vascular spaces between marrow sinuses (Figure 2) (44). Histological examinations of the bone marrow 


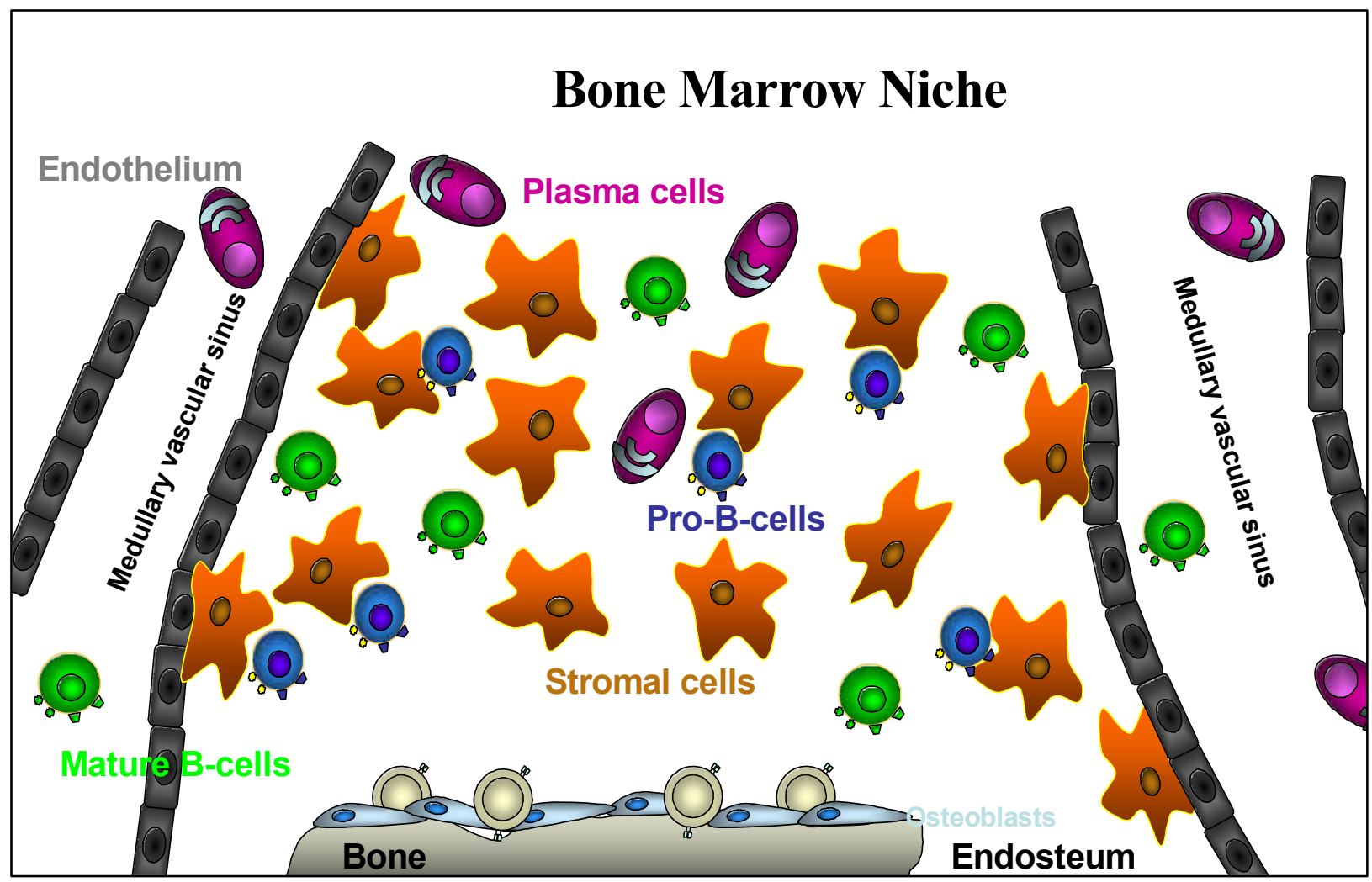

Figure 2. Anatomy of the B-cell niche within the bone marrow microenvironment. 
have identified the location of very immature hematopoietic cells concentrated within the subendosteal areas, while more differentiated hematopoietic cells are located towards the center of bone, away from the endosteum $(45 ; 46)$. The sinus wall is lined with adventitial reticular cells which aid in migration of mature blood cells from the marrow to the circulation (47). Reticular cells comprise the majority of non-hematopoietic bone marrow cells. Along with adventitial reticular cells, the bone marrow microenvironment also contains fibroblastic reticular cells which play a major role in regulation of hematopoiesis (40). Throughout this dissertation "bone marrow stromal cells" or "stroma" specifically refer to the fibroblastic reticular cells described above.

\section{Bone Marrow Stromal Cells}

Bone marrow stromal cells were first identified in culture by the fibroblastic colony forming unit assay (CFU-F) assay (48) and were demonstrated to be capable of supporting hematopoiesis (49). Stromal cells are adherent, clonogenic, non-phagocytic, and can be isolated from the bone marrow of post-natal mammals $(44 ; 50)$. Stromal cells produce several cytokines which are known to regulate hematopoiesis including granulocyte-macrophage colonystimulating factor (GM-CSF), interleukin-1 (IL-1), IL-3, IL-5, IL-6, IL-7, IL-11, IL-12, leukemia inhibitory factor (LIF), fibroblast growth factor (FGF), stem cell factor (SCF), FLT-3 ligand, ckit, macrophage colony stimulating factor (M-CSF), insulin-like growth factor-1 (IGF-1) and tumor necrosis factor- $\alpha$ (TNF- $\alpha$ ) (51-56). Stromal cells also produce interferon- $\gamma$ (INF- $\gamma$ ), transforming growth factor- $\beta$ (TGF- $\beta$ ), and macrophage inflammatory protein-1 $\alpha$ (MIP-1 $1 \alpha)$ which serve as negative regulators of hematopoiesis (53-55). Identification of granulocytestimulating factor (G-CSF), IL-3, and IL-4 in murine and human stromal cell lines has not been repeatedly detected $(51 ; 53 ; 54)$. 
In addition to growth factors, bone marrow stromal cells also express adhesion molecules and receptors responsible for physical contact with hematopoietic cells which are imperative for regulation of hematopoiesis. Stroma express the extra-cellular matrix proteins including collagen I, III, IV, V, VI, fibronectin, vitronectin, laminin, thrombospondin, hemonectin, and tenascin. Stromal cells also produce proteoglycans such as chondroitin sulfate, heparin sulfate, CD44, and hyaluronate and cellular adhesion molecules (CAMs) including intracellular adhesion molecule-1 (ICAM-1/CD54), N-CAM (CD56), vascular cell adhesion molecule-1 (VCAM1/CD106), leukocyte functional antigen-3 (LFA-3/CD58), $\alpha_{v} \beta_{3}$, and Thy-1 (CD90) (57-64). A complete list of proteins expressed by stromal cells have been elucidated by micro-array (52), however, their specific contribution to hematopoiesis, in many cases has yet to be determined. Work described in Chapters 2 and 3 will specifically address the role of matrix metalloproteinase-2 (MMP-2) in stromal cell support of hematopoiesis.

Bone marrow stromal cells were first demonstrated as capable of supporting hematopoietic cells by Dexter, Whitlock, and Witte $(65 ; 66)$ utilizing long-term marrow cultures (LTMCs). While stromal cells also support myelopoiesis (67-69), further discussion will focus specifically on stromal cell support of B-lymphopoiesis.

\section{Stromal Cell Support of B-lymphopoiesis}

Development of B-cells occurs within the bone marrow microenvironment and requires a series of differentiation steps which involve rearrangement of immunoglobulin variable region gene segments. Upon successful rearrangement of a both a heavy and light chain variable region, a highly regulated process involving the enzymes terminal deoxynucleotidyl transferase (Tdt) and recombinase-activating enzymes 1 and 2 (Rag1 and Rag2), B-cells produce and 
express mature IgM. Once maturation is complete, B-cells enter the periphery and provide immune protection through production of antibodies, presentation of antigen, or co-stimulation of T-cells. In addition, a population of mature B-cells, termed plasma memory cells, reside in the bone marrow providing long-term immunological memory (70). Genetic disorders such as X-linked agammaglobulinemia (XLA) or Bruton's disease, resulting in absence or very low number of B-cells, renders individuals susceptible to bacterial infection from lack of circulating antibody (71). Conversely, multiple myeloma, a disease characterized by excessive numbers of abnormal plasma cells in the bone marrow, renders individuals susceptible to bacterial infection due to lack of functional antibody production (72). These diseases which result in the absence of B-cell homeostasis highlight the importance of regulation of B-cell function and development throughout life.

Immature $\mathrm{B}$ cells, termed pre-pro-B, pro-B, and pre-B cells, which have not yet successfully rearranged their variable regions, are dependent on direct bone marrow stromal cell contact. In addition, cytokines produced by stromal cells are also required for pro- and pre-B cell development (73;74). IL-7, produced by bone marrow stromal cells, stimulates the proliferation of immature B-cells $(74 ; 75)$. Along with pro- and pre-B cells, thymocytes, T-cells, and NK cells also express IL-7 receptor (IL-7R) and proliferate in response to IL-7 (76;77). Grabstein and Sudo have demonstrated that mice injected with anti-IL-7 or anti-IL-7R display severely diminished numbers of pre-B cells $(78 ; 79)$, and IL-7 knockout mice demonstrate blocked bone marrow B-lymphopoiesis at the transition from pro-B to pre-B cell stages (80). However, Dittel has demonstrated that IL-7 alone is not sufficient for B-lymphopoiesis and additional stromal cell factors are required for successful lymphopoiesis (81). 
IGF-1 is an essential growth factor for normal development and this is demonstrated by observations that IGF-1 knockout mice exhibit postnatal lethality within the first 24 hours following birth and display severe intrauterine growth retardation (82). IGF-1 is secreted by bone marrow stromal cells and while IL-7 is the primary B-cell proliferative cytokine, IGF-1 enhances the proliferation of IL-7 dependent pro-B cells (83). Injection of mice with recombinant IGF-1 significantly enhances the total number of bone marrow B lineage cells (84). Another factor constitutively produced by stromal cells, stem cell factor (SCF), also enhances pro-B cell proliferative response to IL-7 (85). SCF does not appear to be an absolute requirement for B-cell development because mice that lack the SCF receptor, c-kit, display normal B-lymphopoiesis (86). While IGF-1 and SCF are not essential for B-lymphopoiesis, their role in the enhanced response to IL-7 demonstrates their importance in stromal cell support of B-lymphopoiesis.

Stromal cells produce FLT-3L, an essential factor for B-cell development $(87 ; 88)$. Similar to IGF-1 and SCF, FLT3L stimulates the growth of pre-pro-B cells synergistically with IL-7 (89). FLT3-deficient mice display diminished numbers, by two-fold, of pre-pro-B cells and pro-B cells, while the numbers of pre-B cells, and mature B cells remain normal (90). Similarly, FLT3L-deficient mice display dramatically diminished numbers of pre-pro-B, slightly reduced numbers of pro-B and pre-B, and normal numbers of mature B-cells $(87 ; 88)$.

Along with cytokines, stromal cells also express adhesion molecules which participate in regulation of B-lymphopoiesis. Early studies by Witte utilizing LTMC assays described lymphocytes as, "attached to, or pressed beneath large stromal cells" (91). Chelation of divalent cations inhibited the attachment of lymphocytes to stroma, while adherence was re-established following removal of chelating agents. These observations suggest that lymphocyte precursors express adhesion molecules which selectively recognize ligands on stromal cells (91). One 
particular CAM, VCAM-1, constitutively expressed by stromal cells, has proven functionally important in LTMC. Simmons et al. discovered that VLA-4/ VCAM-1 mediate the binding of immature progenitors to stroma in LTMC (92). Addition of either anti-VCAM-1 antibody or antibody specific for its receptor, VLA-4, to established Whitlock-Witte cultures results in rapid detachment of lymphocytes from the adherent stromal cell layer (93). Additionally, more immature B cells express higher levels of VLA-4, consistent with increased binding to stromal cells (94). While there is strong evidence for VLA-4/VCAM-1 interaction in B-lymphopoiesis, other adhesion molecules are also involved in B-cell adherence to stroma. Antibody specific to CD44, expressed on both stromal cells and pro-B cells, inhibits murine B-lymphopoiesis in vitro (95). Adhesion molecules serve many functions within the bone marrow microenvironment including retention of immature hematopoietic cells within the marrow, and providing growth and survival signals. It is also thought that adhesion of hematopoietic cells to stromal cells and extra-cellular matrix directs cells to microenvironments located within the bone marrow, termed "niches" (96).

SDF-1 is a member of the CXC group of chemokines initially identified as a stromal cell soluble factor which stimulates pre-B cells (97). SDF-1 is constitutively expressed in many organs including brain, heart, lung, liver, thymus, spleen and kidney (97) and is essential for perinatal viability, B-lymphopoiesis, bone marrow myelopoiesis, and cardiac ventricular septal formation (98). CXCR4 was the only identified receptor for SDF-1 for many years and also serves as a co-receptor for HIV entry into T-cells (10). However, recently another SDF-1 receptor, the chemokine orphan receptor-1 or $\mathrm{RDC1/CXCR7,} \mathrm{has} \mathrm{been} \mathrm{identified} \mathrm{(99).}$ $\mathrm{RDC1/CXCR7} \mathrm{is} \mathrm{present} \mathrm{on} \mathrm{T-cells} \mathrm{and} \mathrm{promotes} \mathrm{SDF-1} \mathrm{directed} \mathrm{chemotaxis} \mathrm{which} \mathrm{is} \mathrm{blocked}$ using an antibody specific for RDC1/CXCR7 (99). Recent evidence suggests inhibition of SDF-1 
or CXCR4 with specific neutralizing antibodies in LTMC inhibits the proliferation and cell cycle of immature hematopoietic cells (100). Along with its contribution to B-lymphopoiesis, SDF-1 also plays a major role in homing and mobilization of B-cells and therefore will be discussed in more detail later.

Stromal cells also express inhibitors of B-lymphopoiesis including IL-1, IL-4, TGF- $\beta$, INF- $\gamma$, and estrogenic steroids. While it has been reported that IL-4 and IL-1 $\beta$ up-regulate VCAM-1 expression (101), much evidence suggests both cytokines negatively regulate the proliferation and differentiation of immature B-cells (102-104). Murine S17 stromal cells exposed to either IL-1 $\alpha$ or IL-4 do not support the development of pre-B cells (105). Negative regulation of B-lymphopoiesis may be influenced, in part, by IL-4 and IL-1 $\alpha$ stimulation of stromal cells to up-regulation expression of cytokines that support myelopoiesis including, GMCSF and G-CSF $(106 ; 107)$.

TGF- $\beta$ is another stromal cell product which negatively regulates support of Blymphopoiesis (108). It was originally described for its ability to promote anchorage independent growth of fibroblasts (109) and displays both stimulatory and inhibitory activities depending on the target cell type and presence of other growth factors $(110 ; 111)$. TGF- $\beta$ inhibits lymphocyte proliferation, B-cell antibody secretion, and NK cell function (112;113). Additionally TGF- $\beta$ inhibits the differentiation of pre-B cells to mature, functional B-cells (108). Another negative regulator of hematopoiesis, TNF- $\alpha$, acts similarly to IL-1 $\alpha$ by blocking the growth of immature B-cells (55) and inducing the release of myeloid growth factors (114).

Stromal cell regulation of B-lymphopoiesis is a combination of pathways involving chemokines, cytokines, and adhesion molecules which function in cooperation to inhibit or stimulate B-lymphopoiesis. As mentioned previously, SCF and IGF-1 cooperate with IL-7 to 
stimulate proliferation of pro-B cells. SDF-1 increases the affinity of VLA-4, up-regulating extravasion of cells into the bone marrow (115). In addition, molecules such as c-kit can provide dual functions of proliferation and adhesion which both participate in regulation of Blymphopoiesis (116). Regulation of B-lymphopoiesis is an essential stromal cell function; however, bone marrow stromal cells have other regulatory functions within the bone marrow microenvironment.

\section{Stromal Cell Plasticity}

In 1974 during work establishing the CFU-F assay, Friedenstein et al. first proposed that bone marrow contained a precursor cell for multiple mesenchymal lineages (117). Since that time it has been well established that stromal cells, also called mesenchymal stem cells, are capable of differentiating into bone (118;119), adipose (120), cartilage (121), smooth muscle (122), and neurons (123).

Incubation of stromal cells with bone morphogenic proteins (BMP) induces rapid differentiation towards the osteoblast lineage both in vivo and in vitro $(124 ; 125)$ and cells maintain a phenotype consisting of cuboidal morphology, express alkaline phosphatase and osteocalcin, and form mineralization nodules (126). While osteoblasts differentiate from bone marrow stromal cells, they also aid in regulation of hematopoiesis. Osteoblasts provide structure to the bone marrow microenvironment and influence the differentiation of hematopoietic cells through the secretion of several cytokines which regulate hematopoiesis including G-CSF, GMCSF, IL-6, IL-1 $\beta$, TGF- $\beta$, and TNF- $\alpha$ (127). In addition to osteoblasts, stromal cells can also differentiate into chondrocytes (121) which produce collagen type I, II, and IX (128). Following extensive culture with corticosteroids, stromal cells can give rise to adipocytes (120). Myoblasts 
expressing $\alpha$-smooth muscle actin, metavinculin, calponin, and myosin heavy chain can be generated by stromal cells cultured in the presence of 5-azacytidine and basic fibroblast growth factor (bFGF) (122) or amphotericin B (129). Finally, differentiation of neural cells was demonstrated following culture of stromal cells with bFGF, $\beta$-mercaptoethanol, dimethyl sulfoxide (DMSO), and butylated hydroxyanisole $(123 ; 130)$. The mechanism by which stromal cells differentiate to neuronal cells is not currently understood, but phenotypic changes occur very rapidly, after 5 hours in culture. Additionally, stromal cells injected into the lateral ventricle of mice migrate to neuron-rich areas and differentiate into neurons (131). As stated above, bone marrow stromal cells demonstrate a high degree of plasticity and therefore may be potentially useful in the clinical setting of regenerative medicine.

Bone marrow stromal cells also possess many attributes which makes them likely candidates for transplantation. Transplantation with xenogenic, allogeneic, or gene-transduced stromal cells does not result in rejection (132-134). The mechanism for this could arise from the fact that stromal cells are not well recognized by alloreactive T-cells (132) because they do not express major histocompatibility complex type-II (MHC-II) or co-stimulatory molecules (135). Additionally, stromal cells are capable of engrafting to numerous organs when transplanted (136). Another advantage of utilizing stromal cells for transplantation is that they are easy to obtain in large numbers and can be readily expanded in culture. In addition to the fact that they display plasticity, stromal cells can easily be transduced with vectors or can function as retroviral producer cells and therefore are useful candidates for gene therapy (137-140).

Many studies have already demonstrated the potential clinical utility stromal cells possess. Transplantation of stromal cells into articular spaces completely repairs cartilage defects (122). Transplantation of stromal cells in conjunction with hematopoietic cells enhances 
the engraftment potential of the hematopoietic cells $(141-144 ; 144)$. Transplanted bone marrow stromal cells are capable of integrating into the functional components of the bone marrow microenvironment and maintaining human hematopoiesis (145). Finally, allogeneic stromal cells transplanted into children with osteogenesis imperfecta (OI) engraft, and differentiate into, osteoblasts (146). Following stromal cell transplantation, the number of osteoblasts increased, new lamellar bone formation was detected, an increase in total body mineral content was detected, fewer fractures occurred, and increased growth velocity was observed (146).

\section{Additional Cell Types in the Bone Marrow}

In addition to stromal cells and hematopoietic cells, the bone marrow microenvironment also contains macrophages and microvascular endothelial cells. Macrophages are derived from the hematopoietic stem cells; however, in the bone marrow, macrophages produce many hematopoietic regulatory factors rendering them part of the supportive system. Macrophages produce GM-CSF, G-CSF, M-CSF, IL-6, IL-1, TNF- $\alpha$, and TGF- $\beta$ (40). Within the bone marrow two populations of macrophages exist; the central macrophages and the peri-sinusioidal macrophages. The central macrophages aid in the differentiation of erythroid progenitors and comprise the erythroblastic island while the peri-sinusoidal macrophages destroy defective erythrocytes by penetrating the endothelial walls (147).

Microvascular endothelial cells also contribute to bone marrow hematopoiesis. Bone marrow derived endothelial cells constitutively express IL-6, G-CSF, GM-CSF, M-CSF, SCF, and fetal liver kinase-2 (Flk-2). In addition, endothelial cells also express adhesion molecules including VCAM-1, ICAM-1, E-selectin, and P-selectin. Egress of mature hematopoietic cells 
into the periphery requires extravasion through the endothelial cell layer lining the vasculature in the marrow (148).

\section{Hematopoietic Stem Cell Niche}

As described previously, hematopoiesis requires a specific microenvironment or "supportive niche" within the marrow microenvironment. HSCs require protection from stress, adhesion to niche cells, and a hypoxic environment. Therefore, the HSC niche must meet all of these requirements (149). While molecules involved in the maintenance of HSC quiescence have been identified, including c-kit (150), identity of the microgeographical region in which HSCs reside was only recently identified. In 2003 the HSC supportive niche was identified by Calvi et al, and Zhang et al. and implicated osteoblasts as crucial regulator cells in this environment $(18 ; 151)$. Osteoblasts support the adhesion and quiescence of HSCs, therefore providing essential requirements for HSC populations (18). It has been reported that in contrast to quiescence, a unique population of HSCs in the bone marrow undergoes proliferation. Calvi et al. have demonstrated that proliferating osteoblast populations increase and decrease in correlation with the number of proliferating HSCs. This observation provides evidence for another level of osteoblast regulation of HSCs (152). Further evidence for osteoblast regulation of HSC maintenance comes from mice with osteoblast deficiency. Transgenic mice expressing the herpes virus thymidine kinase gene under control of the collagen $\alpha 1$ promoter display severely suppressed hematopoiesis (153).

\section{B-cell Niche}


Comparable to HSCs, B-cells are also regulated in specialized microenvironments or niches (Figure 2). In 2004 Tokoyoda et al. utilized mice expressing GFP in the SDF-1 locus to identify specific niches in which B-cell development occurs. Common lymphoid progenitors and fully differentiated plasma cells require contact with stromal cells expressing SDF-1, while IL-7 dependant pro- and pre-B-cells are found in a different location within the bone marrow, adjacent to stromal cells expressing IL-7 and SDF-1. This work demonstrates that B-cell development occurs within specialized niches and development proceeds as cells migrate between functionally distinct supportive niches (154). Collectively, the diverse cell types, signals, and anatomically unique niches reflect the complexity of the bone marrow microenvironment. Further regulatory cues are provided by the extra-cellular matrix in this same site, described in the following section. 


\section{Extra-cellular matrix}

\section{Role of ECM in Hematopoiesis}

Stromal cells produce and secrete extra-cellular matrix (ECM) proteins that form the highly organized ECM of the bone marrow microenvironment. The major components of the ECM include collagen types I, III, IV, V, and VI, fibronectin, vitronectin, laminin, thrombospondin, and proteoglycans $(155 ; 156)$. These proteins not only provide a structural support within the bone marrow, but also regulate hematopoiesis by binding, stabilizing, and presenting cytokines and growth factors to developing hematopoietic cells. These roles allow the ECM to directly participate in the control of cell proliferation and differentiation as well as the survival of hematopoietic cells (157).

It is known that cytokines not only interact with their cognate receptors, but also function in cooperation with ECM proteins. Cytokines influence the expression and turnover of specific ECM molecules and conversely, ECM proteins mediate the synthesis of cytokines $(158 ; 159)$. In addition, ECM proteins serve as co-receptors for cytokines and many cell surface receptors are utilized in the clustering of cytokine receptors which influence signal transduction $(160 ; 161)$. Finally, some cytokines can directly bind to ECM proteins which serve to localize and stabilize cytokines for later release (162).

TGF- $\beta$, as described in section II, is a negative regulator of B-cell hematopoiesis and provides an example of the role bone marrow ECM plays in mediating cytokine activity. TGF- $\beta$ is a member of the TGF- $\beta$ super-family which includes not only TGF- $\beta$ s, but also the BMPs. These molecules are involved in regulation of diverse cellular processes and gene knockout studies have confirmed their importance. TGF- $\beta-1^{-/-}$mice develop a severe autoimmune reaction 
two weeks after birth, confirming TGF- $\beta$ 's importance in immune regulation $(163 ; 164)$. TGF- $\beta$ activity is regulated exclusively at the post-translational level by the presence of inhibitory binding proteins (165). TGF- $\beta$ is synthesized in an inactive form, "pre-pro-TGF- $\beta$ ". Upon secretion, cleavage of the pro-peptide of TGF- $\beta$ occurs. However, in order to become active, TGF- $\beta$ inhibitory proteins must be proteolytically cleaved or sequestered away from the active form of TGF- $\beta(165 ; 166)$. Inactive TGF- $\beta$, is bound to both latency associated protein (LAP) and latent TGF- $\beta$ binding proteins (LTBPs). Serine proteases, including MMP-2, are capable of cleaving LAP and LTBPs from TGF- $\beta$ (165) and data presented in Chapter 3 suggests MMP-2 specifically activates bone marrow stromal cell TGF- $\beta$ through cleavage of LAP and LTBP (167).

Upon activation, TGF- $\beta$ can bind to the ECM proteins betaglycan and endoglin or the TGF- $\beta$ receptor. Binding of TGF- $\beta$ to betaglycan or endoglin does not result in transmission of a cellular signal, however it does serve to present TGF- $\beta$ to its receptor (159). Active TGF- $\beta$ bound betaglycan can be shed from the cellular surface. The proteoglycan-bound TGF- $\beta$ acts as a receptor antagonist by inhibiting TGF- $\beta$-receptor binding (168). Regulation of TGF- $\beta$ activity provides one example in which ECM influences cytokine activity and availability.

While all members of ECM contribute to hematopoiesis, proteoglycans provide the majority of ECM-cytokine/growth factor interaction provided within the bone marrow microenvironment. Specific emphasis on one proteoglycan, heparin sulfate, and its direct role in SDF-1 regulation is the primary focus of this section. Both human (169) and murine (155) marrow stromal cells express heparan sulfate proteoglycan on their surface, along with marrow derived stromal cells lines $(170 ; 171)$. Many proteins associate with stroma through direct interaction with heparan sulfated proteoglycans present on stromal cell surfaces $(58 ; 59)$. Work 
by Gallagher and colleagues comparing adherent cells from bone marrow cultures and utilizing $\mathrm{W} / \mathrm{W}^{\mathrm{v}}$ mice indicated that bone marrow stromal cells are the primary source of sulfated GAGs in the marrow (155).

\section{Heparan-Sulfated Proteoglycans}

Proteoglycans are a heterogeneous group of macromolecules characterized by at least one glycosaminoglycan (GAG) chain attached to a core protein. GAG chains are unbranched, acidic heteropolysaccharides consisting of repeating disaccharides. There are three types of sulfated GAGS: chondroitin or dermatan sulfate, heparan sulfate, and keratan sulfate. Heparan sulfate is present in most culture cell extracts and is present as both an integral membrane glycoprotein and as a surface-associated component bound to membrane receptors (172;173). The polysaccharide backbone of heparin sulfate is comprised of $\mathrm{N}$-acetyl glucosamine and glucuronic acid residues which are modified by a series of reactions. During synthesis of the heparan sulfate chain, the modification steps which generate the final structure are often incomplete which results in structural heterogeneity leading to the potential for an enormous variety of molecular interactions $(174 ; 175)$. In addition, heparan sulfate chains can form dimers, (176) further adding to its diversity in regulating cell/ECM interactions. Direct evidence also exists for GAGs in stimulation of hematopoiesis. Addition of xylosides, which synthesize sulfated GAGs (177), to long-term in-vitro bone marrow cultures significantly increases hematopoietic support (178).

Bone marrow stromal cell heparan sulfated proteoglycans bind and present many chemokines on their surface including IL-8, MIP-1 $\beta$, growth-related activity- $\alpha$ (GRO- $\alpha$ ) and SDF-1 (179-182). SDF-1, as described in Section II, is an important factor in hematopoietic 
regulation. Along with in vitro data, in vivo data also suggests SDF-1 is sequestered on heparan sulfated proteoglycans $(183 ; 184)$. Lys $^{24}$ and Lys $^{27}$ mediate the high affinity binding of SDF-1 $\left(\mathrm{K}_{\mathrm{d}}\right.$ of $\left.30 \mathrm{nM}\right)$ to heparan sulfate GAGs (162). Serine substitution of these amino acids results in inability of SDF-1 to bind heparan sulfate (185). Also involved in, but not required for, this interaction are $\mathrm{Lys}^{1}, \mathrm{Arg}^{41}$, and Lys ${ }^{43}$ residues of SDF-1 (162). Heparan sulfated proteoglycans immobilize and enhance the local concentration of SDF-1 which facilitates its presentation to CXCR4 (186;187). Inactivation of the heparan sulfate binding sites does not interfere with SDF1's ability to bind CXCR4 and heparan sulfate bound SDF-1 is capable of binding CXCR4 (185).

Regulation of SDF-1's activity can occur by proteolytic degradation. The high affinity binding of SDF-1 to GAGs of heparan sulfate prevent dipeptidyl peptidase IV (DPP IV)-induced cleavage of the chemokine which results in instability (188-190). In addition to DPP IV, MMPs, including MMP-2, are capable of cleaving SDF-1 (191). MMP-2 cleaves the first 4 amino acids of SDF-1 which renders the protein unstable and unable to support chemotaxis of $\mathrm{CXCR}^{+}$cells. Following the initial cleavage, SDF-1 undergoes auto-degradation. Proteolytic cleavage is the only post-translational regulatory mechanism described for SDF-1 and data presented in chapter II of this dissertation describes a novel role for MMP-2 involvement in regulation of SDF-1.

\section{Matrix Metalloproteinases}

MMPs are endopeptidases that were first recognized for their ability to degrade proteins of the ECM (192). MMPs are involved in regulation of embryonic morphogenesis, angiogenesis, growth, wound healing, and also contribute to pathological processes including arthritis, tumor invasion and metastasis, and the progression of hematopoietic neoplasms (193). Recently, 
evidence has suggested that MMPs are critical for cell/ECM interactions and aid in regulation of cellular differentiation, migration, apoptosis, and cytokine activity.

In 1962 Gross and Lapiere discovered that MMPs were the protein responsible for removing the tail during tadpole metamorphosis (194). Since then, there have been 25 MMPs isolated from vertebrates and 22 human homologues (192). These proteins are widely distributed among the animal kingdom and have been found in sea urchins (195), Drosophila (196), Caenorhabditis elegans (197), and green algae (192;198). MMPs are divided into families based on their structure, substrate specificity, and localization within the cell. The collagenase family contains MMP-1, -8 , and -13 and their substrates include almost all members of the ECM. The gelatinases A and B, MMP 2 and 9 respectively, are another MMP family that cleaves gelatin and most collagens. Stomelysins 1 and 2, also known as MMP-3 and 10, comprise another MMP family. MMP-3 is commonly seen in rheumatoid arthritis and inflammatory bowel diseases. A more heterogeneous population of MMPs known as the classical MMPs, include MMP-12, -19, and -20. This family is recognized for their specific activity in localized environments an example being enamalysin, MMP-20, which is only present in epithelial cells in the oral cavity. The last family of MMPs is the membrane bound members, also designated as membrane type-MMPs (MT-MMPs), and includes MT-MMP-1,-2, -3, -4, and MMP-11. The MT-MMPs are thought to aid in the localization and activation of secreted MMPs.

The structure of MMP molecules exhibit a signal sequence, termed the pre-domain, consisting of approximately 20 amino acids, a pro domain of approximately 80 amino acids, a catalytic domain of roughly 170 residues, a 10-70 residue proline rich linker sequence and a 195 amino acid C-terminal hemopexin-like domain. MT-MMPs also contain a 75-100 residue transmembrane and cytoplasmic fragment (199). All MMPs are secreted as catalytically latent 
enzymes which subsequently become activated in the peri-cellular environment. The catalytic domain contains an essential zinc molecule which dictates the proteolytic activity of MMPs. In latent form, an unpaired cysteine in the pro-domain is bound to the catalytic zinc molecule. In order to become activated, the pro-domain must be removed from the N-terminus of the molecule which interrupts the cysteine-zinc molecular interaction. Once free from the prodomain, the catalytic zinc can interact with substrates. Substrate specificity is dictated, in part, through active site structural requirements as well as binding sites along the MMP molecule. For example, MMP-2 and 9 contain hemopoiexin domains which dictate the substrate specificity of the molecule. As indicated earlier, SDF-1 is a MMP target with specific relevance to the studies included in this dissertation.

\section{Inhibitors of Matrix Metalloproteinases}

MMP activity is highly regulated. One level of regulation is accomplished by the extracellular inhibitors known as tissue inhibitor of matrix metalloproteinases (TIMPs). The four human TIMPs, TIMP-1, $-2,-3$, and -4 , are capable of binding to all MMPs, but these complexes display different inhibition properties. TIMPs are 20-29 KD secreted proteins that reversibly inhibit MMP activity (200). TIMP molecules are comprised of 2 domains: an N-terminal domain consisting of 125 amino acids and a C-terminal domain of 65 amino acids. Three disulfide bonds in each domain stabilize the molecule (200). TIMPs inhibit MMPs through the action of their first five amino acids, Cys-1 through Pro-5. These amino acids form a wedge shape that inserts into the catalytic center of the MMP molecule allowing for chelation of the catalytic Zn molecule. Specifically, the amino $\mathrm{N}$ and carboxyl O of Cys1 perform the chelation effect (201). The N-terminal domain contains the catalytic portion and is more conserved among 
TIMP isoforms. The C-terminal domain is more variable between TIMPs and is the region capable of binding to pro-MMPs $(200 ; 202)$. The interaction between TIMPs and pro-MMPs provides a paradoxical role for TIMPs; TIMPS can aid in the activation of MMP molecules by acting as a membrane-docking molecule. An example of this behavior occurs when the Nterminus of TIMP-2 binds to MTI-MMP-2. This allows the free C-terminus of TIMP-2 to bind the hemopoiexin domain of secreted pro-MMP-2 (203). A second, uninhibited MT-MMP-2 cleaves the pro-domain of MMP-2 and consequently activates the MMP that is bound to TIMP-2 (204). This unorthodox role of TIMP-2 is proposed to localize MMP action near the cell surface (203). Low levels of TIMP-2 promote the activation of MMP-2 and high levels bind MTMMPs so activation cannot occur (202).

In addition to TIMPs, many chemical inhibitors have been designed to inhibit the activity of MMPs both in vitro and in vivo. Chelation of the catalytic zinc molecule of MMPs allows for reversible inhibition, therefore any substance capable of this action can inhibit MMP activity. The most common synthetic inhibitors include o-phenanthroline, which chelates all divalent cations and therefore does not offer specificity (205). Hydroxamates are synthetic MMP inhibitors also capable of chelation, but do so in a different manner. Hydroxamates include batimastat (BB-94), and marimastat (BB-2516), which contain a collagen like backbone that allows binding to MMP active site; they also contain a hydroxamate structure that chelates the catalytic zinc (206). Antibiotic compounds are capable of producing hydroxamates and therefore also possess MMP inhibitory activity. Tetracycline and doxycycline are shown to have IC50 for MMPs both in vivo and in vitro (207). Hydroxamate-based synthetic inhibitors are considered to be the most effective in inhibiting MMPs (208). Additionally, inhibitors have been designed to act as pro-domains of MMP molecules which keep the enzyme in latent form. Macrocylic 
lactones, such as bryostatin-1 have recently been implicated for their role in MMP inhibition. These inhibitors activate PKC through tight binding, but unlike other PKC activators, allow for a rapid PKC down-regulation (209). Bryostatin does not affect the activity of MMPs, but results in the absence of MMP-1, 3, 9, and 11 production (210).

\section{Matrix Metalloproteinase-2}

The bone marrow stromal cells used in our study predominately produce MMP-2. MMP2 was cloned and characterized in 1992 by Reponen (211). The amino acid sequence contains a 29-residue signal peptide, and 80-residue pro-peptide, and 553-residue catalytic and functional domains. Murine and human MMP-2 share 96\% sequence homology with all cysteine residues conserved (211). MMP-2 is expressed in mouse lung, heart, kidney, and muscle tissue while absent from liver, spleen, and brain. Mesenchymal cells from 10-15 day old embryo also show intense staining of MMP-2 (211). MMP-2 knockout mice do not have developmental or reproductive defects; however, they display retarded growth (212). Work by others has demonstrated that MMP-2 knockout mice display an increased incidence of experimental autoimmune encephalomyelitis (EAE) $(213 ; 213)$ and antibody induced asthma (214) as well as disrupted corneal neovascularization (215). In addition, humans with a mutation in the MMP-2 gene (chromosome 16q12-21) display an arthritic syndrome described as multicentric osteolysis or "vanishing bone syndrome" (216). Persons with this nonsense mutation have disrupted hydrogen bond formation between the MMP-2 pro-domain and the catalytic $\mathrm{Zn}$. No enzymatic MMP-2 activity is detected and consequently they display carpal and tarsal resorption, crippling arthritis, osteoporosis, and palmar and plantar subcutaneous nodules. This mutation is prevalent among Saudi Arabian families (217). 
While many in vitro substrates for MMP-2 have been described, including all members of basement membrane, recent work has demonstrated MMP-2 cleaves many proteins involved in regulation of hematopoiesis. As described earlier, McQuibban has shown MMP-2 removes a tetra-peptide from the N-terminus of SDF-1 resulting in a protein that is no longer functional (191). Also discovered by McQuibban et al., MMP-2 can cleave another chemokine, monocyte chemoattractant protein -3 (MCP-3) resulting in a protein no longer capable of supporting chemotaxis (218). Introduced earlier, MMP-2 cleaves TGF- $\beta$ LAP and LTBPs (167). Additionally, MMP-2 has been described by Fowlkes as capable of releasing IGF-1 from inhibitory binding proteins resulting in an active IGF-1 molecule (219). Finally, MMP-2 has been implicated in the cleavage of proteoglycan molecules. Zuo et al. have shown MMP-2 from neurons degrades and inactivates chondroitin sulfate proteoglycans (220). Increasing evidence implicates MMP-2 as a modulator of hematopoietic cytokine activity and defines a novel role for MMP-2 in the regulation of hematopoiesis.

All MMPs, with the exception of MMP-2, which is constitutively expressed by most cell types, are regulated at the transcriptional level (221). Characteristics of MMP-2 mRNA including a high degree of secondary structure and the presence of a $5^{\prime}$ tract of pyrimidines (5'TOP) allow the protein to be controlled by translational regulatory mechanisms (222). The specific pathways which are involved in translational regulation of MMP-2 expression in bone marrow stromal cells are the focus of Chapter IV. 


\section{Hematopoietic Cell Trafficking}

\section{Bone Marrow Transplantation and Engraftment}

In 1951 Lorenz et al. found that administration of hematopoietic cells into mice shortly after receiving high dose $\gamma$-irradiation prevented their death (223). Survival of these mice was the result of the colonization of the irradiated mouse by the injected hematopoietic cells (224). It has now been established that bone marrow transplantation (BMT) is an accepted mode of therapy for immunodeficiency disorders and aplastic anemia (225;226), hematologic malignancies including non-Hodgkin's lymphoma in relapse (227), acute myelogenous leukemia (228), acute lymphocytic leukemia (229), and multiple myeloma (230). In addition, solid tumors including ovarian, breast, and lung carcinoma have been successfully treated with BMT (231;232). A successful BMT is characterized by both numerical recovery of bone marrow cellular elements and functional recovery of cellular interactions. Specifically, immune reconstitution is indicated by appearance of functional B-cells, thymic and extra-thymic T-cell development, reconstitution of effector cells including cytotoxic T-cells and natural killer cells, as well as efficient antigen presentation (233). Because complete reconstitution of the immune system often takes at least one year, patients receiving a BMT are extremely susceptible to lifethreatening bacterial, viral and fungal infections (234).

Intravenous injection of bone marrow cells into recipients receiving a BMT "home" or migrate to several organs, including the bone marrow. The bone marrow microenvironment is the predominant site that supports hematopoietic reconstitution (235-237). Although, hematopoietic reconstitution is established exclusively within the bone marrow, the initial steps in the process of homing are not specific to the bone marrow. Homing of transplanted cells is a 
two-step process where cells must first be recognized by, and interact with, the bone marrow endothelium where they diapedes into the bone marrow extravascular spaces. The second step is the interaction of the stem and hematopoietic progenitors cells with bone marrow stromal cells that support proliferation and maturation (238).

The adhesion molecules VCAM-1/VLA-4 are required for efficient engraftment. Hematopoietic cells incubated with anti-VLA-4 antibody prior to infusion into mice display $50 \%$ reduction in the ability to engraft to the bone marrow (239). In similar studies, a $54 \%$ reduction in bone marrow engraftment was obtained when recipient mice were treated with anti-VCAM-1 antibody prior to transplantation (239).

The SDF-1/CXCR4 axis, described previously, also plays a role in the ability of cells to engraft to the bone marrow microenvironment. Immature hematopoietic cells isolated from the fetal liver of $\mathrm{CXCR}^{-/-}$mice are unable to home to the bone marrow microenvironment, indicating the role of CXCR4 in engraftment (240). In addition, the migration of HSCs isolated from adult mice, is supported exclusively by SDF-1 as indicated by in vitro chemotaxis assays (241). Taken together, these results demonstrate essential roles for SDF-1 and CXCR4 interactions in HSC homing.

\section{Mobilization}

Terminally differentiated, mature hematopoietic cells egress from the bone marrow into the periphery. The mechanism by which mature cells leave the marrow sinusoids and enter into circulation is poorly understood. In addition to mature cells, mobilization of hematopoietic stem and progenitor cells from the bone marrow into the periphery can be induced by cytokines such as GM-CSF (242), G-CSF (243), IL-3 (244), IL-7 (244), SCF (245), chemokines such as IL-8 
(246), and MIP-1 $\alpha$ (244), chemotherapy (247), and antibodies to adhesion molecules (248). Mobilized hematopoietic cells are often used in place of bone marrow cells for transplantation and have been established as capable of repopulating the hematopoietic compartment. Prior to the discovery of mobilizing agents, patients receiving a BMT were infused with allogeneic or syngenic bone marrow cells. Advantages of utilizing mobilized HSCs are that they lead to faster recovery in transplanted recipients as compared to patients transfused with bone marrow cells and the mobilized cells are easier to collect. The faster engraftment is due to the increased number of mobilized cells as compared to the number of cells that are able to be collected by bone marrow aspiration for subsequent transplantation $(249 ; 250)$.

Evidence implicates fluctuations in SDF-1 levels provide the cue for cells to leave the bone marrow and enter circulation. A rapid increase in SDF-1 protein is observed in circulation of mice and primates treated with the mobilizing agent fucoidan (183), and patients exposed to G-CSF (251). Petit and colleagues suggest diminished levels of bone marrow SDF-1 is due to its degradation by proteases. In accordance with elevated peripheral blood SDF-1, HSC mobilization occurs with diminished levels of bone marrow SDF-1 (252).

Adhesion molecules are also implicated in mobilization of HSCs from the marrow. The adhesion molecule expressed on stromal cells, VCAM-1, is proteolytically cleaved following exposure to the mobilizing agent G-CSF (253). Consistent with its ability to inhibit engraftment, administration of antibody specific to either VLA-4 or VCAM-1 results in mobilization of immature hematopoietic cells (239).

While proteases have been implicated by Levesque's group as the primary mechanism for cytokine-induced mobilization of HSCs, elevated protease levels do not entirely account for this phenomenon. Neutrophil elastase, cathepsin G, and MMP-9 knockout mice are able to mobilize 
hematopoietic cells in the presence of G-CSF (254). Very recently a novel mechanism for fucoidan and G-CSF induced mobilization was elucidated by Frenette. Mice lacking UDPgalactose ceremide galactosyltransferase (Cgt), an enzyme necessary for myelin sheath formation, were demonstrated to be unable to mobilize HSC or other immature hematopoietic cells in the presence of fucoidan and G-SCF (255). The sympathetic nervous system, specifically the neurotransmitter norepinephrine (NE), was implicated as the responsible mediator since dopamine $\beta$-hydroxylase (Dbh) deficient mice which lack NE are also unable to mobilize HSCs. The authors also found that bone marrow SDF-1 levels remained elevated in both $\mathrm{Cgt}^{-/}$and $\mathrm{Dbh}^{-/}$mice exposed to mobilizing agents while bone marrow SDF-1 levels were diminished in wild-type mice exposed to the same mobilizing agents. While the mechanism for trafficking of hematopoietic cells between the periphery and the extra-vascular spaces of the bone marrow is still not completely understood, adhesion molecules, chemokines, proteases, and neuro-transmitters may all impact on this process.

\section{Bone Marrow Damage}

To this point, regulation of hematopoiesis by a "healthy" bone marrow microenvironment has been described. In contrast, our experimental model that was designed to determine how chemotherapy disrupts the "normal function" of the bone marrow microenvironment. It has been established that following high-dose cytotoxic therapy and/or radiation exposure, given prior to transplantation, patient derived bone marrow stromal cells display functional deficits (256-258).

Studies by Galotta et al. found that BMT recipient CFU-F frequencies were reduced $60-90 \%$ and did not recover for up to 12 years following transplant (259). Another study found that patients who received a BMT with mobilized HSCs display diminished stromal function one year 
following the BMT (260). Acute lymphoblastic leukemia (ALL) patients who received chemotherapy prior to a BMT were found to have significantly reduced hematopoietic supportive stroma, due partially to an increase in TGF- $\beta$ levels (261). Both irradiated and chemotherapy exposed mice display similar functional deficits in the ability of their stromal cells to support hematopoiesis $(258 ; 262 ; 263)$.

The mechanisms by which stromal cell support of hematopoietic cells is diminished following chemotherapy exposure has yet to be determined. Studies performed in our laboratory have determined that stromal cells exposed to chemotherapy display diminished VCAM-1 expression due to alterations in NF-kB transcription (264;265). Additionally, SDF-1 production is diminished resulting in diminished support of pro-B cell chemotaxis in stromal cells exposed to chemotherapy (266). Consistent with diminished ability to support hematopoietic cell development, data described in chapters II-IV describes our observations regarding altered stromal cell function. These data suggest mechanisms by which chemotherapy alters the stromal cell microenvironment consistent with diminished ability to support hematopoietic cell development. 


\section{REFERENCES}

1. Fliedner, T. M. (1998) Stem Cells 16, 361-374

2. Wong, P. M., Chung, S. W., Chui, D. H., and Eaves, C. J. (1986) Proc. Natl. Acad. Sci. U. S. A 83, 3851-3854

3. Johnson, G. R. and Barker, D. C. (1985) Exp. Hematol. 13, 200-208

4. Medvinsky, A. and Dzierzak, E. (1996) Cell 86, 897-906

5. Muller, A. M., Medvinsky, A., Strouboulis, J., Grosveld, F., and Dzierzak, E. (1994) Immunity. 1, 291-301

6. Morrison, S. J., Hemmati, H. D., Wandycz, A. M., and Weissman, I. L. (1995) Proc. Natl. Acad. Sci. U. S. A 92, 10302-10306

7. Hirsch, E., Iglesias, A., Potocnik, A. J., Hartmann, U., and Fassler, R. (1996) Nature 380, $171-175$

8. Arroyo, A. G., Yang, J. T., Rayburn, H., and Hynes, R. O. (1996) Cell 85, 997-1008

9. Nagasawa, T., Hirota, S., Tachibana, K., Takakura, N., Nishikawa, S., Kitamura, Y., Yoshida, N., Kikutani, H., and Kishimoto, T. (1996) Nature 382, 635-638

10. Nagasawa, T., Tachibana, K., and Kishimoto, T. (1998) Semin. Immunol. 10, 179-185

11. Zou, Y. R., Kottmann, A. H., Kuroda, M., Taniuchi, I., and Littman, D. R. (1998) Nature 393, 595-599 
12. Ema, H. and Nakauchi, H. (2000) Blood 95, 2284-2288

13. Peault, B. (1996) J. Hematother. 5, 369-378

14. Maximow, A. A. (1924) Physiol Rev. 4, 533-563

15. TILL, J. E. and McCULLOCH, E. A. (1961) Radiat. Res. 14, 213-222

16. GOODMAN, J. W. and HODGSON, G. S. (1962) Blood 19, 702-714

17. Calvi, L. M., Adams, G. B., Weibrecht, K. W., Weber, J. M., Olson, D. P., Knight, M. C., Martin, R. P., Schipani, E., Divieti, P., Bringhurst, F. R., Milner, L. A., Kronenberg, H. M., and Scadden, D. T. (2003) Nature 425, 841-846

18. Zhang, J., Niu, C., Ye, L., Huang, H., He, X., Tong, W. G., Ross, J., Haug, J., Johnson, T., Feng, J. Q., Harris, S., Wiedemann, L. M., Mishina, Y., and Li, L. (2003) Nature 425, $836-841$

19. To, L. B., Haylock, D. N., Dowse, T., Simmons, P. J., Trimboli, S., Ashman, L. K., and Juttner, C. A. (1994) Blood 84, 2930-2939

20. Metcalf, D. (1993) Blood 82, 3515-3523

21. Kinashi, T., Inaba, K., Tsubata, T., Tashiro, K., Palacios, R., and Honjo, T. (1988) Proc. Natl. Acad. Sci. U. S. A 85, 4473-4477

22. Shivdasani, R. A., Mayer, E. L., and Orkin, S. H. (1995) Nature 373, 432-434

23. Yamada, Y., Warren, A. J., Dobson, C., Forster, A., Pannell, R., and Rabbitts, T. H. (1998) Proc. Natl. Acad. Sci. U. S. A 95, 3890-3895 
24. Pevny, L., Lin, C. S., D'Agati, V., Simon, M. C., Orkin, S. H., and Costantini, F. (1995) Development 121, 163-172

25. Shalaby, F., Rossant, J., Yamaguchi, T. P., Gertsenstein, M., Wu, X. F., Breitman, M. L., and Schuh, A. C. (1995) Nature 376, 62-66

26. Takakura, N., Huang, X. L., Naruse, T., Hamaguchi, I., Dumont, D. J., Yancopoulos, G. D., and Suda, T. (1998) Immunity. 9, 677-686

27. Oike, Y., Takakura, N., Hata, A., Kaname, T., Akizuki, M., Yamaguchi, Y., Yasue, H., Araki, K., Yamamura, K., and Suda, T. (1999) Blood 93, 2771-2779

28. Castilla, L. H., Wijmenga, C., Wang, Q., Stacy, T., Speck, N. A., Eckhaus, M., MarinPadilla, M., Collins, F. S., Wynshaw-Boris, A., and Liu, P. P. (1996) Cell 87, 687-696

29. Tsai, F. Y., Keller, G., Kuo, F. C., Weiss, M., Chen, J., Rosenblatt, M., Alt, F. W., and Orkin, S. H. (1994) Nature 371, 221-226

30. Mucenski, M. L., McLain, K., Kier, A. B., Swerdlow, S. H., Schreiner, C. M., Miller, T. A., Pietryga, D. W., Scott, W. J., Jr., and Potter, S. S. (1991) Cell 65, 677-689

31. Bernstein, A., Forrester, L., Reith, A. D., Dubreuil, P., and Rottapel, R. (1991) Semin. Hematol. 28, 138-142

32. Wu, H., Liu, X., Jaenisch, R., and Lodish, H. F. (1995) Cell 83, 59-67

33. Lin, C. S., Lim, S. K., D'Agati, V., and Costantini, F. (1996) Genes Dev. 10, 154-164 
34. Neubauer, H., Cumano, A., Muller, M., Wu, H., Huffstadt, U., and Pfeffer, K. (1998) Cell 93, 397-409

35. Scott, E. W., Fisher, R. C., Olson, M. C., Kehrli, E. W., Simon, M. C., and Singh, H. (1997) Immunity. 6, 437-447

36. Georgopoulos, K., Bigby, M., Wang, J. H., Molnar, A., Wu, P., Winandy, S., and Sharpe, A. (1994) Cell 79, 143-156

37. Porter, F. D., Drago, J., Xu, Y., Cheema, S. S., Wassif, C., Huang, S. P., Lee, E., Grinberg, A., Massalas, J. S., Bodine, D., Alt, F., and Westphal, H. (1997) Development 124, 2935-2944

38. Jepsen, K., Hermanson, O., Onami, T. M., Gleiberman, A. S., Lunyak, V., McEvilly, R. J., Kurokawa, R., Kumar, V., Liu, F., Seto, E., Hedrick, S. M., Mandel, G., Glass, C. K., Rose, D. W., and Rosenfeld, M. G. (2000) Cell 102, 753-763

39. Grossmann, M., Metcalf, D., Merryfull, J., Beg, A., Baltimore, D., and Gerondakis, S. (1999) Proc. Natl. Acad. Sci. U. S. A 96, 11848-11853

40. Mayani, H., Guilbert, L., and Janowska-Wieczorek, A. (1992) Eur J Haematol 49, $225-$ 233

41. Curry, J. L. and Trentin, J. J. (1967) Dev. Biol. 15, 395-413

42. Trentin, J. J. (1971) Am. J Pathol. 65, 621-628

43. Lord, B. I., Testa, N. G., and Hendry, J. H. (1975) Blood 46, 65-72 
44. Lichtman, M. A. (1981) Exp. Hematol. 9, 391-410

45. Gong, J. K. (1978) Science 199, 1443-1445

46. Nilsson, S. K., Johnston, H. M., and Coverdale, J. A. (2001) Blood 97, 2293-2299

47. Shaklai, M. and Tavassoli, M. (1979) J Ultrastruct. Res. 69, 343-361

48. Castro-Malaspina, H., Gay, R. E., Resnick, G., Kapoor, N., Meyers, P., Chiarieri, D., McKenzie, S., Broxmeyer, H. E., and Moore, M. A. (1980) Blood 56, 289-301

49. Friedenstein, A. J., Chailakhyan, R. K., Latsinik, N. V., Panasyuk, A. F., and KeilissBorok, I. V. (1974) Transplantation 17, 331-340

50. Dorshkind, K. (1990) Annu. Rev. Immunol. 8, 111-137

51. Thalmeier, K., Meissner, P., Reisbach, G., Hultner, L., Mortensen, B. T., Brechtel, A., Oostendorp, R. A., and Dormer, P. (1996) Exp. Hematol. 24, 1-10

52. Silva, W. A., Jr., Covas, D. T., Panepucci, R. A., Proto-Siqueira, R., Siufi, J. L., Zanette, D. L., Santos, A. R., and Zago, M. A. (2003) Stem Cells 21, 661-669

53. Dormady, S. P., Bashayan, O., Dougherty, R., Zhang, X. M., and Basch, R. S. (2001) J Hematother. Stem Cell Res. 10, 125-140

54. Kittler, E. L., McGrath, H., Temeles, D., Crittenden, R. B., Kister, V. K., and Quesenberry, P. J. (1992) Blood 79, 3168-3178

55. Ryan, D. H., Nuccie, B. L., Ritterman, I., Liesveld, J. L., and Abboud, C. N. (1994) $J$ Immunol. 152, 5250-5258 
56. Hogan, M. B., Piktel, D., and Landreth, K. S. (2000) J Allergy Clin. Immunol. 106, 329336

57. Campbell, A. D., Long, M. W., and Wicha, M. S. (1990) Blood 76, 1758-1764

58. Gallagher, J. T. (1989) Curr. Opin. Cell Biol. 1, 1201-1218

59. Gordon, M. Y. (1988) Br. J Haematol 70, 1-4

60. Long, M. W. and Dixit, V. M. (1990) Blood 75, 2311-2318

61. Simmons, P. J., Masinovsky, B., Longenecker, B. M., Berenson, R., Torok-Storb, B., and Gallatin, W. M. (1992) Blood 80, 388-395

62. Teixido, J., Hemler, M. E., Greenberger, J. S., and Anklesaria, P. (1992) J Clin. Invest 90, $358-367$

63. Yoder, M. C. and Williams, D. A. (1995) Exp. Hematol. 23, 961-967

64. Zuckerman, K. S. and Wicha, M. S. (1983) Blood 61, 540-547

65. Dexter, T. M., Allen, T. D., and Lajtha, L. G. (1977) J Cell Physiol 91, 335-344

66. Whitlock, C. A. and Witte, O. N. (1982) Proc. Natl. Acad. Sci. U. S. A 79, 3608-3612

67. Dorshkind, K. (1990) Annu. Rev. Immunol. 8, 111-137

68. Dexter, T. M. (1982) J. Cell Physiol Suppl 1, 87-94

69. Dorshkind, K., Schouest, L., and Fletcher, W. H. (1985) Cell Tissue Res. 239, 375-382 
70. Manz, R. A., Thiel, A., and Radbruch, A. (1997) Nature 388, 133-134

71. Sideras, P. and Smith, C. I. (1995) Adv. Immunol. 59, 135-223

72. Kyle, R. A. (2000) Br. J Haematol 111, 1035-1044

73. McGinnes, K., Quesniaux, V., Hitzler, J., and Paige, C. (1991) Exp. Hematol. 19, 294303

74. Namen, A. E., Lupton, S., Hjerrild, K., Wignall, J., Mochizuki, D. Y., Schmierer, A., Mosley, B., March, C. J., Urdal, D., and Gillis, S. (1988) Nature 333, 571-573

75. Goodwin, R. G. and Namen, A. E. (1989) Year Immunol. 6, 127-139

76. Gimble, J. M., Pietrangeli, C., Henley, A., Dorheim, M. A., Silver, J., Namen, A., Takeichi, M., Goridis, C., and Kincade, P. W. (1989) Blood 74, 303-311

77. Park, L. S., Friend, D. J., Schmierer, A. E., Dower, S. K., and Namen, A. E. (1990) J Exp. Med. 171, 1073-1089

78. Grabstein, K. H., Waldschmidt, T. J., Finkelman, F. D., Hess, B. W., Alpert, A. R., Boiani, N. E., Namen, A. E., and Morrissey, P. J. (1993) J Exp. Med. 178, 257-264

79. Sudo, T., Nishikawa, S., Ohno, N., Akiyama, N., Tamakoshi, M., Yoshida, H., and Nishikawa, S. (1993) Proc. Natl. Acad. Sci. U. S. A 90, 9125-9129

80. von Freeden-Jeffry, U., Vieira, P., Lucian, L. A., McNeil, T., Burdach, S. E., and Murray, R. (1995) J Exp. Med. 181, 1519-1526

81. Dittel, B. N. and LeBien, T. W. (1995) J Immunol. 154, 58-67 
82. Liu, J. P., Baker, J., Perkins, A. S., Robertson, E. J., and Efstratiadis, A. (1993) Cell 75, $59-72$

83. Gibson, L. F., Piktel, D., and Landreth, K. S. (1993) Blood 82, 3005-3011

84. Jardieu, P., Clark, R., Mortensen, D., and Dorshkind, K. (1994) J Immunol. 152, 43204327

85. Funk, P. E., Varas, A., and Witte, P. L. (1993) J Immunol. 150, 748-752

86. Landreth, K. S., Kincade, P. W., Lee, G., and Harrison, D. E. (1984) J Immunol. 132, $2724-2729$

87. Sitnicka, E., Bryder, D., Theilgaard-Monch, K., Buza-Vidas, N., Adolfsson, J., and Jacobsen, S. E. (2002) Immunity. 17, 463-472

88. Sitnicka, E., Brakebusch, C., Martensson, I. L., Svensson, M., Agace, W. W., Sigvardsson, M., Buza-Vidas, N., Bryder, D., Cilio, C. M., Ahlenius, H., Maraskovsky, E., Peschon, J. J., and Jacobsen, S. E. (2003) J Exp Med. 198, 1495-1506

89. Hunte, B. E., Hudak, S., Campbell, D., Xu, Y., and Rennick, D. (1996) J Immunol. 156, $489-496$

90. Mackarehtschian, K., Hardin, J. D., Moore, K. A., Boast, S., Goff, S. P., and Lemischka, I. R. (1995) Immunity. 3, 147-161

91. Witte, P. L., Robinson, M., Henley, A., Low, M. G., Stiers, D. L., Perkins, S., Fleischman, R. A., and Kincade, P. W. (1987) Eur J Immunol. 17, 1473-1484 
92. Simmons, P. J., Masinovsky, B., Longenecker, B. M., Berenson, R., Torok-Storb, B., and Gallatin, W. M. (1992) Blood 80, 388-395

93. Miyake, K., Medina, K., Ishihara, K., Kimoto, M., Auerbach, R., and Kincade, P. W. (1991) J. Cell Biol. 114, 557-565

94. Ryan, D. H., Nuccie, B. L., Abboud, C. N., and Winslow, J. M. (1991) J. Clin. Invest 88, 995-1004

95. Miyake, K., Medina, K. L., Hayashi, S., Ono, S., Hamaoka, T., and Kincade, P. W. (1990) J Exp. Med. 171, 477-488

96. Lemischka, I. R. (1997) Stem Cells 15 Suppl 1, 63-68

97. Tashiro, K., Tada, H., Heilker, R., Shirozu, M., Nakano, T., and Honjo, T. (1993) Science 261, 600-603

98. Nagasawa, T., Hirota, S., Tachibana, K., Takakura, N., Nishikawa, S., Kitamura, Y., Yoshida, N., Kikutani, H., and Kishimoto, T. (1996) Nature 382, 635-638

99. Balabanian, K., Lagane, B., Infantino, S., Chow, K. Y., Harriague, J., Moepps, B., renzana-Seisdedos, F., Thelen, M., and Bachelerie, F. (2005) J Biol. Chem. 280, 3576035766

100. Van Overstraeten-Schlogel, N., Beguin, Y., and gothot, A. (2006) Eur J Haematol epub, $1-6$

101. Dittel, B. N., McCarthy, J. B., Wayner, E. A., and LeBien, T. W. (1993) Blood 81, 22722282 
102. Billips, L. G., Petitte, D., and Landreth, K. S. (1990) Blood 75, 611-619

103. Hirayama, F., Clark, S. C., and Ogawa, M. (1994) Proc. Natl. Acad. Sci. U. S. A 91, 469473

104. Pandrau, D., Saeland, S., Duvert, V., Durand, I., Manel, A. M., Zabot, M. T., Philippe, N., and Banchereau, J. (1992) J Clin. Invest 90, 1697-1706

105. Billips, L. G., Petitte, D., and Landreth, K. S. (1990) Blood 75, 611-619

106. Lovhaug, D., Pelus, L. M., Nordlie, E. M., Boyum, A., and Moore, M. A. (1986) Exp. Hematol. 14, 1037-1042

107. Tushinski, R. J., Larsen, A., Park, L. S., Spoor, E., Williams, D. E., and Mochizuki, D. Y. (1991) Exp. Hematol. 19, 238-244

108. Lee, G., Ellingsworth, L. R., Gillis, S., Wall, R., and Kincade, P. W. (1987) J Exp. Med. 166, 1290-1299

109. Roberts, A. B., Anzano, M. A., Lamb, L. C., Smith, J. M., and Sporn, M. B. (1981) Proc. Natl. Acad. Sci. U. S. A 78, 5339-5343

110. Roberts, A. B., Anzano, M. A., Wakefield, L. M., Roche, N. S., Stern, D. F., and Sporn, M. B. (1985) Proc. Natl. Acad. Sci. U. S. A 82, 119-123

111. Sporn, M. B., Roberts, A. B., Wakefield, L. M., and Assoian, R. K. (1986) Science 233, $532-534$ 
112. Kehrl, J. H., Wakefield, L. M., Roberts, A. B., Jakowlew, S., varez-Mon, M., Derynck, R., Sporn, M. B., and Fauci, A. S. (1986) J Exp. Med. 163, 1037-1050

113. Rook, A. H., Kehrl, J. H., Wakefield, L. M., Roberts, A. B., Sporn, M. B., Burlington, D. B., Lane, H. C., and Fauci, A. S. (1986) J Immunol. 136, 3916-3920

114. Zucali, J. R., Broxmeyer, H. E., Gross, M. A., and Dinarello, C. A. (1988) J Immunol. 140, $840-844$

115. Peled, A., Kollet, O., Ponomaryov, T., Petit, I., Franitza, S., Grabovsky, V., Slav, M. M., Nagler, A., Lider, O., Alon, R., Zipori, D., and Lapidot, T. (2000) Blood 95, 3289-3296

116. Kodama, H., Nose, M., Niida, S., Nishikawa, S., and Nishikawa, S. (1994) Exp. Hematol. 22, 979-984

117. Friedenstein, A. J., Deriglasova, U. F., Kulagina, N. N., Panasuk, A. F., Rudakowa, S. F., Luria, E. A., and Ruadkow, I. A. (1974) Exp. Hematol. 2, 83-92

118. Beresford, J. N. (1989) Clin. Orthop. Relat Res. 270-280

119. Haynesworth, S. E., Goshima, J., Goldberg, V. M., and Caplan, A. I. (1992) Bone 13, 8188

120. Gimble, J. M. (1990) New Biol. 2, 304-312

121. Lennon, D. P., Haynesworth, S. E., Young, R. G., Dennis, J. E., and Caplan, A. I. (1995) Exp. Cell Res. 219, 211-222 
122. Wakitani, S., Goto, T., Pineda, S. J., Young, R. G., Mansour, J. M., Caplan, A. I., and Goldberg, V. M. (1994) J Bone Joint Surg. Am. 76, 579-592

123. Woodbury, D., Schwarz, E. J., Prockop, D. J., and Black, I. B. (2000) J Neurosci. Res. 61, 364-370

124. Kataoka, H. and Urist, M. R. (1993) Clin. Orthop. Relat Res. 262-270

125. Chen, D., Ji, X., Harris, M. A., Feng, J. Q., Karsenty, G., Celeste, A. J., Rosen, V., Mundy, G. R., and Harris, S. E. (1998) J Cell Biol. 142, 295-305

126. Jaiswal, N., Haynesworth, S. E., Caplan, A. I., and Bruder, S. P. (1997) J Cell Biochem. 64, 295-312

127. Taichman, R. S. and Emerson, S. G. (1998) Stem Cells 16, 7-15

128. Fang, J. and Hall, B. K. (1997) Anat. Embryol. (Berl) 196, 349-362

129. Prockop, D. J. (1997) Science 276, 71-74

130. Sanchez-Ramos, J., Song, S., Cardozo-Pelaez, F., Hazzi, C., Stedeford, T., Willing, A., Freeman, T. B., Saporta, S., Janssen, W., Patel, N., Cooper, D. R., and Sanberg, P. R. (2000) Exp. Neurol. 164, 247-256

131. Kopen, G. C., Prockop, D. J., and Phinney, D. G. (1999) Proc. Natl. Acad. Sci. U. S. A 96, $10711-10716$

132. McIntosh, K. and Bartholomew, A. (2000) Graft 3, 324-328 
133. Klyushnenkova, E., Shustova, V., Mosca, J., Moseley, A., and McIntosh, K. (1999) Exp Hematol 27, 122

134. Bartholomew, A., Patil, S., Mackay, A., Nelson, M., Buyaner, D., Hardy, W., Mosca, J., Sturgeon, C., Siatskas, M., Mahmud, N., Ferrer, K., Deans, R., Moseley, A., Hoffman, R., and Devine, S. M. (2001) Hum. Gene Ther. 12, 1527-1541

135. Schoeberlein, A., Holzgreve, W., Dudler, L., Hahn, S., and Surbek, D. V. (2005) Am. J Obstet. Gynecol. 192, 1044-1052

136. Liechty, K. W., MacKenzie, T. C., Shaaban, A. F., Radu, A., Moseley, A. M., Deans, R., Marshak, D. R., and Flake, A. W. (2000) Nat. Med. 6, 1282-1286

137. Marx, J. C., Allay, J. A., Persons, D. A., Nooner, S. A., Hargrove, P. W., Kelly, P. F., Vanin, E. F., and Horwitz, E. M. (1999) Hum. Gene Ther. 10, 1163-1173

138. Conget, P. A. and Minguell, J. J. (2000) Exp. Hematol. 28, 382-390

139. Frolova-Jones, E. A., Ensser, A., Stevenson, A. J., Kinsey, S. E., and Meredith, D. M. (2000) J Hematother. Stem Cell Res. 9, 573-581

140. Reese, J. S., Koc, O. N., and Gerson, S. L. (1999) J Hematother. Stem Cell Res. 8, $515-$ 523

141. Anklesaria, P., FitzGerald, T. J., Kase, K., Ohara, A., and Greenberger, J. S. (1989) Blood 74, 1144-1151

142. Hashimoto, F., Sugiura, K., Inoue, K., and Ikehara, S. (1997) Blood 89, 49-54 
143. El-Badri, N. S., Wang, B. Y., Cherry, and Good, R. A. (1998) Exp. Hematol. 26, 110-116

144. Noort, W. A., Kruisselbrink, A. B., in't Anker, P. S., Kruger, M., van Bezooijen, R. L., de Paus, R. A., Heemskerk, M. H., Lowik, C. W., Falkenburg, J. H., Willemze, R., and Fibbe, W. E. (2002) Exp. Hematol. 30, 870-878

145. Muguruma, Y., Yahata, T., Miyatake, H., Sato, T., Uno, T., Itoh, J., Kato, S., Ito, M., Hotta, T., and Ando , K. (2006) Blood 107, 1878-1887

146. Horwitz, E. M., Prockop, D. J., Fitzpatrick, L. A., Koo, W. W., Gordon, P. L., Neel, M., Sussman, M., Orchard, P., Marx, J. C., Pyeritz, R. E., and Brenner, M. K. (1999) Nat. Med. 5, 309-313

147. BESSIS, M. C. and BRETON-GORIUS, J. (1962) Blood 19, 635-663

148. Hudson, G. and Yoffey, J. M. (1968) J Anat. 103, 515-525

149. Suda, T., Arai, F., and Hirao, A. (2005) Trends Immunol. 26, 426-433

150. Driessen, R. L., Johnston, H. M., and Nilsson, S. K. (2003) Exp. Hematol. 31, 1284-1291

151. Calvi, L. M., Adams, G. B., Weibrecht, K. W., Weber, J. M., Olson, D. P., Knight, M. C., Martin, R. P., Schipani, E., Divieti, P., Bringhurst, F. R., Milner, L. A., Kronenberg, H. M., and Scadden, D. T. (2003) Nature 425, 841-846

152. Calvi, L. M., Adams, G. B., Weibrecht, K. W., Weber, J. M., Olson, D. P., Knight, M. C., Martin, R. P., Schipani, E., Divieti, P., Bringhurst, F. R., Milner, L. A., Kronenberg, H. M., and Scadden, D. T. (2003) Nature 425, 841-846 
153. Yamashita, Y. M., Jones, D. L., and Fuller, M. T. (2003) Science 301, 1547-1550

154. Tokoyoda, K., Egawa, T., Sugiyama, T., Choi, B. I., and Nagasawa, T. (2004) Immunity. 20, 707-718

155. Gallagher, J. T., Spooncer, E., and Dexter, T. M. (1983) J Cell Sci. 63, 155-171

156. Owen, M. (1988) J Cell Sci. Suppl 10, 63-76

157. Frisch, S. M. and Ruoslahti, E. (1997) Curr. Opin. Cell Biol. 9, 701-706

158. Kovacs, E. J. and DiPietro, L. A. (1994) FASEB J 8, 854-861

159. Lopez-Casillas, F., Wrana, J. L., and Massague, J. (1993) Cell 73, 1435-1444

160. Rapraeger, A. C., Krufka, A., and Olwin, B. B. (1991) Science 252, 1705-1708

161. Schneller, M., Vuori, K., and Ruoslahti, E. (1997) EMBO J 16, 5600-5607

162. Sadir, R., Baleux, F., Grosdidier, A., Imberty, A., and Lortat-Jacob, H. (2001) J Biol. Chem. 276, 8288-8296

163. Kulkarni, A. B., Ward, J. M., Yaswen, L., Mackall, C. L., Bauer, S. R., Huh, C. G., Gress, R. E., and Karlsson, S. (1995) Am. J Pathol. 146, 264-275

164. Boivin, G. P., O'Toole, B. A., Orsmby, I. E., Diebold, R. J., Eis, M. J., Doetschman, T., and Kier, A. B. (1995) Am. J Pathol. 146, 276-288

165. Munger, J. S., Harpel, J. G., Gleizes, P. E., Mazzieri, R., Nunes, I., and Rifkin, D. B. (1997) Kidney Int. 51, 1376-1382 
166. Ribeiro, S. M., Poczatek, M., Schultz-Cherry, S., Villain, M., and Murphy-Ullrich, J. E. (1999) J Biol. Chem. 274, 13586-13593

167. Wang, L., Clutter, S., Benincosa, J., Fortney, J., and Gibson, L. F. (2005) Stem Cells 23, $1122-1134$

168. Lopez-Casillas, F., Cheifetz, S., Doody, J., Andres, J. L., Lane, W. S., and Massague, J. (1991) Cell 67, 785-795

169. Wight, T. N., Kinsella, M. G., Keating, A., and Singer, J. W. (1986) Blood 67, 1333-1343

170. Drzeniek, Z., Siebertz, B., Stocker, G., Just, U., Ostertag, W., Greiling, H., and Haubeck, H. D. (1997) Biochem. J 327 ( Pt 2), 473-480

171. Bentley, S. A., Kirby, S. L., Anklesaria, P., and Greenberger, J. S. (1988) J Cell Physiol 136, $182-187$

172. Oldberg, A., Kjellen, L., and Hook, M. (1979) J Biol. Chem. 254, 8505-8510

173. Kjellen, L., Pettersson, I., and Hook, M. (1981) Proc. Natl. Acad. Sci. U. S. A 78, 53715375

174. Hardingham, T. E. and Fosang, A. J. (1992) FASEB J 6, 861-870

175. Netelenbos, T., Drager, A. M., van het, H. B., Kessler, F. L., Delouis, C., Huijgens, P. C., van den, B. J., and van, D. W. (2001) Exp Hematol 29, 884-893

176. Fransson, L. A. (1981) Eur J Biochem. 120, 251-255 
177. Robinson, H. C., Brett, M. J., Tralaggan, P. J., Lowther, D. A., and Okayama, M. (1975) Biochem. J 148, 25-34

178. Spooncer, E., Gallagher, J. T., Krizsa, F., and Dexter, T. M. (1983) J Cell Biol. 96, 510514

179. Tanaka, Y., Adams, D. H., Hubscher, S., Hirano, H., Siebenlist, U., and Shaw, S. (1993) Nature 361, 79-82

180. Weber, K. S., von, H. P., Clark-Lewis, I., Weber, P. C., and Weber, C. (1999) Eur J Immunol. 29, 700-712

181. Tanaka, Y., Adams, D. H., and Shaw, S. (1993) Immunol. Today 14, 111-115

182. Netelenbos, T., van den, B. J., Kessler, F. L., Zweegman, S., Merle, P. A., van Oostveen, J. W., Zwaginga, J. J., Huijgens, P. C., and Drager, A. M. (2003) Leukemia 17, 175-184

183. Sweeney, E. A., Lortat-Jacob, H., Priestley, G. V., Nakamoto, B., and Papayannopoulou, T. (2002) Blood 99, 44-51

184. Pablos, J. L., Santiago, B., Galindo, M., Torres, C., Brehmer, M. T., Blanco, F. J., and Garcia-Lazaro, F. J. (2003) J Immunol. 170, 2147-2152

185. Valenzuela-Fernandez, A., Palanche, T., Amara, A., Magerus, A., Altmeyer, R., Delaunay, T., Virelizier, J. L., Baleux, F., Galzi, J. L., and renzana-Seisdedos, F. (2001) J Biol. Chem. 276, 26550-26558

186. Hoogewerf, A. J., Kuschert, G. S., Proudfoot, A. E., Borlat, F., Clark-Lewis, I., Power, C. A., and Wells, T. N. (1997) Biochemistry 36, 13570-13578 
187. Lortat-Jacob, H., Grosdidier, A., and Imberty, A. (2002) Proc. Natl. Acad. Sci. U. S. A 99, $1229-1234$

188. Ohtsuki, T., Hosono, O., Kobayashi, H., Munakata, Y., Souta, A., Shioda, T., and Morimoto, C. (1998) FEBS Lett. 431, 236-240

189. Proost, P., Struyf, S., Schols, D., Durinx, C., Wuyts, A., Lenaerts, J. P., De, C. E., De, M., I, and Van, D. J. (1998) FEBS Lett. 432, 73-76

190. Shioda, T., Kato, H., Ohnishi, Y., Tashiro, K., Ikegawa, M., Nakayama, E. E., Hu, H., Kato, A., Sakai, Y., Liu, H., Honjo, T., Nomoto, A., Iwamoto, A., Morimoto, C., and Nagai, Y. (1998) Proc. Natl. Acad. Sci. U. S. A 95, 6331-6336

191. McQuibban, G. A., Butler, G. S., Gong, J. H., Bendall, L., Power, C., Clark-Lewis, I., and Overall, C. M. (2001) J Biol. Chem. 276, 43503-43508

192. Sternlicht, M. D. and Werb, Z. (2001) Annu. Rev. Cell Dev. Biol. 17, 463-516

193. Janowska-Wieczorek, A., Matsuzaki, A., and Marquez, A. (2000) Hematol 4, 515-527

194. Gross, J. and Lapiere, C. M. (1962) Proc. Natl. Acad. Sci. U. S. A 48, 1014-1022

195. Lepage, T. and Gache, C. (1990) EMBO J 9, 3003-3012

196. Llano, E., Pendas, A. M., za-Blanc, P., Kornberg, T. B., and Lopez-Otin, C. (2000) $J$ Biol. Chem. 275, 35978-35985

197. Wada, K., Sato, H., Kinoh, H., Kajita, M., Yamamoto, H., and Seiki, M. (1998) Gene 211, 57-62 
198. Kinoshita, T., Fukuzawa, H., Shimada, T., Saito, T., and Matsuda, Y. (1992) Proc. Natl. Acad. Sci. U. S. A 89, 4693-4697

199. Bode, W., Fernandez-Catalan, C., Grams, F., Gomis-Ruth, F. X., Nagase, H., Tschesche, H., and Maskos, K. (1999) Ann. N. Y. Acad. Sci. 878, 73-91

200. Murphy, G. and Willenbrock, F. (1995) Methods Enzymol. 248, 496-510

201. O'Shea, M., Willenbrock, F., Williamson, R. A., Cockett, M. I., Freedman, R. B., Reynolds, J. J., Docherty, A. J., and Murphy, G. (1992) Biochemistry 31, 10146-10152

202. Morgunova, E., Tuuttila, A., Bergmann, U., Isupov, M., Lindqvist, Y., Schneider, G., and Tryggvason, K. (1999) Science 284, 1667-1670

203. Deryugina, E. I., Ratnikov, B., Monosov, E., Postnova, T. I., DiScipio, R., Smith, J. W., and Strongin, A. Y. (2001) Exp Cell Res. 263, 209-223

204. Guile, G. R., Rudd, P. M., Wing, D. R., Prime, S. B., and Dwek, R. A. (1996) Anal. Biochem. 240, 210-226

205. Cameron, B. F. (1969) Electromyography. 9, 515-517

206. Wojtowicz-Praga, S. M., Dickson, R. B., and Hawkins, M. J. (1997) Invest New Drugs $15,61-75$

207. Burns, F. R., Stack, M. S., Gray, R. D., and Paterson, C. A. (1989) Invest Ophthalmol. Vis. Sci. 30, 1569-1575

208. Brown, P. (1993) Cur Opin Invest Drugs 2, 617-626 
209. Kraft, A. S., Baker, V. V., and May, W. S. (1987) Oncogene 1, 111-118

210. Johnson, M. D., Torri, J. A., Lippman, M. E., and Dickson, R. B. (1999) Exp Cell Res. 247, $105-113$

211. Reponen, P., Sahlberg, C., Huhtala, P., Hurskainen, T., Thesleff, I., and Tryggvason, K. (1992) J Biol. Chem. 267, 7856-7862

212. Itoh, T., Ikeda, T., Gomi, H., Nakao, S., Suzuki, T., and Itohara, S. (1997) J Biol. Chem. 272, 22389-22392

213. Esparza, J., Kruse, M., Lee, J., Michaud, M., and Madri, J. A. (2004) FASEB J 18, $1682-$ 1691

214. Corry, D. B., Kiss, A., Song, L. Z., Song, L., Xu, J., Lee, S. H., Werb, Z., and Kheradmand, F. (2004) FASEB J 18, 995-997

215. Samolov, B., Steen, B., Seregard, S., van, d. P., I, Montan, P., and Kvanta, A. (2005) Exp Eye Res. 80, 159-166

216. Martignetti, J. A., Aqeel, A. A., Sewairi, W. A., Boumah, C. E., Kambouris, M., Mayouf, S. A., Sheth, K. V., Eid, W. A., Dowling, O., Harris, J., Glucksman, M. J., Bahabri, S., Meyer, B. F., and Desnick, R. J. (2001) Nat. Genet. 28, 261-265

217. Al-Mayouf, S. M., Majeed, M., Hugosson, C., and Bahabri, S. (2000) Am. J Med. Genet. 93, 5-10

218. McQuibban, G. A., Gong, J. H., Tam, E. M., McCulloch, C. A., Clark-Lewis, I., and Overall, C. M. (2000) Science 289, 1202-1206 
219. Fowlkes, J. L., Thrailkill, K. M., Serra, D. M., Suzuki, K., and Nagase, H. (1995) Prog. Growth Factor Res. 6, 255-263

220. Zuo, J., Ferguson, T. A., Hernandez, Y. J., Stetler-Stevenson, W. G., and Muir, D. (1998) J Neurosci. 18, 5203-5211

221. Strongin, A. Y., Collier, I., Bannikov, G., Marmer, B. L., Grant, G. A., and Goldberg, G. I. (1995) J Biol. Chem. 270, 5331-5338

222. Bradley, J. M., Kelley, M. J., Rose, A., and Acott, T. S. (2003) Invest Ophthalmol. Vis. Sci. 44, 5174-5181

223. LORENZ, E. and CONGDON, C. C. (1954) J Natl. Cancer Inst. 14, 955-965

224. FORD, C. E., HAMERTON, J. L., BARNES, D. W., and LOUTIT, J. F. (1956) Nature $177,452-454$

225. Thomas, E., Storb, R., Clift, R. A., Fefer, A., Johnson, F. L., Neiman, P. E., Lerner, K. G., Glucksberg, H., and Buckner, C. D. (1975) N. Engl. J Med. 292, 832-843

226. Storb, R. and Thomas, E. D. (1983) Immunol. Rev. 71, 77-102

227. Philip, T., Guglielmi, C., Hagenbeek, A., Somers, R., Van der, L. H., Bron, D., Sonneveld, P., Gisselbrecht, C., Cahn, J. Y., Harousseau, J. L., and . (1995) N. Engl. J Med. 333, 1540-1545

228. Zittoun, R. A., Mandelli, F., Willemze, R., de, W. T., Labar, B., Resegotti, L., Leoni, F., Damasio, E., Visani, G., Papa, G., and . (1995) N. Engl. J Med. 332, 217-223 
229. Graw, R. G., Jr., Brown, J. A., Yankee, R. A., Leventhal, B. G., Whang-Peng, J., Rogentine, G. N., and Henderson, E. S. (1970) Blood 36, 736-747

230. Attal, M., Harousseau, J. L., Stoppa, A. M., Sotto, J. J., Fuzibet, J. G., Rossi, J. F., Casassus, P., Maisonneuve, H., Facon, T., Ifrah, N., Payen, C., and Bataille, R. (1996) N. Engl. J Med. 335, 91-97

231. Humblet, Y., Symann, M., Bosly, A., Delaunois, L., Francis, C., Machiels, J., Beauduin, M., Doyen, C., Weynants, P., Longueville, J., and . (1987) J Clin. Oncol. 5, 1864-1873

232. Bezwoda, W. R., Seymour, L., and Dansey, R. D. (1995) J Clin. Oncol. 13, 2483-2489

233. Atkinson, K. (1990) Bone Marrow Transplant. 5, 209-226

234. Atkinson, K., Meyers, J. D., Storb, R., Prentice, R. L., and Thomas, E. D. (1980) Transplantation 29, 47-50

235. Kretchmer, A. and Conover, W. (1969) Transplantation 8, 576-581

236. Lahiri, S. and van Putten, L. (1969) Cell Tissue Kinet 2, 21-28

237. Testa, N. G., Lord, B. I., and Shore, N. A. (1972) Blood 40, 654-661

238. Aizawa, S. and Tavassoli, M. (1988) Exp Hematol 16, 811-813

239. Papayannopoulou, T., Craddock, C., Nakamoto, B., Priestley, G. V., and Wolf, N. S. (1995) Proc. Natl. Acad. Sci. U. S. A 92, 9647-9651 
240. Kawabata, K., Ujikawa, M., Egawa, T., Kawamoto, H., Tachibana, K., Iizasa, H., Katsura, Y., Kishimoto, T., and Nagasawa, T. (1999) Proc. Natl. Acad. Sci. U. S. A 96, $5663-5667$

241. Wright, D. E., Bowman, E. P., Wagers, A. J., Butcher, E. C., and Weissman, I. L. (2002) $J$ Exp Med. 195, 1145-1154

242. Socinski, M. A., Cannistra, S. A., Elias, A., Antman, K. H., Schnipper, L., and Griffin, J. D. (1988) Lancet 1, 1194-1198

243. Schneider, J. G., Crown, J. P., Wasserheit, C., Kritz, A., Wong, G., Reich, L., Norton, L., and Moore, M. A. (1994) Bone Marrow Transplant. 14, 877-884

244. Haas, R., Hohaus, S., Goldschmidt, H., Witt, B., and Hunstein, W. (1993) J Hematother. 2, 357-359

245. Andrews, R. G., Briddell, R. A., Knitter, G. H., Opie, T., Bronsden, M., Myerson, D., Appelbaum, F. R., and McNiece, I. K. (1994) Blood 84, 800-810

246. Laterveer, L., Lindley, I. J., Heemskerk, D. P., Camps, J. A., Pauwels, E. K., Willemze, R., and Fibbe, W. E. (1996) Blood 87, 781-788

247. Reid, C. D., Kirk, A., and Chanarin, I. (1988) Lancet 2, 518-519

248. Papayannopoulou, T., Craddock, C., Nakamoto, B., Priestley, G. V., and Wolf, N. S. (1995) Proc. Natl. Acad. Sci. U. S. A 92, 9647-9651

249. Verfaillie, C. M. (2002) Nat. Immunol. 3, 314-317 
250. Korbling, M. and Anderlini, P. (2001) Blood 98, 2900-2908

251. Gazitt, Y. and Liu, Q. (2001) Stem Cells 19, 37-45

252. Petit, I., Szyper-Kravitz, M., Nagler, A., Lahav, M., Peled, A., Habler, L., Ponomaryov, T., Taichman, R. S., renzana-Seisdedos, F., Fujii, N., Sandbank, J., Zipori, D., and Lapidot, T. (2002) Nat. Immunol. 3, 687-694

253. Levesque, J. P., Takamatsu, Y., Nilsson, S. K., Haylock, D. N., and Simmons, P. J. (2001) Blood 98, 1289-1297

254. Levesque, J. P., Liu, F., Simmons, P. J., Betsuyaku, T., Senior, R. M., Pham, C., and Link, D. C. (2004) Blood 104, 65-72

255. Katayama, Y., Battista, M., Kao, W. M., Hidalgo, A., Peired, A. J., Thomas, S. A., and Frenette, P. S. (2006) Cell 124, 407-421

256. Tavassoli, M. and Friedenstein, A. (1983) Am. J Hematol 15, 195-203

257. Fried, W. and Barone, J. (1980) Exp Hematol 8, 610-614

258. Piersma, A. H., Ploemacher, R. E., and Brockbank, K. G. (1983) Exp Hematol 11, 884890

259. Galotto, M., Berisso, G., Delfino, L., Podesta, M., Ottaggio, L., Dallorso, S., Dufour, C., Ferrara, G. B., Abbondandolo, A., Dini, G., Bacigalupo, A., Cancedda, R., and Quarto, R. (1999) Exp Hematol 27, 1460-1466 
260. del, C. C., Lopez, N., Caballero, D., Fernandez, E., Brufau, A., Vazquez, L., Mateos, V., Gutierrez, N., and San Miguel, J. F. (1999) Bone Marrow Transplant. 23, 901-905

261. Corazza, F., Hermans, C., Ferster, A., Fondu, P., Demulder, A., and Sariban, E. (2004) Pediatr. Res. 55, 152-158

262. Chamberlin, W., Barone, J., Kedo, A., and Fried, W. (1974) Blood 44, 385-392

263. Fried, W., Kedo, A., and Barone, J. (1977) Cancer Res. 37, 1205-1209

264. Hall, B. M., Fortney, J. E., and Gibson, L. F. (2001) Biochem. Pharmacol. 61, 1243-1252

265. Gibson, L. F., Fortney, J., Landreth, K. S., Piktel, D., Ericson, S. G., and Lynch, J. P. (1997) Biol. Blood Marrow Transplant. 3, 122-132

266. Hall, B., Fortney, J., and Gibson, L. (2003) Analytical Pharmacology 4, 21-29 


\title{
CHAPTER II
}

MMP-2 Is Required for Bone Marrow Stromal Cell Support of Chemotaxis

\author{
Suzanne D. Clutter ${ }^{*}$, James Fortney ${ }^{\dagger}$, and Laura F. Gibson ${ }^{*,+, *}$
}

Department of Microbiology, Immunology, and Cell Biology ${ }^{*}$, Department of Pediatrics ${ }^{\dagger}$, and Blood and Marrow Transplant and Hematologic Malignancy Program, Mary Babb Randolph Cancer Center ${ }^{\ddagger}$, West Virginia University, Morgantown, WV 26505.

This manuscript was published in the journal of Experimental Hematology, Vol 33 (2005) 11921200. 


\begin{abstract}
It has become increasingly evident that chemotherapy regimens used to condition patients prior to bone marrow transplantation damage the hematopoietic microenvironment as doseescalation reveals problems with hematopoietic recovery or engraftment. We have previously demonstrated that bone marrow stromal cells exposed to dose escalated etoposide (VP-16) have reduced support of CXCR4+ cell chemotaxis and diminished stromal cell derived factor-1 (CXCL12) in the supernatants. Based on the identification of CXCL12 as a matrix metalloproteinase-2 (MMP-2) substrate, we investigated potential dysregulation of MMP-2 expression or activity in chemotherapy-treated stromal cells. Stromal cell exposure to VP-16 resulted in an immediate, but transient, increase in MMP-2 followed by reduced MMP-2 protein expression correlated with diminished CXCL12 protein and reduced chemotactic support. Consistent with these observations, stromal cells derived from MMP-2 knockout mice had significantly less chemotactic support of CXCR4+ cells than wild-type controls. Inhibition of stromal cell MMP-2 activity by the specific inhibitor, OA-Hy, also reduced chemotactic support and CXCL12 protein detected in supernatants. VP-16-induced reduction of bone marrow stromal cell support of hematopoietic cell migration was restored by supplementing cultures with physiological levels of recombinant MMP-2 protein. These data suggest that MMP-2 is sensitive to chemotherapy-induced stress, and may regulate stromal cell support of hematopoietic cell chemotaxis through diverse mechanisms. Increased MMP-2 expression during the acute phase of chemotherapy potentially mediates inactivation of CXCL12. Subsequently, chronic exposure to chemotherapy, with the associated downregulation of MMP-2, interrupts CXCL12 release from the extracellular matrix.
\end{abstract}




\section{INTRODUCTION}

Chemotaxis of hematopoietic progenitor or stem cells to the bone marrow microenvironment is essential for efficient hematopoietic recovery following bone marrow transplantation ${ }^{1,2}$. CXCL12 is the primary chemokine released by bone marrow stromal cells that promotes chemotaxis of transplanted progenitors to the bone marrow microenvironment ${ }^{3,4}$. Following migration to the bone marrow, hematopoietic progenitors interact with stromal cells which provide support to developing hematopoietic cells through the production of soluble cytokines and chemokines, and adhesion molecules that facilitate physical interaction ${ }^{5,6}$. In addition, bone marrow stromal cells deposit extracellular matrix that provides structural support and stabilizes hematopoietic growth factors in concentrated niches ${ }^{7-10}$. CXCL12 is concentrated and stabilized in the bone marrow microenvironment on heparin sulfated proteoglycans produced by stroma ${ }^{11}$.

Preparative regimens used prior to transplantation are aggressive, and have the potential to damage the hematopoietic microenvironment ${ }^{12-15}$. One chemotherapeutic agent, etoposide (VP-16), has previously been shown to negatively influence bone marrow stromal cell support of hematopoiesis, in part, by diminishing vacsular cell adhesion molecule (VCAM-1) protein ${ }^{16}$. Studies from our own laboratory have shown that VP-16 exposure also results in reduced ability of stromal cells to support pro-B cell chemotaxis ${ }^{17}$. Together, these observations highlight the vulnerability of stroma to chemotherapy damage, and prompted our investigation of the mechanisms by which chemotherapy reduces efficiency of pro-B cell chemotaxis. 
MMPs have traditionally been considered in the context of extracellular matrix regulation, however additional roles have been identified, including regulation of hematopoiesis ${ }^{18-20}$. Based on studies by others that documented the ability of MMP-2 to cleave and inactivate CXCL12 ${ }^{21}$, we determined whether VP-16 exposure increased MMP-2 activity or expression in bone marrow stromal cells, contributing to reduced chemotactic support. An immediate increase in MMP-2 activity following initiation of VP-16 exposure was observed, that was pronounced and transient. Bone marrow stromal cells exposed to greater than 5 hours of chemotherapy expressed less MMP-2 protein than control stromal cells. Coincident with reduced MMP-2 expression is a reduction of CXCL12 protein and chemotactic support capacity. These observations position MMP-2 as a factor in the bone marrow microenvironment that can respond to external stresses, including chemotherapy, and influence support of hematopoietic reconstitution through regulation of the CXCL12 gradient. 


\section{MATERIALS AND METHODS}

\section{Reagents}

VP-16 (etoposide, Bristol Laboratories, Princeton, NJ) was stored at a stock concentration of $33.98 \mathrm{mM}$ at $-20^{\circ} \mathrm{C}$ and was diluted in $\alpha$-Modification of Eagles Medium $(\alpha-$ MEM, GIBCO, Grand Island, NY) immediately prior to use. MMP-2 Inhibitor I (Cis-9Octadeconyl-N-hydroxylamide, OA-Hy, Calbiochem, San Diego, CA) was reconstituted in DMSO at 10mM immediately prior to use. Recombinant human MMP-2 (Biomol International L.P., Plymouth Meeting, PA) and recombinant murine MMP-2 (R\&D Systems Inc., Minneapolis, MN) were diluted in media at the indicated concentrations. Mouse anti-human MMP-2 (Ab 3) monoclonal antibody was obtained from Calbiochem, Boston, MA.

\section{Cell lines and culture conditions}

Stromal cell cultures were initiated from human bone marrow from consenting donors, with approval by the West Virginia University Institutional Review Board, as previously described ${ }^{15}$. All primary bone marrow stromal cells cultures were initiated from donors with no previous chemotherapy exposure. Bone marrow stromal cells were maintained in $\alpha$-MEM supplemented with 10\% fetal bovine serum (Hyclone, Logan, UT), 1\% L-glutamine (GIBCO, Grand Island, NY), 1\% Penicillin/Streptomycin (Sigma, St. Louis, MO), and 0.1\% 2-betamercapthanol (Sigma, St. Louis, MO).

Murine bone marrow stromal cell line S10 was provided by Dr. Kenneth Dorshkind (University of California Los, Angeles). Characterization and maintenance of S10 has been previously described in detail ${ }^{22}$. S10 stromal cells were grown to confluence in $\alpha$-MEM 
supplemented with $2.5 \%$ fetal bovine serum, $1 \%$ L-glutamine (GIBCO, Grand Island, NY), $1 \%$ Penicillin/Streptomycin (Sigma, St. Louis, MO), and 0.1\% 2-beta-mercapthanol (Sigma, St. Louis, MO).

Murine pro-B cell clone C1.92 was provided by Dr. Kenneth S. Landreth (West Virginia University). Derivation of C1.92 has been previously described ${ }^{23}$. C1.92 was maintained in the presence of the bone marrow stromal cell line S-10 and 50U/mL recombinant murine IL-7 (mIL7, Biosource International, Westlake Village, CA).

MMP-2-/- and wild type (WT) bone marrow stromal cells were initiated from femurs isolated from C57BL/6 WT and C57BL/6 MMP-2 knockout mice (kindly provided by Dr. Farrah Kheradmand; Baylor College of Medicine) ${ }^{24}$. WT and MMP-2-/- stromal cells were cultured in $\alpha$-MEM supplemented with 2.5\% fetal bovine serum, $1 \%$ L-glutamine (GIBCO, Grand Island, NY), 1\% Penicillin/Streptomycin (Sigma, St. Louis, MO), and 0.1\% 2-beta-mercapthanol (Sigma, St. Louis, MO).

\section{Gelatin Zymography}

Bone marrow stromal cells supernatants were collected following 2 hours treatment in

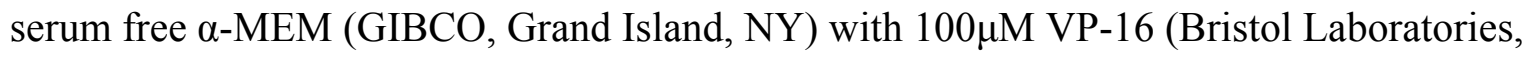
Princeton, NJ). Supernatants were concentrated 10X using Amicon ${ }^{\circledR}$ Ultra-15 Centrifugal Filters (Millipore, Billerica, MA). Samples were resolved in SDS-PAGE gels containing $1 \mathrm{mg} / \mathrm{mL}$ gelatin (Sigma, St. Louis, MO). Following electrophoresis, gels were incubated for 30 minutes in 2.5\% Triton-X-100 (Mallinckrodt, Inc., Paris, KY) and subsequently incubated overnight at $37^{\circ} \mathrm{C}$ in $1 \mathrm{X}$ developing buffer $(1.2 \%$ Tris Base, $6.3 \%$ Tris $\mathrm{HCl}, 11.7 \% \mathrm{NaCl}, 0.7 \%$ $\mathrm{CaCl}, 0.2 \%$ Brij 35). Gels were then stained with 0.5\% Coomassie Blue R-250 (Bio-Rad 
Laboratories, Richmond, CA) for 30 minutes at room temperature and then destained (50\%

Methanol, $10 \%$ acetic acid, $40 \% \mathrm{dH}_{2} 0$ ) until clear bands were detected indicative of MMP-2 and/or MMP-9.

\section{Western blot analysis}

Confluent bone marrow stromal cells were treated with $25-100 \mu \mathrm{M}$ VP-16 for 24 hours. To determine protein stability, confluent stromal cells were set up in duplicate and treated with both $100 \mu \mathrm{M}$ VP-16 and 25:g/mL cycloheximide or VP-16 alone for 2 to 24 hours. Supernatants were collected following treatment and concentrated 10x using Amicon ${ }^{\circledR}$ Ultra-15 Centrifugal Filter Devices (Millipore, Billerica, MA). Media was centrifuged at 3,000xg for 10 minutes at room temperature. Concentrated supernatants were resolved on SDS-PAGE gels and transferred to nitrocellulose membranes (Schleicher \& Schuell bioscience, Inc., Keene, NH). Membranes were blocked in TBS/5\% nonfat dry milk/0.1\% Tween-20 at room temperature for 1 hour and probed with mouse anti-human MMP-2 monoclonal antibody. Proteins were detected by incubation with horseradish peroxidase-conjugated secondary antibody and visualized with ECL reagents (Amersham, Pharmacia Biotech, Piscataway, NJ).

\section{Confocal Microscopy}

Bone marrow stromal cells were grown to confluence on glass coverslips and treated with $100 \mu \mathrm{M}$ VP-16 for 24 hours. Following treatment, stromal cells were rinsed in autoclaved $1 \mathrm{X}$ PBS and fixed in 1:1 methanol:acetone for 20 minutes. Non-specific antibody binding was blocked by incubation of stroma for 15 minutes in autoclaved 1X PBS/ 5\% BSA. Intracellular MMP-2 was evaluated by incubation of stromal cells with MMP-2 monoclonal antibody for $1 \mathrm{hr}$. 
PE conjugated secondary antibody was then added to stroma for 60 minutes and coverslips were inverted on slides and evaluated by confocal microscopy (Zeiss LSM 510, Thornwood, NY).

\section{RNA Isolation}

Total RNA was isolated from bone marrow stromal cells using the Micro-to-Midi Total RNA Isolation kit following the recommendations of the manufacturer (Invitrogen, Carlsbad, CA). Pelleted stromal cells were lysed by centrifugation through QIA shredder Spin Columns (QIAGEN Inc, Santa Clarita, CA). RNA was treated with $1 \mathrm{U}$ DNAse for 30 minutes at $37^{\circ} \mathrm{C}$ and samples were quantitated at 260nm (GENESYS-10UV, Spectronic Unicam, Rochester, NY).

\section{PCR}

To evaluate MMP-2 and $\beta$-actin RNA levels, semi-quantitative “One-Step” RT-PCR (QIAGEN Inc., Valencia, CA) was completed using 0.1 $\mu \mathrm{g}$ RNA isolated from untreated or VP16 treated bone marrow stromal cells. Reverse transcription was completed by incubation of samples at $42^{\circ} \mathrm{C}$ for 90 minutes and amplification initiated by a hot start at $95^{\circ} \mathrm{C}$ for 5 minutes, followed by 35 cycles of $94^{\circ}-1$ minute, $55^{\circ}-1$ minute, and $72^{\circ}-1$ minute (Perkin-Elmer GeneAmp PCR System 9600). Actin and MMP-2 primers (0.1 $\mu \mathrm{g} / \mathrm{sample})$ were added to each reaction. Actin specific primers included 5'TGACGGGGTCACCCACACTGTGCCCATCTA-3' and 5'TAGAAGCATTTGCGGTGGACGATGGAGGG-3' (Stratagene, La Jolla, CA) to generate an amplicon of 661 base pairs. MMP-2 primers were 5'-GGCCCTGTCACTCCTGAGAT3' and 5'-GGCATCCAGGTTATCGGGGA-3' (Biosource International, Camarillo, CA) to generate an amplicon of 474 base pairs. MMP-2 to actin ratios were quantitated by EagleSight Version 3.21 
(Stratagene, La Jolla, CA) densitometric analysis. The linear range of amplification was determined for each primer set prior to use.

\section{RNAse protection assay}

Confluent bone marrow stromal cell layers were treated with 25,50 or $100 \mu \mathrm{M}$ VP-16 for 24 hours. RNAse protection assays were performed using an RPAIII kit according to the

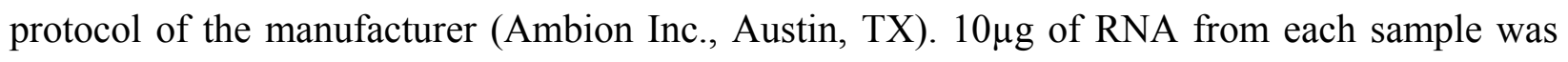
hybridized to $32 \mathrm{P}-1$ labeled MMP-2, GAPDH, and L-32 specific probes. Anti-sense 32P-RNA probes were generated using T7 RNA polymerase-directed synthesis from RiboQuant DNA templates (PharMingen, San Diego, CA). Nucleic acids were treated with RNAse A and T1 to digest unhybridized sequences. Protected RNA fragments that corresponded to MMP-2 and GAPDH were visualized by exposure to Phospho Imager cassettes (Molecular Dynamics, Sunnyvale, CA). MMP-2 band intensities were normalized to GAPDH or L-32 controls in each treatment group.

\section{CXCL12 and MMP-2 ELISA}

Confluent bone marrow stromal cells were treated with $1 \mu \mathrm{M}$ OA-Hy or $100 \mu \mathrm{M}$ VP-16 for 24 hours. $100 \mu \mathrm{L}$ of 24 -hour stromal cell conditioned supernatant was collected from each well to evaluate CXCL12 or MMP-2 protein by ELISA, following the recommendations of the manufacturer (R\&D Systems, Inc, Minneapolis, MN). All samples were evaluated in triplicate. Colorimetric values were read on a plate reader (Biotek Instruments, Inc., Winoski, VT) and analyzed by the KC Junior software with reference wavelengths set at $450 \mathrm{nM}$ and correction wavelength set at $540 \mathrm{nM}$. 


\section{Intracellular CXCL12 Staining}

Bone marrow stromal cells were grown to confluence and exposed to $100 \mu \mathrm{M}$ VP-16, $1 \mu \mathrm{M}$ OA-Hy or DMSO for 24 hours. Following treatment, stromal cells were trypsinized, collected, and fixed in 10\% formaldehyde for 30 minutes. Stromal cells were rinsed in 1X PBS and permeabolized in $70 \% \mathrm{EtOH}$ for 30 minutes on ice. To prevent non specific antibody binding, stromal cells were blocked in PBS/5\% BSA for 15 minutes and subsequently incubated with 2 ug of CXCL12 specific antibody or isotype control for 20 minutes. PE conjugated secondary antibody was added to stromal cells for 20 minutes. Stromal cells were rinsed, evaluated by flow cytometry and data were analyzed using CellQuest software (Becton Dickinson, San Jose, CA).

\section{Chemotaxis assay}

Confluent bone marrow stromal cell layers, grown in 24-well tissue culture plates (Becton Dickinson, Franklin Lakes, NJ), were treated with $100 \mu \mathrm{M}$ VP-16, $1 \mu \mathrm{M}$ OA-Hy, or left untreated for 24 hours. Stromal cells were then rinsed with fresh medium and $350 \mu \mathrm{L}$ of medium, or medium supplemented with $10 \mathrm{ng} / \mathrm{mL}$ recombinant murine MMP-2 or $25 \mathrm{ng} / \mathrm{mL}$ recombinant human MMP-2 was placed in the bottom chamber of each well for 2 hours. In addition, C57BL/6 WT or MMP-2-/- bone marrow stromal cells were grown in $350 \mu \mathrm{L} \alpha-\mathrm{MEM}$ in 24-well tissue culture plates for 24 hours. Following incubation, transwells with $5 \mu$ pores (Corning Inc., Corning, NY) containing $1.5 \times 10^{5} \mathrm{C} 1.92$ were placed into each well. Following incubation at $37^{\circ} \mathrm{C}$ for 4 hours, cells migrating to the lower chamber were enumerated by flow cytometry (number of events/30-second collection). Recombinant CXCL12 (100ng/mL R\&D Systems Inc., 
Minneapolis, MN), and medium alone served as the positive and negative control respectively. All samples were evaluated in triplicate.

\section{Statistical Analysis}

Statistical analysis was performed using Student's T-test to detect differences among means (SigmaStat Version 4.0 software, SPSS Inc., Chicago, IL). All statistical comparisons represent treated samples compared to control levels. Statistically significant differences are indicated by and asterisk on appropriate graphs. 


\section{RESULTS}

\section{MMP-2 expression is regulated distinctly during acute and chronic VP-16 exposure.}

To evaluate alterations in MMP-2 protein, we performed gelatin zymography on supernatants from bone marrow stromal cells that were exposed to VP-16. Following treatment, stromal cell MMP-2 levels increased at 30 minutes and subsequently began to diminish following 5 hours of VP-16 exposure (Figure 1A).

To determine whether VP-16 alters bone marrow stromal cell production of MMP-2 during long-term exposure, we evaluated several primary human bone marrow stromal cell lines by ELISA following 24 hours of exposure to VP-16. MMP-2 protein was diminished in supernatants of stromal cells to approximately $12 \%$ to $58 \%$ of that in untreated controls (Data not shown). MMP-2 protein was also evaluated by western blot and the amount of active and latent MMP-2 protein in concentrated supernatants was determined to be reduced by VP-16 exposure compared to untreated controls (Figure 1B). MMP-2 protein was not altered in stromal cells treated with VP-16 solvent control (Data not shown). Reduction of MMP-2 protein in stromal cells exposed to VP-16 for 24 hours was not due to intracellular accumulation (Figure 1C) or reduced protein stability (Figure 1D).

In contrast to MMP-2 protein, MMP-2 mRNA was not reduced during VP-16 exposure. Semi-quantitative RT-PCR (Figure 2A) illustrates that stromal cells treated with $100 \mu \mathrm{M}$ VP-16 do not have diminished MMP-2 mRNA. This result was confirmed by RNAse protection (Figure 2B).

MMP-2 protein is necessary for optimal stromal cell support of chemotaxis. 
To determine if MMP-2 protein is necessary for bone marrow stromal cell support of proB cell chemotaxis we compared control stromal cells with stromal cells treated with OA-Hy or Bone marrow stromal cells derived from WT and MMP-2/- mice. Addition of OA-Hy to stromal cells resulted in approximately 50\% reduction in the ability of human primary (P151) and murine S-10 bone marrow stromal cells to support C1.92 pro-B cell chemotaxis (Figure 3A). Direct addition of OA-Hy to CXCL12 did not reduce support of chemotaxis (Figure 3A). MMP$2^{-/-}$bone marrow stromal cells also had diminished ability to support chemotaxis compared to WT control stromal cells (Figure 3B). Addition of recombinant CXCL12 restored MMP-2/stromal cell support of chemotaxis to approximately 93\% of control stromal cells. (Figure 3B).

\section{CXCL12 protein is diminished in supernatants following MMP-2 inhibition.}

To determine whether MMP-2 is required for release of CXCL12 protein into supernatants of adherent bone marrow stromal cells, stromal cells were treated with $1 \mu \mathrm{M}$ OA-Hy for 24 hours. CXCL12 protein was diminished in OA-Hy treated stromal cell supernatants compared to DMSO solvent control treated stromal cells (Figure 4A). The reduction of CXCL12 in supernatants was not due to intracellular accumulation of CXCL12 protein (Figure 4B). CXCL12 mRNA was not altered by OA-Hy treatment, determined by RT-PCR (Data not shown).

Recombinant MMP-2 protein restores VP-16 treated bone marrow stromal cell support of chemotaxis.

To determine whether addition of MMP-2 protein could restore VP-16 treated bone marrow stromal cell support of chemotaxis; we first determined the amount of MMP-2 protein 
that primary human stromal cell line (P156) and C57BL/6 stromal cells produced at steady state (Data not shown). Based on our ELISA results, we added 25ng/mL rhMMP-2 to VP-16-treated P156 bone marrow stromal cells or $10 \mathrm{ng} / \mathrm{mL}$ rmMMP-2 to C57BL/6 MMP-2 ${ }^{-/-}$bone marrow stromal cells to approximate physiological levels. Addition of MMP-2 restored VP-16-treated and MMP-2 $2^{-/-}$stromal cell support of chemotaxis to greater than $100 \%$ of untreated human P156 stromal cells (Figure 5A) and 85\% of that supported by WT murine stromal cells (Figure 5B). 


\section{DISCUSSION}

In the current study we found that bone marrow stromal cell MMP-2 is affected differentially by acute and chronic exposure to VP-16. Increased MMP-2 expression was transient in VP-16 stromal cells. Subsequent to the acute response, MMP-2 protein was reduced when stromal cells were exposed to VP-16 for longer periods of time. The consequence of chronic exposure of stromal cells to VP-16 is the main focus of the current study. Our data suggest that chemotherapy down regulates MMP-2 protein expression and disrupts CXCL12 supported chemotaxis, potentially, by inhibiting CXCL12 release from the stromal cell surface. This novel role for MMP-2 in CXCL12 regulation broadens the context in which MMPs may influence hematopoiesis. Further, it contributes to our understanding of factors that may impact on chemotactic support by the bone marrow microenvironment following aggressive chemotherapy.

We have previously shown that VP-16 induces many alterations in bone marrow stromal

cells that result in disrupted support of hematopoiesis ${ }^{16,17}$. In the current report, we show that VP-16 treatment $(100 \mu \mathrm{M})$ increases, and then subsequently reduces, the amount of MMP-2 protein detected in stromal cell supernatants (Figure 1). VP-16 exposure rapidly increases stromal cell ROS generation, potentially allowing for immediate activation of MMP-2 through conformation changes resulting in auto-catalytic cleavage of MMP-2's pro-domain (Chapter III). The mechanism of diminished MMP-2 protein during chronic VP-16 exposure is not due to reduced MMP-2 mRNA or intracellular accumulation of protein (Figure 1,2). Further, the stability of MMP-2 protein is not reduced by VP-16 (Figure 1). 
Based on this study, future investigations will focus, in part, on disruption of translation efficiency of MMP-2 transcripts in VP-16 treated bone marrow stromal cells. In other models VP-16 has been shown to blunt phosphorylation of Eukaryotic Initiation Factor $4 \alpha(\text { EIF } 4 \alpha)^{25}$ which is necessary for MMP-2 translational initiation to occur ${ }^{26}$. Additionally, VP-16 treatment of Swiss 3T3 fibroblast cells increased association of cap binding protein eIF-4E with its inhibitory binding protein $4 \mathrm{E}-\mathrm{BP}{ }^{27}$. Unsequestered eIF-4E is also necessary for efficient translation of MMP-2 message ${ }^{26}$. These observations suggest that disrupted translation may be one consequence of VP-16-induced damage, resulting in potentially diverse effects on stromal cell function.

Initial observations that preceded this study indicated that the addition of OA-Hy to established bone marrow stromal cell pro-B cell co-cultures resulted in diminished adhesion of pro-B cells to stromal cells, a subsequent accumulation of pro-B cells in G0/G1 phase of cell cycle, and increased apoptosis (Data not shown). Clearly, the effects of OA-Hy on the co-culture may be due to a direct effect of MMP-2 inhibition on stromal cell function, pro-B cell proliferation or survival, or a combination of effects on both cell types. The current study was aimed at isolating the effects of diminished MMP-2 on stromal cell influence of hematopoietic support capacity.

B lymphopoiesis has not been evaluated in MMP-2 $2^{-/}$mice. However, MMP-2 ${ }^{-/-}$mice have been used to study antibody induced asthma, arthritis, and Experimental Autoimmune Encephalomyelitis (EAE) ${ }^{28-30}$. Increased incidence of EAE in MMP-2 ${ }^{-/}$mice is due to an increase in T-cell MMP-9 expression. B cells were not evaluated in this model so no conclusion can be drawn regarding B lymphopoiesis in the absence of MMP-2 in vivo ${ }^{28}$. However, it has become increasingly evident that MMPs influence hematopoietic cell support in the bone 
marrow microenvironment from other studies. One report indicates that MMP-9 is required to release soluble Kit-ligand within the bone marrow microenvironment, which regulates stem cells movement from quiescent to proliferative niches ${ }^{31}$. This study is just one that provides precedent for MMPs function within the bone marrow microenvironment as a regulator of growth-factor availability.

To determine whether diminished MMP-2 expression in bone marrow stromal cells exposed to VP-16 contributes to reduced support of chemotaxis, we treated stromal cells with OA-Hy, and quantitated the ability of treated stroma to support pro-B cell chemotaxis. Consistent with VP-16 exposure, MMP-2 inhibition by OA-Hy diminished stromal cell support of chemotaxis (Figure 3A). Because the use of chemical inhibitors has the limitation of nonspecific effects, we chose to further investigate MMP-2 in a more specific manner. To do so, we established bone marrow stromal cells from MMP-2 knockout mice. MMP-2/- stromal cells used in this study were established from the only MMP- $2^{-/ 2}$ mice currently available to our laboratory (femurs generously provided by Dr. Farrah Kheradmand). This MMP-2 ${ }^{-/}$was generated on the C57BL/6 background. We have previously noted that C57BL/6 bone marrow stromal cells are very resistant to chemotherapy and display enhanced support of pro-B cells when compared to human or Balb/c derived bone marrow stromal cells (unpublished data). MMP-2 ${ }^{-/}$stromal cells were less able to support pro-B cell chemotaxis than stromal cells established from wild-type control mice, further supporting a role for MMP-2 protein in CXCL12 directed migration of proB cells (Figure 3B).

OA-Hy treated stromal cells secrete less CXCL12 protein than controls (Figure 4A), however, we have confirmed that this is not due to intracellular accumulation of the CXCL12 protein (Figure 4B). This suggests that MMP-2 may regulate release of CXCL12 from the 
stromal cell surface. Potentially, when MMP-2 protein is below physiological levels, as observed following VP-16 exposure or OA-Hy treatment, proteoglycan bound CXCL12 is not efficiently released and an optimal chemotactic gradient is not established. Consistent with a role for MMPs in regulating chemokine gradients, MMP- $2^{-/-}$mice used in an antibody-induced asthma model have inflammatory cells sequestered in lung parenchyma resulting in asphyxiation. Notably, MMP-2 protein is required for release of eotaxin chemokine (CCL11) ${ }^{24}$ which is necessary for directed migration of inflammatory cells out of the lung parenchyma.

Restoration of diminished bone marrow stromal cell chemotactic support by VP-16 treated stroma occurred only when recombinant MMP-2 protein was added back at physiological levels (Figure 5B). Levels that exceeded baseline decreased chemotactic support of stromal cells. A previous report indicates that MMP-2 can cleave and inactivate CXCL12, resulting in reduced chemotactic support ${ }^{21}$. Our data suggest that inactivation of CXCL12 by MMP-2 may occur when active MMP-2 is elevated during the acute response to chemotherapy. This may reduce the concentration of active CXCL12 in the bone marrow microenvironment, contributing to diminished recruitment of CXCR4+ pro-B cells. Consistent with the report noted above, we found that increased MMP-2 diminished CXCL12 supported chemotaxis in a dose responsive manner (Data not shown). Our data suggest that at physiological levels bone marrow stromal cell MMP-2 may release proteoglycan bound CXCL12 establishing a chemotactic gradient, while inappropriately high levels observed during tissue damage inactivate CXCL12 protein. Potentially, dysregulation of MMP-2 that occurs during VP-16 exposure may contribute to diminished bone marrow stromal cell chemotactic support by this combination of effects on CXCL12 activity and availability. 


\section{ACKNOWLEDGEMENTS}

This work was supported, in part, by NIH ROI HL056888 (LFG) and NRSA Institutional Training Grant in Environmental Science ES010953 (SDC). 


\section{REFERENCES}

1. Hendrikx, P. J., C. M. Martens, A. Hagenbeek, J. F. Keij, and J. W. Visser. 1996. Homing of fluorescently labeled murine hematopoietic stem cells. Exp.Hematol. 24:129-140.

2. Papayannopoulou, T. and C. Craddock. 1997. Homing and trafficking of hemopoietic progenitor cells. Acta Haematol. 97:97-104.

3. Jo, D. Y., S. Rafii, T. Hamada, and M. A. Moore. 2000. Chemotaxis of primitive hematopoietic cells in response to stromal cell-derived factor-1. J.Clin.Invest 105:101-111.

4. D'Apuzzo, M., A. Rolink, M. Loetscher, J. A. Hoxie, I. Clark-Lewis, F. Melchers, M. Baggiolini, and B. Moser. 1997. The chemokine CXCL12, stromal cell-derived factor 1, attracts early stage B cell precursors via the chemokine receptor CXCR4. Eur.J.Immunol. 27:1788-1793.

5. Janczewska, S., A. Ziolkowska, M. Durlik, E. Cybulska, W. L. Olszewski, and B. Lukomska. 1999. Requirement of stromal cells in the bone marrow transplant for rapid lymphoid replenishment. Transplant.Proc. 31:696-699.

6. Strobel, E. S., D. Mobest, S. von Kleist, M. Dangel, S. Ries, R. Mertelsmann, and R. Henschler. 1997. Adhesion and migration are differentially regulated in hematopoietic progenitor cells by cytokines and extracellular matrix. Blood 90:3524-3532.

7. Morris, A. J., J. E. Turnbull, G. P. Riley, M. Y. Gordon, and J. T. Gallagher. 1991. Production of heparan sulphate proteoglycans by human bone marrow stromal cells. J.Cell Sci. 99 ( Pt 1):149-156. 
8. Gallagher, J. T., E. Spooncer, and T. M. Dexter. 1983. Role of the cellular matrix in haemopoiesis. I. Synthesis of glycosaminoglycans by mouse bone marrow cell cultures. J.Cell Sci. 63:155-171.

9. Drzeniek, Z., B. Siebertz, G. Stocker, U. Just, W. Ostertag, H. Greiling, and H. D. Haubeck. 1997. Proteoglycan synthesis in haematopoietic cells: isolation and characterization of heparan sulphate proteoglycans expressed by the bone-marrow stromal cell line MS-5. Biochem.J. 327 ( Pt 2):473-480.

10. Roberts, R., J. Gallagher, E. Spooncer, T. D. Allen, F. Bloomfield, and T. M. Dexter. 1988. Heparan sulphate bound growth factors: a mechanism for stromal cell mediated haemopoiesis. Nature 332:376-378.

11. Amara, A., O. Lorthioir, A. Valenzuela, A. Magerus, M. Thelen, M. Montes, J. L. Virelizier, M. Delepierre, F. Baleux, H. Lortat-Jacob, and F. Arenzana-Seisdedos. 1999. Stromal cell-derived factor-1alpha associates with heparan sulfates through the first betastrand of the chemokine. J.Biol.Chem. 274:23916-23925.

12. Verdrengh, M. and A. Tarkowski. 2003. Impact of topoisomerase II inhibition on cytokine and chemokine production. Inflamm.Res. 52:148-153.

13. Galotto, M., G. Berisso, L. Delfino, M. Podesta, L. Ottaggio, S. Dallorso, C. Dufour, G. B. Ferrara, A. Abbondandolo, G. Dini, A. Bacigalupo, R. Cancedda, and R. Quarto. 1999. Stromal damage as consequence of high-dose chemo/radiotherapy in bone marrow transplant recipients. Exp.Hematol. 27:1460-1466. 
14. Chamberlin, W., J. Barone, A. Kedo, and W. Fried. 1974. Lack of recovery of murine hematopoietic stromal cells after irradiation-induced damage. Blood 44:385-392.

15. Gibson, L. F., J. Fortney, K. S. Landreth, D. Piktel, S. G. Ericson, and J. P. Lynch. 1997. Disruption of bone marrow stromal cell function by etoposide. Biol.Blood Marrow Transplant. 3:122-132.

16. Hall, B. M., J. E. Fortney, and L. F. Gibson. 2001. Alteration of nuclear factor-kappaB (NF-6B) expression in bone marrow stromal cells treated with etoposide. Biochem.Pharmacol. 61:1243-1252.

17. Hall, B. M. Human Bone Marrow Stromal Cell CXCL12 Production Is Reduced Following Exposure To Topoisosmerase II Inhibitors, Etoposide Or Doxorubicin. Fortney, J. E. and Gibson, L. F. Analytical Pharmacology 4(2), 21-29. 2003.

18. Sternlicht, M. D. and Z. Werb. 2001. How matrix metalloproteinases regulate cell behavior. Annu.Rev.Cell Dev.Biol. 17:463-516.

19. Marquez-Curtis, L. A., A. Dobrowsky, J. Montano, A. R. Turner, J. Ratajczak, M. Z. Ratajczak, and A. Janowska-Wieczorek. 2001. Matrix metalloproteinase and tissue inhibitors of metalloproteinase secretion by haematopoietic and stromal precursors and their production in normal and leukaemic long-term marrow cultures. Br.J.Haematol. 115:595-604. 
20. Janowska-Wieczorek, A., A. Matsuzaki, and A. Marquez. 2000. The Hematopoietic Microenvironment: Matrix Metalloproteinases in the Hematopoietic Microenvironment. Hematol. 4:515-527.

21. McQuibban, G. A., G. S. Butler, J. H. Gong, L. Bendall, C. Power, I. Clark-Lewis, and C. M. Overall. 2001. Matrix metalloproteinase activity inactivates the CXC chemokine stromal cell-derived factor-1. J.Biol.Chem. 276:43503-43508.

22. Collins, L. S. and K. Dorshkind. 1987. A stromal cell line from myeloid long-term bone marrow cultures can support myelopoiesis and B lymphopoiesis. J.Immunol. 138:10821087.

23. Gibson, L. F., D. Piktel, and K. S. Landreth. 1993. Insulin-like growth factor-1 potentiates expansion of interleukin-7-dependent pro-B cells. Blood 82:3005-3011.

24. Corry, D. B., K. Rishi, J. Kanellis, A. Kiss, L. Z. Song Lz, J. Xu, L. Feng, Z. Werb, and F. Kheradmand. 2002. Decreased allergic lung inflammatory cell egression and increased susceptibility to asphyxiation in MMP2-deficiency. Nat.Immunol. 3:347-353.

25. Jeffrey, I. W., M. Bushell, V. J. Tilleray, S. Morley, and M. J. Clemens. 2002. Inhibition of protein synthesis in apoptosis: differential requirements by the tumor necrosis factor alpha family and a DNA-damaging agent for caspases and the double-stranded RNA-dependent protein kinase. Cancer Res. 62:2272-2280.

26. Bradley, J. M., M. J. Kelley, A. Rose, and T. S. Acott. 2003. Signaling pathways used in trabecular matrix metalloproteinase response to mechanical stretch. Invest Ophthalmol.Vis.Sci. 44:5174-5181. 
27. Tee, A. R. and C. G. Proud. 2000. DNA-damaging agents cause inactivation of translational regulators linked to mTOR signalling. Oncogene 19:3021-3031.

28. Esparza, J., M. Kruse, J. Lee, M. Michaud, and J. A. Madri. 2004. MMP-2 null mice exhibit an early onset and severe experimental autoimmune encephalomyelitis due to an increase in MMP-9 expression and activity. FASEB J. 18:1682-1691.

29. Corry, D. B., A. Kiss, L. Z. Song, L. Song, J. Xu, S. H. Lee, Z. Werb, and F. Kheradmand. 2004. Overlapping and independent contributions of MMP2 and MMP9 to lung allergic inflammatory cell egression through decreased CC chemokines. FASEB J. 18:995-997.

30. Itoh, T., H. Matsuda, M. Tanioka, K. Kuwabara, S. Itohara, and R. Suzuki. 2002. The role of matrix metalloproteinase- 2 and matrix metalloproteinase- 9 in antibody-induced arthritis. J.Immunol. 169:2643-2647.

31. Heissig, B., K. Hattori, S. Dias, M. Friedrich, B. Ferris, N. R. Hackett, R. G. Crystal, P. Besmer, D. Lyden, M. A. Moore, Z. Werb, and S. Rafii. 2002. Recruitment of stem and progenitor cells from the bone marrow niche requires MMP-9 mediated release of kitligand. Cell 109:625-637. 


\section{FIGURE LEGENDS}

Figure 1. MMP-2 protein is dysregulated in bone marrow stromal cells exposed to VP-16. (A) Stromal cell supernatants were conditioned in serum-free medium for 8 hours. At each time point (30 minutes -8 hours) 100:M VP-16 was added to the conditioned stromal cell media. After 8 hours the supernatants were collected and gelatin zymography performed to detect MMP-2. (B) Supernatants were collected from VP-16 treated bone marrow stromal cells and concentrated as described in Materials and Methods. MMP-2 monoclonal antibody was used to detect MMP-2 protein in VP-16 treated groups compared to supernatants collected from untreated control stromal cells. Data are representative of three independent experiments. (C) Bone marrow stromal cells treated with $100 \mu \mathrm{M}$ VP-16 for 24 hours were fixed and stained with MMP-2 monoclonal antibody and subsequently incubated with PE-tagged secondary antibody. Fluorescence was detected by confocal microscopy. (D) Confluent bone marrow stromal cells were treated with either VP-16 or VP-16 and cycloheximide for 2-24 hours. At each time point the supernatants were collected, concentrated 10X, and subjected to western blot with antibody specific to MMP-2.

Figure 2. MMP-2 mRNA is not diminished following VP-16 exposure. (A) MMP-2 mRNA is not altered by VP-16 treatment of bone marrow stromal cells. Stromal cells were treated for the indicated times with 100uM VP-16. Semi-quantitative RT-PCR was performed to estimate the amount of MMP-2 message in each sample relative to $\beta$-actin. Representative data from three independent experiments are shown. (B) Bone marrow stromal cells were treated with 50 or 
$100 \mu \mathrm{M}$ VP-16 for 24 hours, RNA was extracted, and RNAse protection assay was completed with probes specific for MMP-2 and GAPDH sequences.

Figure 3. MMP-2 is necessary for optimal bone marrow stromal cell support of pro-B cell chemotaxis. (A) Murine S10 or P151 primary human bone marrow stromal cells were left untreated or treated with $1 \mu \mathrm{M}$ OA-Hy for 24 hours in the bottom chamber of a transwell plate. Following 4 hours of chemotaxis towards stromal cells, media, or rCXCL12, the number of C1.92 cells that migrated to the bottom chamber was evaluated by flow cytometry. (B) C57BL/6 WT and C57BL/6 MMP-2/- bone marrow stromal cells were evaluated for their ability to support chemotaxis of $\mathrm{C} 1.92$ cells. Following 4 hours of incubation, C1.92 cells were collected from lower wells that contained either adherent WT or MMP-2 $2^{-/-}$stromal cell layers. C1.92 cells that migrated to the bottom chamber were enumerated by flow cytometry $(\mathrm{p}<.05)$.

Figure 4. CXCL12 protein is diminished in the supernatants of bone marrow stromal cells with diminished MMP-2 protein levels. (A) Stromal cells were either untreated, or treated with $1 \mu \mathrm{M}$

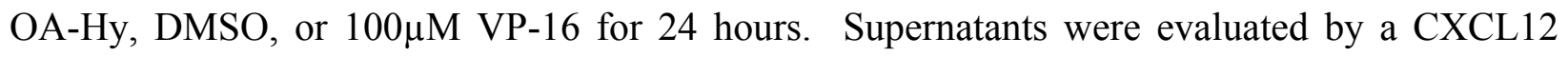
specific ELISA $(\mathrm{p}<.01)$. (B) CXCL12 intracellular staining was performed on stromal cells exposed to $1 \mu \mathrm{M}$ OA-Hy or DMSO for 24 hours. All samples were compared to isotype controls.

Figure 5. Recombinant MMP-2 protein restores VP-16 treated bone marrow stromal cell support of chemotaxis. P156 primary stromal cells were treated with $100 \mu \mathrm{M}$ VP-16 for 24 hours and C57BL/6 MMP-2 $2^{-/-}$stromal cells were cultured for 24 hours prior to the addition of CXCR4 ${ }^{+}$ cells to the top chamber. P156 stromal cells were then rinsed and either $10 \mathrm{mg} / \mathrm{mL}$ murine or 25 
$\mathrm{ng} / \mathrm{mL}$ human recombinant MMP-2 was added in $350 \mu \mathrm{L}$ of media to $\mathrm{C} 57 \mathrm{BL} / 6 \mathrm{MMP}-2^{-/}$or P156 stromal cells respectively for 2 hours. $5 \mu \mathrm{m}$ transwells were placed on top of the cells and $1 \times 10^{6}$ C1.92 were evaluated for their ability to migrate into the bottom chamber over a 4-hour period $(\mathrm{p}<.05)$. 
Figure 1. MMP-2 protein is dysregulated in bone marrow stromal cells exposed to VP-16.
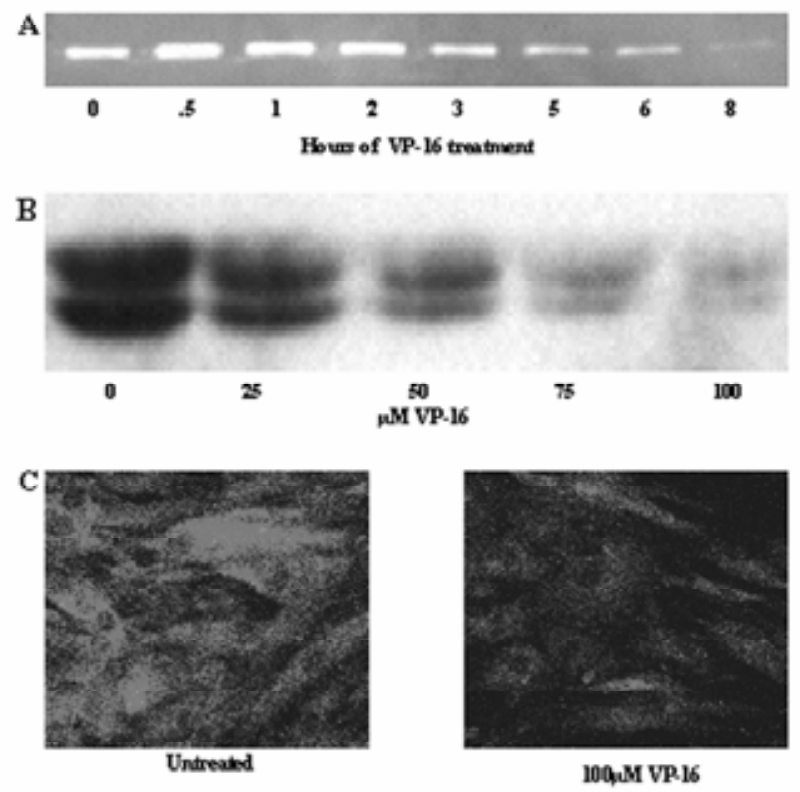

D

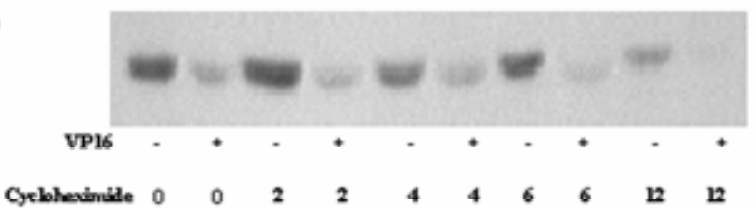


Figure 2. MMP-2 mRNA is not diminished following VP-16 exposure

A
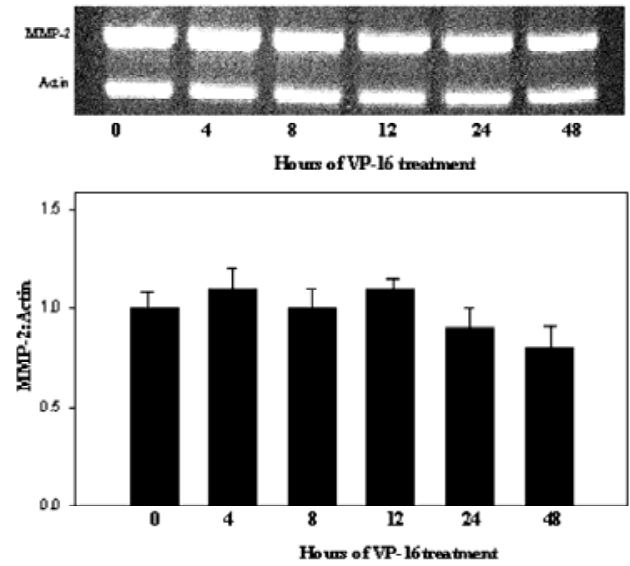

B
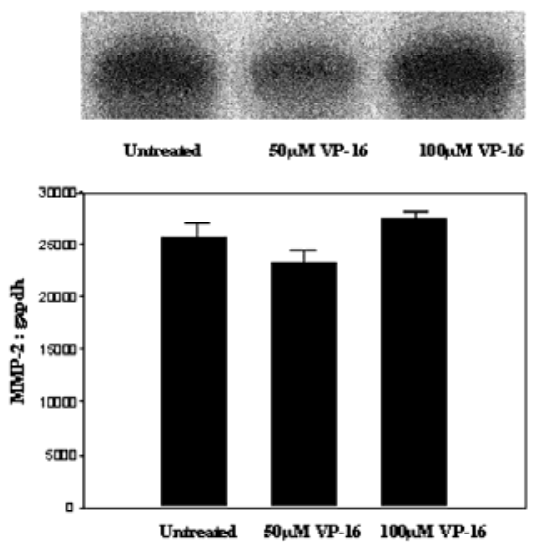
Figure 3. MMP-2 is necessary for optimal bone marrow stromal cell support of pro-B cell chemotaxis.
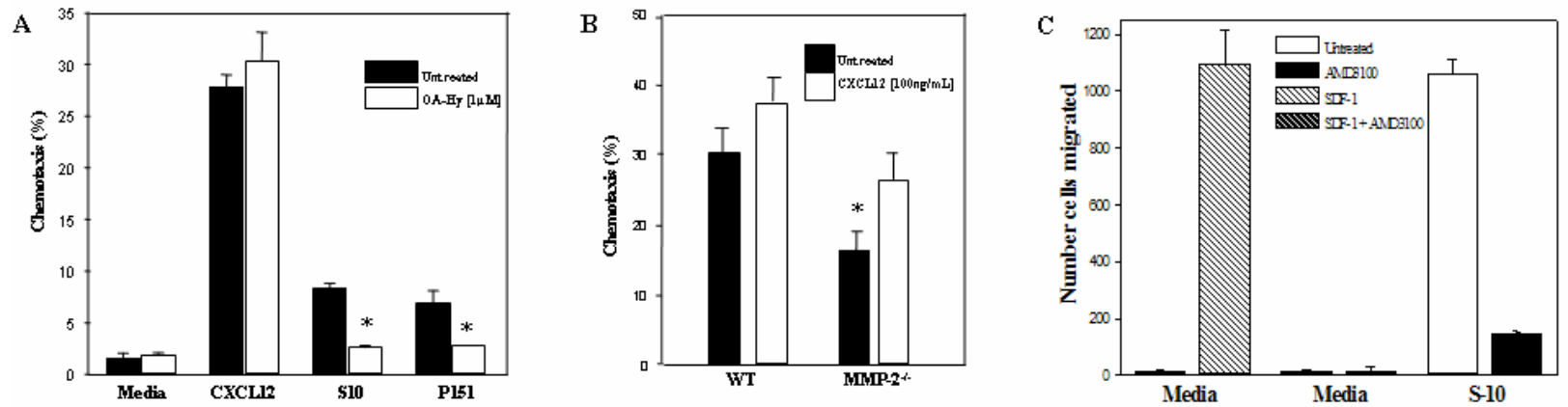
Figure 4. CXCL12 protein is diminished in the supernatants of bone marrow stromal cells with diminished MMP-2 protein levels
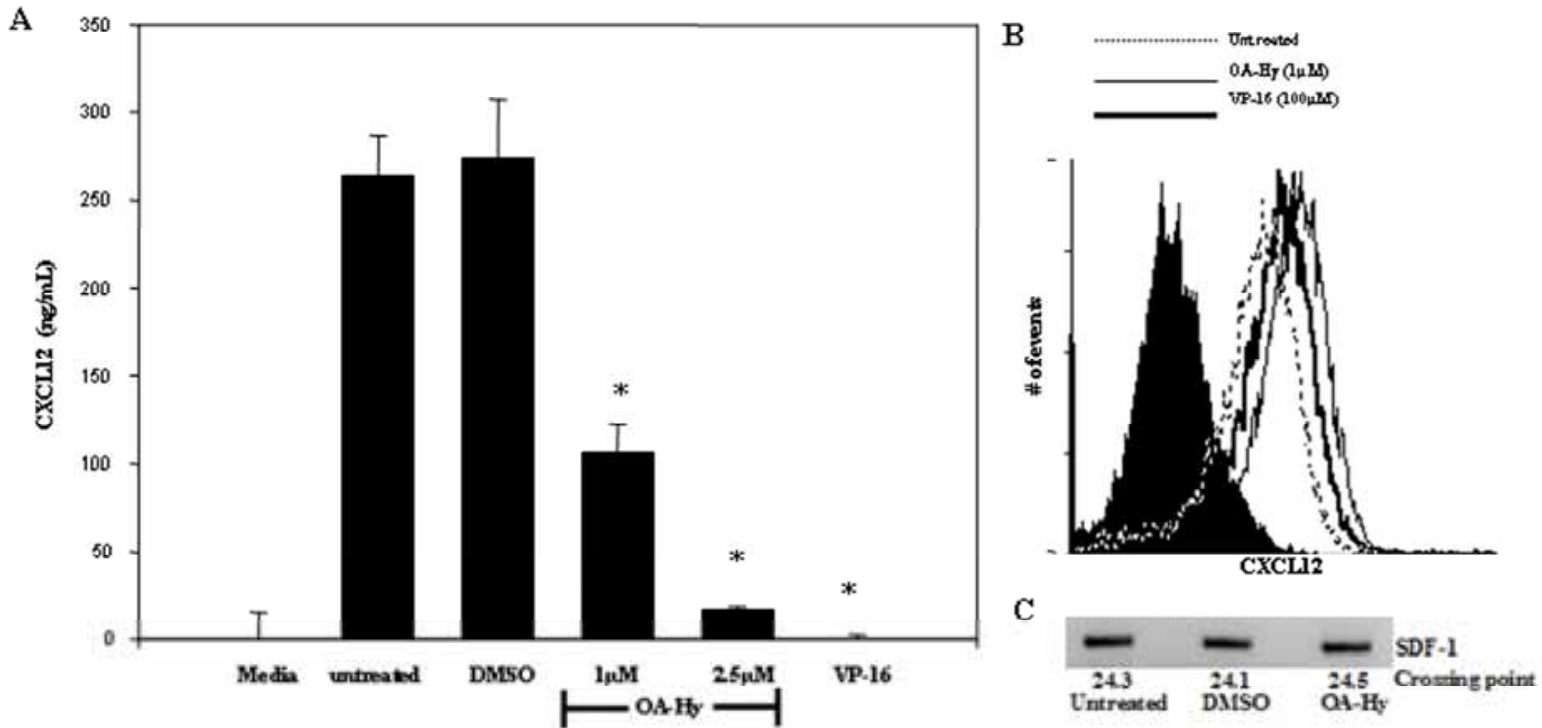
Figure 5. Recombinant MMP-2 protein restores VP-16-treated bone marrow stromal cell support of chemotaxis.
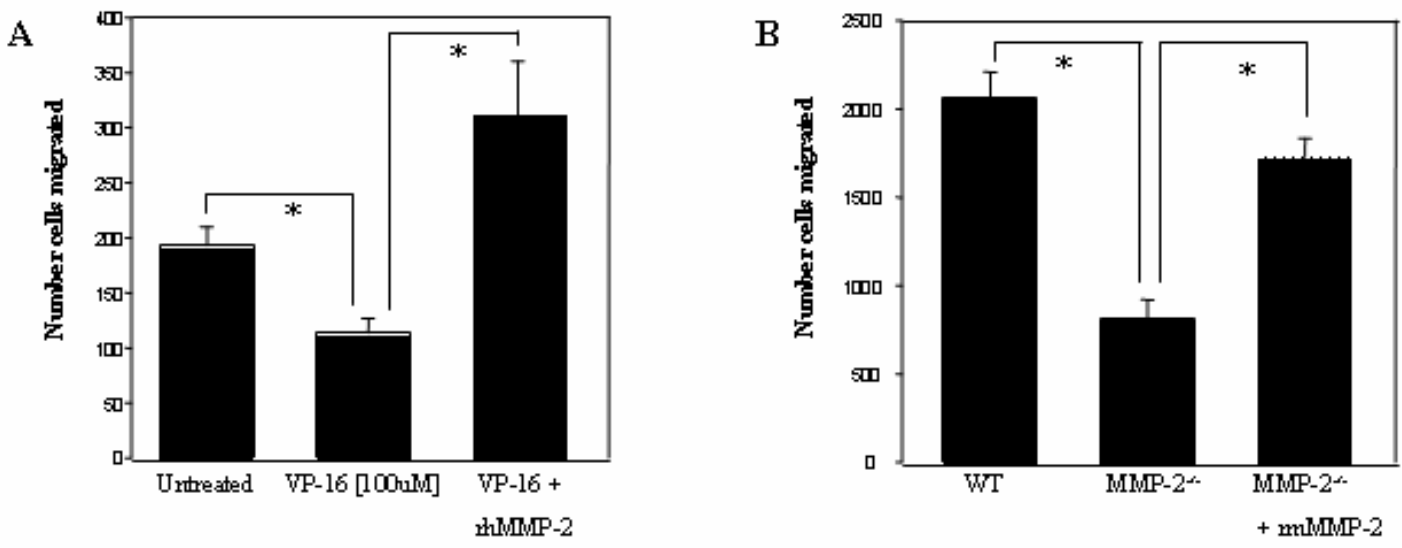


\section{CHAPTER III}

\section{Activation of TGF- $\beta 1 / p 38 /$ Smad3 Signaling in Stromal Cells}

Requires ROS-Mediated MMP-2 Activity During Bone Marrow Damage

Lin Wang ${ }^{a}$, Suzanne Clutter ${ }^{\mathrm{b}}$, Jonathan Benincosa ${ }^{\mathrm{c}}$, James Fortney ${ }^{\mathrm{a}}$, and Laura F. Gibson $^{\text {a,b,c }}$

Department of Pediatrics ${ }^{\mathrm{a}}$, Department of Microbiology, Immunology and Cell Biology ${ }^{\mathrm{b}}$, and the Mary Babb Randolph Cancer Center ${ }^{\mathrm{c}}$, Robert C. Byrd Health Sciences Center, West Virginia University, School of Medicine, Morgantown, WV, 26506, USA

This manuscript was published in the journal Stem Cells, Vol 23 (2005) 93-102. 


\begin{abstract}
Dose-escalated chemotherapy has proven utility in a variety of treatment settings, including preparative regimens prior to bone marrow or hematopoietic stem cell transplantation (BMT/HSCT). However, the potential damage imposed by aggressive regimens on the marrow microenvironment warrants further investigation. In the present study, we tested the hypothesis that dose-escalated chemotherapy, with etoposide as a model chemotherapeutic agent, activates the transforming growth factor beta-1 (TGF- $\beta 1$ ) signaling pathway in bone marrow stromal cells. Following high-dose etoposide exposure in vitro, Smad3 protein was phosphorylated in a timeand dose dependent manner in marrow derived stromal cells, coincident with the release of active and latent TGF- $\beta 1$ from the extracellular matrix (ECM). Phosphorylation was modulated by p38 kinase, with translocation of Smad3 from the cytoplasm to the nucleus subsequent to its phosphorylation. Etoposide-induced activation of TGF- $\beta 1$ followed the generation of reactive oxygen species (ROS) and required MMP-2 protein availability. Chemotherapy effects were diminished in MMP-2 ${ }^{-/-}$knockout stromal cells and TGF- $\beta 1$ knockdown siRNA-transfected stromal cells, in which phosphorylation of Smad3 was negligible following etoposide exposure. Stable transfection of a human MMP-2 cDNA into bone marrow stromal cells resulted in elevated phosphorylation of Smad3 during chemotherapy. These data suggest TGF$\beta 1 / \mathrm{p} 38 / \mathrm{Smad} 3$ signaling cascades are activated in bone marrow stromal cells following doseescalation chemotherapy, and may contribute to chemotherapy-induced alterations of the marrow microenvironment.
\end{abstract}




\section{INTRODUCTION}

The bone marrow microenvironment serves as the primary site of normal postnatal hematopoiesis and supports hematopoietic recovery following myelosuppressive chemotherapy or irradiation-induced injury of the immune system $[1,2]$. Hematopoietic reconstitution requires efficient migration of transplanted stem/progenitor cells to the bone marrow and relocation to stromal cell niches in this microenvironment [3]. The effects of preparative regimens on the marrow microenvironment remain an area requiring further investigation. The assumption that aggressive chemotherapy spares the bone marrow microenvironment grows increasingly more suspect as dose-escalation of chemotherapy reveals unexpected problems with hematopoietic recovery $[4,5]$. The dilemma remains maintaining efficacy of tumor eradication while reducing damage to the microenvironment.

Of the signaling molecules in the bone marrow microenvironment that may be involved in chemotherapy-induced bone marrow damage, TGF- $\beta 1$ is specifically noteworthy. TGF- $\beta 1$ regulates a variety of biological responses including angiogenesis, chemotaxis, cell cycle progression, differentiation and apoptosis of target cells in a context- and cell-specific manner [6, 7]. TGF- $\beta 1$ is also involved in regulating extracellular matrix remodeling, collagen gene expression and degradation of matrix proteins during the processes of tissue injury and repair $[6$, 7]. Up-regulated expression or activation of TGF- $\beta 1$ at sites of injury is associated with proliferation of fibroblasts, progressive fibrosis, and subsequent organ dysfunction in diverse systems including kidney, liver and lung [8-11]. In contrast to its promotion of mesenchymal cell proliferation and survival, TGF- $\beta 1$ is a potent inhibitor of hematopoietic stem cells $[12,13]$. 
TGF- $\beta 1$ is initially synthesized as a large precursor which is processed to a mature protein during secretion. Following secretion, mature TGF- $\beta 1(25 \mathrm{kD})$ non-covalently associates with its N-terminal propeptide, the $75 \mathrm{kD}$ latency-associated protein (LAP) [14]. The TGF- $\beta 1$-LAP complex predominantly binds to a latent TGF- $\beta$ 1-binding protein (LTBP) which mediates deposition of the latent complex $(230 \mathrm{kD}$ and $195 \mathrm{kD})$ to the extracellular matrix (ECM) [14]. Release of mature TGF- $\beta 1$ from the latent complex can be accomplished by different mechanisms such as proteolytic cleavage of LAP by plasmin [15], deglycosylation of LAP [16], or interaction with thrombospondin-1 [17], platelet [18], or integrin $\alpha 4, \beta 6$ [19]. Following TGF$\beta 1$ ligand binding, TGF- $\beta 1$ receptor II recruits and activates TGF- $\beta 1$ I receptor, which in turn phosphorylates and activates the R-Smads including Smad2 or Smad3 [20]. Phosphorylated RSmads homodimerize, form a transcriptional complex with Smad4, and translocate into the nucleus to regulate target gene expression [20].

Data presented in the current study suggest that the TGF- $\beta 1 / \mathrm{p} 38 / \mathrm{Smad} 3$ signaling cascades are activated through ROS-mediated MMP-2 activity in bone marrow stromal cells during etoposide chemotherapy. Increased availability of active TGF- $\beta 1$ has the potential to alter stromal cell function through regulation of diverse Smad-driven gene expression in stromal cells. Moreover, release of TGF- $\beta 1$ from extracellular matrix during chemotherapy may also directly regulate growth and proliferation of transplanted hematopoietic stem cells. This in vitro model provides a setting in which we can further delineate the effects of chemotherapy on marrow stromal cells and evaluate the role of TGF- $\beta 1$ in influencing hematopoietic recovery following transplantation. 


\section{MATERIALS AND METHODS}

\section{Cell cultures}

HS-27A human bone marrow derived stromal cells [21] (ATCC\# CRL-2496) were maintained in alpha-modification of Eagle's medium ( $\alpha$-MEM, GIBCO, Grand Island, NY) with supplements as recommended by the ATCC (Manassas, VA). Ped604, P148 and P156 are primary bone marrow stromal cells derived from consenting donors with WVU IRB approval. Establishment of bone marrow stromal cells and their characterization by our laboratory have been previously described in detail [22]. Bone marrow aspirates from MMP-2 knockout (MMP$\left.2^{-/-}, \mathrm{KO}\right)$ or wild type (MMP-2 $\left.2^{+/+}, \mathrm{WT}\right) \mathrm{C} 57 \mathrm{BL} / 6$ mice were generously provided by Dr. Farrah Kheradmand [23], Baylor College of Medicine. Murine bone marrow stromal cell line S-10 (provided by Dr. Kenneth Dorshkind (University of California at Los Angeles, CA), and stromal cell- and IL-7 dependent murine pro-B cell line, C1.92, has been previously described [24].

\section{Chemotherapeutic and other chemical agents}

Etoposide (VP-16, Bristol Laboratories, Princeton, NJ) was stored at a stock concentration of $33.98 \mathrm{mM}$ and was used as the model chemotherapeutic agent throughout the experiments. A final concentration of $100 \mu \mathrm{M}$ was utilized to mimic pre-transplant clinical treatment [25]. Cytarabine (Ara-C, Sigma, St. Louis, MO) was reconstituted at $10 \mathrm{mg} / \mathrm{mL}$ and stored at $-20^{\circ} \mathrm{C}$. Doxorubicin (Dox, $3 \mathrm{mM}$ ) was purchased from Gensia (Irvine, CA) and 4hydroperoxycyclophosphamide (4-HC, $10 \mathrm{mg} / \mathrm{mL}$ ) was a gift from Dr. T. Ball (University of California, San Diego). Danunorubicin (DNR, Sigma), Melphalan (Mel, Sigma) and Vincristine 
(VCR, Sigma) were reconstituted at $10 \mu \mathrm{g} / \mu \mathrm{L}$ immediately prior to use. Experimental concentrations of chemotherapeutic drugs are noted in appropriate figure legends.

The MMP-2 inhibitor cis-9-octadecenoyl-N-hydroxylamide (OA-Hy), Erk1/2 kinase inhibitor U0126, p38 kinase inhibitor SB220025, and JNK/SAPK inhibitor SP600125 were purchased from Calbiochem (La Jolla, CA). Reactive oxygen species scavenger N-acetylcysteine (NAC) was purchased from Sigma. Recombinant active MMP-2 and pro-MMP-2 were purchased from BioMol (Plymouth Meeting, PA) and Calbiochem, repectively. Recombinant human TGF- $\beta 1$ (rh-TGF- $\beta 1$ ) was obtained from R\&D Systems (Minneapolis, MN).

In the indicated experiments, stromal cells were preincubated with $1 \mu \mathrm{M}$ OA-Hy for 30 mins, or $250 \mathrm{ng} / \mathrm{mL}$ active or pro-MMP-2 for 15 mins prior to exposure to chemotherapy for 1 hour. For in vitro activation of MMP-2, pro-MMP-2 was incubated with $10 \mu \mathrm{M}$ hydrogen peroxide $\left(\mathrm{H}_{2} \mathrm{O}_{2}, 8.8 \mathrm{~N}\right.$, Sigma) at $37{ }^{\circ} \mathrm{C}$ for 15 minutes immediately prior to use. Where indicated, stromal cells were pretreated with $10 \mu \mathrm{M}$ U0126, $20 \mu \mathrm{M}$ SB220025 or $5 \mu \mathrm{M}$ SP600125 for 30 minutes prior to etoposide exposure for an additional 1 hour.

\section{Transfection of murine stromal cells with human MMP-2}

A 2,119-bp EcoRI cDNA fragment encoding the full-length human MMP-2 was cut from the entry plasmid pBR322-MMP-2-amp(+) (ATCC\#65016) and inserted into the multiple cloning site of the mammalian expression plasmid pUSE-CMV-neo (Upstate, Placid, NY). Subcloning was carried out following purification using the MiniElute gel purification kit (Qiagen Sciences, MD) with the cDNA ligated with T4 DNA liagase (Invitrogen, Carlsbad, CA). Transfection of stromal cells with the pUSE-MMP-2-neo construct or its empty vector control pUSE-CMV-neo was conducted following the protocols described previously [26,27]. Briefly, 
16 hours prior to transfection, S-10 stromal cells were cultured in $\alpha$-MEM supplemented with 5\% FBS with no antibiotics (transfection growth medium, TGM). Plasmid DNAs and Lipofectamine 2000 (Invitrogen) were diluted with Opti-MEM (Invitrogen) and mixed at variable ratios at room temperature for 20 minutes. Murine stromal S-10 cells were transfected with either the vector or MMP-2 construct followed by G418 selection $(0.5 \mathrm{mg} / \mathrm{mL})$. Stable clones expressing both the human MMP-2 and neomycin resistant gene product, neomycin phosphotransferase II (NPT II), or the NPT II alone were selected for further experiments. These are designated SM-8 and SV-2 respectively.

\section{TGF- $\beta 1$ knockdown by siRNA}

For transient TGF- $\beta 1$ siRNA transfection, Lipofectamine 2000 and non-targeting dsRNA control or TGF- $\beta 1$ knockdown siRNA (Dharmacon, Boulder, CO) were diluted and combined. HS-27A and P148 human stromal cells were cultured in TGM overnight and transfected with 50150 nM TGF- $\beta 1$ knockdown siRNA or control dsRNA. Control siRNA was consistently used at the highest concentration of TGF- $\beta 1$ siRNA in all experiments. 48 hours post-transfection, TGM was replaced with serum-free medium and stromal cells were treated with $100 \mu \mathrm{M}$ etoposide for 1 hour. Stromal cell supernatants and cell pellets were collected for ELISA, zymography or Western blot analyses.

\section{Quantitation of active and total TGF- $\beta 1$ by ELISA}

Quantitation of the release of active and total TGF- $\beta 1$ from stromal cell ECM during chemotherapy was measured by ELISA according to the recommendations of the manufacturer (R\&D systems). Briefly, confluent stromal cells were plated in 6-well plates in serum-free 
medium overnight. Following exposure to $0-100 \mu \mathrm{M}$ of etoposide for 1 hour, or $100 \mu \mathrm{M}$ etoposide for 5 minutes to 6 hours, stromal cell supernatants were collected. Ten minutes prior to each treatment, $0.5 \mu \mathrm{g} / \mathrm{mL}$ anti-TGF- $\beta 1$ antibody was added to each well to stabilize the released TGF$\beta 1$. Supernatants were acidified with $1.0 \mathrm{~N} \mathrm{HCl}$ solution and neutralized with $1.2 \mathrm{~N} \mathrm{NaOH} / 0.5 \mathrm{M}$ HEPES solution immediately prior to assay to measure total TGF- $\beta 1$. For quantitation of active/free TGF- $\beta 1$, supernatants were directly subjected to ELISA without acid activation. Both acidified and non-acidified samples were measured in triplicate and colorimetric development was determined at $450 \mathrm{~nm}$ with correction wavelength at $540 \mathrm{~nm}$ on a multi-well plate reader (BioTek Instruments).

\section{Antibodies and Western blot analysis}

Rabbit polyclonal anti-phospho-Smad3 (Ser433/435), rabbit monoclonal anti-phosphop38 kinase (Thr180/Tyr182), rabbit monoclonal anti-phospho-Erk1/2 MAPK (Thr202/Tyr204), and rabbit monoclonal anti-phospho-JNK/SAPK (Thr183/Tyr185) were purchased from Cell Signaling Technology (Beverly, MA). Mouse monoclonal anti-p38 kinase, and rabbit polyclonal anti-JNK2 antibodies were also from Cell Signaling Technology. Rabbit polyclonal anti-Erk2 and rabbit polyclonal anti-Erk1 were from Santa Cruz Biotechnology (Santa Cruz, CA). Mouse monoclonal anti-Smad3 was from BD Transduction Laboratories (San Diego, Ca). Mouse monoclonal anti-human TGF- $\beta 1$, LAP/TGF- $\beta 1$ and LTBP-1/TGF- $\beta 1$ antibodies were obtained from R\&D Systems. Rabbit polyclonal anti-NPT II antibody was purchased from Upstate.

Cells were lysed in complete cell lysis buffer (CCLB, $50 \mathrm{mM}$ Tris-HCl, pH 7.4, $150 \mathrm{mM}$ $\mathrm{NaCl}, 1 \%$ TritonX-100, 0.25\% Na-deoxycholate, $1 \mathrm{mM}$ EDTA, and $1 \mathrm{mM} \mathrm{NaF,} 1 \mathrm{mM}$ DTT, 1 mM PMSF, $1 \mathrm{mM}$ activated $\mathrm{Na}_{3} \mathrm{VO}_{4}, 1 \mathrm{~g} / \mathrm{mL}$ aprotinin, $1 \mu \mathrm{g} / \mathrm{mL}$ leupeptin, and $1 \mu \mathrm{g} / \mathrm{mL}$ 
pepstatin) on ice for 15 minutes. Following centrifugation at $14,000 \mathrm{rpm}$ for 15 minutes, supernatants were collected and protein concentration determined using the BCA protein assay (Pierce, Rockford, IL). Proteins were resolved on SDS-PAGE gels and transferred to nitrocellulose membranes. Membranes were blocked in TBS/5\%/0.05\% Tween-20 nonfat dry milk and probed with the indicated primary antibodies. Following incubation with HRPconjugated secondary antibodies, signal was visualized using ECL reagents (Amersham, Piscataway, NJ).

\section{Immunoprecipitation of TGF- $\beta 1$}

Confluent stromal cells were rinsed with serum-free $\alpha$-MEM, then re-cultured in serumfree media. Anti-human TGF- $\beta 1$, LAP/TGF- $\beta 1$ and LTBP-1/TGF- $\beta 1$ antibodies were added at a final concentration of $3 \mu \mathrm{g} / \mathrm{mL}$ for 15 minutes prior to addition of etoposide for 1 hour. Supernatants were collected and combined with protein $\mathrm{A} / \mathrm{G}$ agarose beads (Santa Cruz Biotechnology) at $4 \mathrm{C}^{\circ}$ for 4 hours. The immunoprecipitates were washed with CCLB and heated to $100 \mathrm{C}^{\circ}$ for 5 minutes prior to separation on SDS-PAGE gels under both reducing and non-reducing conditions.

Heavy and light chains served as the loading controls for the IP experiments.

\section{Gelatin zymography}

Bone marrow stromal cell supernatants were collected following $100 \mu \mathrm{M}$ etoposide treatment in serum free $\alpha$-MEM. Supernatants were concentrated 10x using Amicon Ultra-15 centrifugal filters (Millipore, Billerica, MA) spun at 3,000g for 95, 30 and 10 minutes, respectively at room temperature. For gelatinolytic analysis with cell lysates, cell pellets were 
lysed in CCLB without $\mathrm{NaVO}_{3}, \mathrm{NaF}$, EDTA and DTT. Following quantitation of supernatant and cell lysate protein by the BCA protein assay, samples were resolved in 10\% SDS-PAGE gels containing 1\% gelatin (Sigma) under non-reducing conditions. Following electrophoresis, gels were incubated for 30 minutes in $2.5 \%$ Triton-X-100 (Mallinckrodt, Inc., Paris, KY) and subsequently incubated overnight at $37{ }^{\circ} \mathrm{C}$ in $1 \mathrm{X}$ developing buffer $(1.2 \%$ Tris Base, $6.3 \%$ Tris $\mathrm{HCl}, 11.7 \% \mathrm{NaCl}, .7 \% \mathrm{CaCl}, .2 \%$ Brij 35). Gels were then stained with $0.5 \%$ Coomassie Blue R250 (Bio-Rad Laboratories, Richmond, CA) for 30 minutes at room temperature and then destained (50\% Methanol, 10\% acetic acid, 40\% dH20) until clear bands were detected, indicative of active MMP-2.

\section{Detection of intracellular ROS by flow cytometry}

Detection of intracellular ROS generation by flow cytometry was performed as previously described [28]. Briefly, confluent stromal cells were pretreated with $10 \mu \mathrm{M}$ carboxyl$\mathrm{H}_{2}$ DCF-DA (Molecular Probes, Eugene, OR) for 30 minutes followed by etoposide exposure for various time points. Nonfluorescent carboxyl- $\mathrm{H}_{2}$ DCF-DA was hydrolyzed to $\mathrm{H}_{2} \mathrm{DCF}$, which is oxidized in the presence of $\mathrm{H}_{2} \mathrm{O}_{2}$ and emits fluorescence detected in the FL1-H channel. Cells were trypsinized, rinsed with PBS buffer and immediately run on a BD Biosciences FACScan. Data were analyzed and processed with CellQuest Pro software (Becton Dickson).

\section{Confocal microscopy}

Stromal cells were cultured on coverslips and exposed to etoposide for 30 minutes to 6 hours. After fixation with Methanol/Acetone (1:1) for 30 minutes at room temperature, stromal cells were incubated with $3 \mu \mathrm{g} / 100 \mu \mathrm{L}$ anti-phospho-Smad3 antibody or isotype control antibody 
for 3 hours. Following 3 washes with autoclaved PBS, cells were incubated with goat anti-rabbit IgG-FITC (Southern Biotechnology Associates, Birmingham, AL) for 1 hour. Propidium iodide (PI, $5 \mu \mathrm{g} / 100 \mu \mathrm{L}$ ) was used to counterstain the nuclei. Coverslips were mounted onto slides with Fluormount-B (Fisher Scientific, Orangeburg, NY) and evaluated by confocal microscopy (Carl Zeiss LSM510).

\section{Pro-B cell adhesion assays}

Stromal cells were plated in 96 -well plates and exposed to $0-5 \mathrm{ng} / \mathrm{mL}$ rhTGF- $\beta 1$ for 72 hours. Cells were thoroughly rinsed with fresh medium 3 times prior to establishment of C1.92 pro-B/stromal cell co-culture. Prior to co-culture, C1.92 pro-B cells were labeled with the fluorescence dye PKH-26 (Sigma) for 3 minutes and then washed with medium. 5 x10 $0^{5}$ C1.92 cells were co-cultured with stromal cells for an additional 2 hours. Non-adherent C1.92 cells were removed by three PBS rinses. 96-well plates were then analyed on a multi-well fluorimetric reader (CytoFluor, PerSeptive Biosystems) to quantitate fluorescence as a measure of stromal cell-bound C1.92 cells. Stromal cells alone were included to determine any background fluorescence.

\section{Pro-B cell proliferation assay}

The effect of TGF- $\beta 1$ on the ability of murine S10 or human-derived stromal cells to support pro-B cell proliferation was investigated by exposing $100 \%$ confluent stromal cell layers to increasing doses of rhTGF- $\beta 1(0-5 \mathrm{ng} / \mathrm{mL})$ for 72 hours in 96 well plates. Following exposure of stroma to TGF- $\beta 1$ in vitro, stromal cells were thoroughly rinsed from culture, and $5 \times 10^{5}$ pro-B cells $/ \mathrm{mL}$ were added to each well in fresh $\alpha$-MEM. The proliferative response of 
pro-B cell clone C1.92 to murine stromal cell line S10 has been well characterized [24], therefore, this combination of cells is particularly informative in determining the effect of TGF$\beta 1$ on the ability of stromal cells to support pro-B cell expansion. $25 \mathrm{U} / \mathrm{mL}$ recombinant murine IL-7 (Biosource, Camarillo, CA) was included as the established primary proliferative signal for C1.92 in all samples. Wells were pulsed with $1 \mathrm{Ci}{ }^{3} \mathrm{H}-\mathrm{TdR} 16$ hours after the addition of $\mathrm{C} 1.92$, and harvested onto glass wool fiber strips 6 hours later. Incorporated radioactivity was determined by liquid scintillation counting (LKB/Wallac Model 1410, Gaithersburg, MD) in an aqueous fluor (Biosafe-II; Research Products International, Mount Prospect, IL). Control wells of untreated stroma were included in each experiment.

\section{Statistical analysis}

Data presented were expressed as mean $+/$ - SEM for triplicate samples. Statistic significance was determined using the Student's $t$-test. $P$ values less than 0.05 were considered significant. 


\section{RESULTS}

Chemotherapy activates Smad3 through phosphorylation at serines 433/435 in human bone marrow derived stromal cells.

To investigate the phosphorylation of Smad3 in stromal cells following chemotherapeutic stimulation, stromal cells were treated either for different times, or with various concentrations of etoposide. Exposure of stromal cells to etoposide resulted in phosphorylation of Smad3 at serines 433/435 in a time-(Fig 1A) and dose (Fig 1B) dependent manner. Etoposide induced a rapid elevation of phospho-Smad3 signal as early as 30 minutes which was sustained for approximately 6 7 hours (Fig 1A). Following the transient increase, phospho-Smad3 levels diminished for up to 24 hours in the presence of chemotherapy. Etoposide, melphalan, vincristine, daunorubicin, doxorubicin, 4-hydroperocyclophosphomide and ara-C induced Smad3 phosphorylation in stromal cells to varying degrees (Fig 3C). Treatment of stromal cells with recombinant TGF- $\beta 1$ served as a positive control and induced the most pronounced phosphorylation of Smad3. Total Smad3 protein remained unchanged and served as the lane loading control throughout the experiments.

\section{Chemotherapy-induced Smad3 phosphorylation is mediated by TGF- $\beta 1$.}

To investigate the potential involvement of TGF- $\beta 1$ in phosphorylation of Smad3 of bone marrow stromal cells during chemotherapy, HS-27A stromal cells were exposed to etoposide for different times or at various concentrations. Quantitative analysis of TGF- $\beta 1$ by ELISA was performed using the cell supernatants following treatment. To better distinguish the free (active) and latent (total) TGF- $\beta 1$ that may be released, non-acidification and acidification of the stromal 
supernatants were simultaneously utilized prior to assay as described. Exposure of stromal cells to chemotherapy resulted in elevated TGF- $\beta 1$ release from stromal cells both in a time- and dose dependent manner (Fig 2A). Chemotherapy rapidly induced the release of active and latent forms of TGF- $\beta 1$ from stromal cell extracellular matrix. In our stromal cell model, active TGF- $\beta 1$ constituted approximately $5-9 \%$ of the total TGF- $\beta 1$ pool during each treatment phase. Activation of TGF- $\beta 1$ preceded phosphorylation of Smad3 with initial increases rapidly following etoposide treatment for 15 minutes and further elevated at 1 hour. Activation of TGF$\beta 1$ in stromal cells appeared to be a transient event, as longer than 1 hour exposure of stromal cells to chemotherapy correlated with gradual regression of active and total TGF- $\beta 1$ to the baseline level.

Immunoprecipitation of TGF- $\beta 1$ from the stromal cell supernatants indicated that baseline TGF- $\beta 1$ in untreated stromal cell supernatants was negligible, with increased TGF- $\beta 1$ immunoprecipitated from etoposide treated stromal cell supernatants in a dose dependent fashion (Fig 2B).

Because the anti-TGF- $\beta 1$ antibody we used for immunoprecipitation of TGF- $\beta 1$ may recognize both active and latent form of TGF- $\beta 1$, we performed additional immunoprecipitation experiments with antibodies recognizing the free and total TGF- $\beta 1$ (i.e. anti-TGF- $\beta 1$ ), the small latent complex (i.e. anti-LAP/TGF- $\beta 1$ ), or the large latent complex (anti-LTBP-1/TGF- $\beta 1$ ) to further address this issue. As shown in Fig 2C, under non-reducing electrophoretic condition, the major forms of TGF- $\beta 1$ activated via etoposide treatment are $230 \mathrm{kD}$ and $195 \mathrm{kD}$ large latency complexes (i.e. LTBP-1/LAP/TGF- $\beta 1$ ) as immunoprecipitated by anti-TGF- $\beta 1$, anti-LAP/TGF$\beta 1$ and anti-LTBP-1/TGF- $\beta 1$ antibodies. In addition, a $100 \mathrm{kD}$ band which represents the small 
latency complex (i.e. LAP/TGF- $\beta 1$ ) and a $75 \mathrm{kD}$ LAP band were also detected in etoposidetreated samples. When the same samples were electrophoresed under reducing conditions, the high molecular weight large and small latency complexes were almost dissociated and two bands of molecular size of $195 \mathrm{kD}$ (LTBP-1/LAP- TGF- $\beta 1$ ) and $25 \mathrm{kD}$ (TGF- $\beta 1$ ) were observed.

\section{Disruption of the availability of TGF- $\beta 1$ blocks the signal transduction initiated by chemotherapy.}

To better understand the role of TGF- $\beta 1$ in mediating chemotherapy-triggered signals during bone marrow damage, marrow-derived stromal cells were treated with chemotherapeutic agents in the presence or absence of anti-TGF- $\beta 1$ neutralizing antibody. Etoposide, Melphalan and 4-HC promoted phosphorylation of Smad3 when cells were pretreated with the isotype control antibody, while phosphorylation of Smad3 was diminished in the presence of TGF- $\beta 1$ neutralizing antibody (Fig 3A).

This prompted us to more specifically test whether chemotherapy-induced effects on marrow stromal cells could be disrupted through downregulation of TGF- $\beta 1$ expression. Human HS-27A and P148 stromal cells were transiently transfected with TGF- $\beta 1$ knockdown siRNA prior to exposure to etoposide. TGF- $\beta 1$ targeting siRNA transfection diminished the amount of total TGF- $\beta 1$ release induced by etoposide treatment in a concentration dependent manner compared to control dsRNA transfection (Fig 3B, upper panel). Complete loss of TGF- $\beta 1$ release occurred when stromal cells were exposed to $150 \mathrm{nM}$ siRNA in the presence of chemotherapy. Consistent with the diminished availability of TGF- $\beta 1$ presented in the supernatants, phosphorylation of Smad3 was also reduced following transfection of stromal cells with various concentrations of TGF- $\beta 1$ siRNA during chemotherapy (Fig 3B, lower panel). 
Chemotherapy-induced MMP-2 activity is required for activation of latent TGF- $\beta 1$.

Gelatin zymography revealed that MMP-2 activity was elevated in S10 stromal cell supernatants following etoposide exposure as early as 5 minutes, and increased further at 30-60 minutes (Fig 4A). Inhibition of MMP-2 activity by OA-Hy diminished phosphorylation of Smad3 following etoposide treatment of stromal cells (Fig 4B). To determine whether MMP-2 was required for bone marrow stromal cell activation of TGF- $\beta 1$, we established stromal cells from MMP-2 ${ }^{-/}$knockout mice. Etoposide, Melphalan or 4-HC exposure induced Smad3 phosphorylation in murine MMP- $2^{+/+}$stromal cells, while phospho-Smad3 signals were less pronounced in $\mathrm{MMP}^{-2^{-/}}$stromal cells (Fig 4C). Addition of active MMP-2 partially restored treatment-induced phospho-Smad3 signals in $\mathrm{MMP}-2^{-/}$cells, and further increased phosphorylation of Smad3 in MMP-2 $2^{+/+}$stromal cells treated with etoposide (Fig 4D).

To further investigate the role of MMP-2 in mediating activation of TGF- $\beta 1$ in marrow stromal cells during chemotherapy, S-10 murine stromal cells transfected with a human MMP-2 construct or vector control were established. Stromal cell clones with comparable expression of the neomycin resistance gene, NPT II, were selected for further experiments. As shown in Fig 4E, while no substantial differences were observed between S-10 parental and SV-2 vector transfected cells in terms of activation of Smad3 and MMP-2 during treatment, overexpression of MMP-2 in SM-8 stromal cells increased baseline and etoposide-induced Smad3 phsophorylation.

Activation of latent MMP-2 by chemotherapy requires the generation of reactive oxygen species. 
Because MMP-2 exists largely as a latent form in stromal cell matrix, we next sought to explore the mechanism underlying the activation of pro-MMP-2 during etoposide chemotherapy. Reactive oxygen species (ROS) was generated following etoposide treatment and was required for conversion of pro-MMP-2 to its active form. Etoposide rapidly induced production of intracellular ROS in HS-27A stromal cells as early as 5 minutes following etoposide exposure, which preceded activation of MMP-2 and TGF- $\beta 1$ (Fig 5A, upper panel).

Comparable to the activation of MMP- 2 and TGF- $\beta 1$, ROS generation is also a transient event during chemotherapy in our stromal cell model. The mean fluorescence intensity (MFI) emitted by oxidized DCF in etoposide treated stromal cells was increased greater than 2-3 fold in all lines evaluated when compared to untreated controls. Uniquely, ara-C did not stimulate stromal cell production of $\mathrm{H}_{2} \mathrm{O}_{2}$ during short-term (1 hour) chemotherapy (Fig 5A, lower panel). Reduction of intracellular ROS accumulation with the hydroxyl radical scavenger, N-acetyl cysteine (NAC), reduced phospho-Smad3 in stromal cells treated with etoposide (Fig 5B).

To confirm the role of ROS in activation of MMP-2, pro-MMP-2 was activated in vitro by hydrogen peroxide. As shown in Fig 5C, treatment of HS-27A stromal cells with in vitro activated MMP-2 induced phosphorylation of Smad3 in a dose dependent manner. Because inhibition of extracellular MMP-2 activity and reduction of intracellular ROS both disrupted etoposide-induced Smad3 phosphorylation, we sought to determine which one was the initiating factor in modulating TGF- $\beta 1 / \mathrm{Smad} 3$ signaling. Hydrogen peroxide induced phosphorylation of Smad3 only occurred in MMP- $2^{+/+}$but not MMP- $2^{-/-}$cells, whereas in the presence of pro-MMP2, oxidative stress led to phosphorylation of Smad3 in MMP-2 ${ }^{-/}$cells (Fig 5D).

\section{P38 mediates etoposide-induced Smad3 phosphorylation in bone marrow stromal cells.}


Smad3 was not directly phosphorylated by TGF- $\beta 1$ receptor I in a classic fashion, but appeared to be regulated by p38 MAP kinase in this specific setting. As indicated in Fig 6A, all the chemotherapeutic drugs evaluated in this study activated p38 kinase. Chemotherapy induced phosphorylation and activation of both Erk1/2 and p38 kinases in HS-27A cells (Fig 6B), however, inhibition of Erk1/2 MAPK with U0126 did not result in diminished phosphorylation of Smad3. In contrast, interruption of p38 kinase activity with SB220025 blocked etoposidetriggered Smad3 phosphorylation. JNK/SAPK was not involved in chemotherapy induced activation of TGF- $\beta 1$ signaling in bone marrow stromal cells.

Etoposide treatment results in redistribution of phosphorylated Smad3 protein in human stromal cells

Changes in cellular distribution of Smad3 protein following etoposide-induced phosphorylation were evaluated (Fig 7). The phospho-Smad3 signal was negligible in untreated stromal cells, with only the PI-counterstained cell nuclei clearly detected. Cytoplasmic Smad3 was rapidly phosphorylated in response to etoposide stimulation as early as 30 minutes. Longer exposure of stromal cells to etoposide induced a gradual redistribution and accumulation of Smad3 protein in nucleus. After approximately 4 hours of etoposide treatment, the majority of phospho-Smad3 had translocated into the stromal cell nuclei.

Recombinant TGF- $\beta 1$ activates Smad3 and impairs stromal cells support of pro-B cell adhesion and proliferation

To characterize the response of stromal cells to TGF- $\beta 1$ exposure, human primary P156 stromal cells were treated with rhTGF- $\beta 1$ (Fig 8 A). TGF- $\beta 1$ rapidly induced phosphorylation of 
Smad3 in P156 stromal cells in a time dependent manner with elevated Smad3 phosphorylaton as early as 30 minutes and decreased phospho-Smad3 signals thereafter (Fig 8A upper panel). In contrast to the Smad3 activation pattern induced by chemotherapy, rhTGF- $\beta 1$ treatment resulted in the most pronounced Smad3 phosphorylation at 1 and $5 \mathrm{ng} / \mathrm{mL}$ of TGF- $\beta 1$, however, 10 and 20ng/mL, resulted in diminished phospho-Smad3 signals (Fig 8A lower panel).

To explore the functional consequences of activation of TGF- $\beta 1 / \mathrm{Smad} 3$ signaling during bone marrow damage, bone marrow stromal cells were treated with rhTGF- $\beta 1$ followed by coculture with C1.92 hematopoietic stem cells. Stromal cells pretreated with TGF- $\beta 1$ diminished the ability to support $\mathrm{C} 1.92$ cell adhesion to the stromal cell layer (Fig 8B). In addition to diminished adhesion of the pro-B cells, C1.92 cells co-cultured on TGF- $\beta 1$ pretreated human or murine stromal cells had lower cell proliferation (Fig 8C) compared to those on control stromal cells. 


\section{DISCUSSION}

BMT/HSCT has proven an effective treatment for many malignancies that are refractory to less aggressive approaches [29-32]. Preparative regimens require that pretreatment achieves maximal killing of tumor cells in peripheral blood and bone marrow, and that it establish adequate space for subsequently transplanted hematopoietic stem and progenitor cells. During this process, one challenge is maintaining the hematopoietic support capacity of the bone marrow microenvironment. Complications associated with HSCT include aplastic anemia or pancytopenia, delay of hematopoietic recovery and severe immunosuppression-related infections [33-35] and secondary myelofibrosis [36-37]. These observations emphasize the challenge of utilizing high-dose chemotherapy while attempting to maintain function of bone marrow stromal cell niches that support hematopoietic recovery.

We have previously reported that high-dose etoposide exposure, while not reducing the viability of bone marrow stromal cells, resulted in a plethora of functional alterations. Etoposidetreated stromal cells have diminished surface VCAM-1 protein [22] and reduced ability to support chemotaxis of CXCR4 positive progenitor cells [38]. In addition, stromal cell- and IL-7 dependent pro-B cells grown on etoposide pre-treated stromal cells accumulate in $\mathrm{G}_{0} / \mathrm{G}_{1}$ phase of the cell cycle and subsequently initiate apoptosis [22]. These observations suggest a variety of treatment-induced stromal cell alterations that potentially influence hematopoietic support capacity.

Because TGF- $\beta 1$ has a variety of direct inhibitory effects on hematopoietic cells, we hypothesized that etoposide induced disruption of bone marrow stromal cell support of pro-B cells may result, in part, from activation of TGF- $\beta 1$. Initial studies indicated that bone marrow 
stromal cells responded to chemotherapeutic exposure with downstream phosphorylation of Smad3. Etoposide treatment rapidly resulted in a dose- and time dependent phosphorylation of Smad3 protein in bone marrow stromal cells (Fig $1 \mathrm{~A}, \mathrm{~B}$ ). The response of stromal cells to a variety of drugs, including our model drug etoposide, was similar to that induced by rh-TGF- $\beta 1$ treatment alone (Fig 1C). These data suggested an intracellular signal transducer of TGF- $\beta 1$ was activated in response to chemotherapy, and provided indirect evidence that TGF- $\beta 1$ may be involved in chemotherapy-induced stromal cell alterations. It should be noted that although higher doses of etoposide induced stronger phospho-Smad3 signals, longer exposure of stromal cells to $100 \mu \mathrm{M}$ etoposide for up to 24 hours did not lead to sustained Smad3 phosphorylation.

Several mechanisms may underlie the transient phosphorylation of Smad3. It is generally recognized that the protein phosphatases, specifically protein phosphatase $2 \mathrm{~A}$, are activated following stress in a number of cell models [39]. Elevated PP2A activity may subsequently result in dephosphorylation of signaling molecules, such as Smad3, in stromal cells treated with etoposide. However, sustained phosphorylation of Smad3 may not be required to elicit a significant effect. Transit of Smad3 to the nucleus following phosphorylation provides the potential for diverse changes in expression of Smad3 responsive genes and subsequent alteration of stromal cell function.

Because R-Smads can also be phosphorylated/activated in response to other members of the TGF- $\beta 1$ superfamily [7], we performed several experiments using chemical and genetic approaches to verify that TGF- $\beta 1$ is specifically involved in chemotherapy-induced Smad3 phosphorylation (Fig 2 and 3). Treatment of stromal cells with chemotherapy resulted in the release of active and total TGF- $\beta 1$ in the supernatants. The free/active form TGF- $\beta 1$ only accounts for approximately 5-9\% of the total TGF- $\beta 1$ pool released from chemotherapy-treated 
stromal cells. However, MMP-2 may cleave and release LAP from extracellular matrix and subsequently release TGF- $\beta 1$ from LAP or LTBP-1 complexes $[40,41]$. Therefore it can be postulated that TGF- $\beta 1$ activated through chemotherapy may exert its biological functions in an extended-release manner influenced at multiple regulatory levels by MMP-2.

Central to our model is the role of MMP- 2 in activation of latent TGF- $\beta 1$ in chemotherapy-treated stromal cells. We have previously determined that bone marrow stromal cells used in our model predominantly express high levels of MMP-2 (data not shown). In the current study we demonstrated that MMP- 2 acted as an activator of TGF- $\beta 1$ in human bone marrow stromal cells and was required for optimal Smad3 phosphorylation following etoposide exposure. The rationale for focusing on MMP-2 was based on the observation that MMP-2 is secreted into ECM in association with remodeling during tissue injury and repair [42, 43], and our own data which indicated that MMP-2 activity is rapidly elevated following etoposide treatment (Fig 4A). MMP-2 activation paralleled phosphorylation of Smad3, occurring as early as 5 minutes following treatment. Inhibition of MMP-2 activity with OA-Hy diminished chemotherapy-induced phospho-Smad3 signals in stromal cells (Fig 4B). These data suggested a critical role of MMP-2 in converting ECM-bound latent TGF- $\beta 1$ into its active form. Evaluation of MMP-2 knockout derived stroma indicated a critical role for MMP-2 during activation of chemotherapy-induced TGF- $\beta 1 / \mathrm{Smad} 3$ signaling in bone marrow stromal cells (Fig 4C and 4D). Transfection of human MMP-2 into murine stromal cells further suggest that MMP-2 plays a pivotal role in chemotherapy-induced activation of TGF- $\beta 1$ in our model (Fig 4E). Upregulation of MMP-2 and MMP-9 expression following TGF- $\beta 1$ stimulation in several cell types has been well-documented [44-47]. Thus, the current finding suggests there is potentially a regulatory feedback loop in the bone marrow matrix during chemotherapeutic stress. 
Evidence suggests that generation of ROS can serve as a secondary message to initiate signal transduction, in addition to its role in mediating apoptosis [48, 49]. In our model, we found that following chemotherapeutic stimulation, ROS was rapidly generated in bone marrow stromal cells (Fig 5A). The drugs that induced phosphorylation of Smad3 were those that also induced ROS generation. Reduction of intracellular ROS by NAC reduced the phospho-Smad3 level induced by etoposide (Fig 5B).

These data suggest a connection between ROS and MMP-2 activity when combined with the evidence that in vitro activation of pro-MMP-2 by hydrogen peroxide induced a dose dependent phosphorylation of stromal cell Smad3 (Fig 5C). The connection is strengthened by the observation that ROS activation of TGF- $\beta 1$ is dependent on the presence of MMP-2 (Fig 5D). In contrast to a recent report in which latent TGF- $\beta 1$ could be directly activated by asbestos-derived ROS in A549 and mink pulmonary epithelial cells [50], our data indicate that dependence of TGF- $\beta 1$ activation on MMP-2 cannot be circumvented during chemotherapeutic stress in marrow stromal cells. Consistent with the reports $[51,52]$ in which MMP-2 was activated by ROS in other cell models, our results suggest that generation of reactive oxygen species is an early event that initiates the TGF- $\beta 1$ signaling pathway in bone marrow stromal cells during chemotherapy. Of note, Ara-C exposure induced phosphorylation of Smad3 in stromal cells, but did not promote intracellular ROS production. This suggests that other mechanisms are responsible for activation of Smad3 during Ara-C treatment.

C-terminal phosphorylation by the type I receptor is considered a key event in Smad activation [7], however, there is evidence indicating other kinase pathways may also regulate Smad signaling [53, 54]. In our stromal cell model, P38, but not Erk1/2 or JNK, modulated Smad3 phosphorylation following etoposide treatment (Fig 6B). This indicates p38 may serve as 
a signal transducer that is downstream of TGF- $\beta 1 /$ receptor ligation and directly mediates phosphorylation of Smad3. Phosphorylation of Smad3 by TGFR I in its C-terminus, or by p38 in its joint region [55], may initiate distinct signaling and induce different biological consequences.

Translocation of Smad3 from the cytoplasm into the nucleus of stromal cells treated with etoposide is the hallmark of activation of TGF- $\beta 1$ signaling (Fig 7). As a transcriptional regulator, nuclear Smads target a variety of genes $[6,7,20]$. Interestingly, a recent report documented that TGF- $\beta 1$ stimulation led to downregulation of SDF-1 expression in bone marrow MS-5 stromal cells although it was not investigated whether this was a Smad3-dependent effect [56]. It has also been shown that TGF- $\beta 1$ treated stromal cells have less cell surface VCAM-1 expression [57]. These reports are consistent with our earlier findings that etoposide treated stromal cells have diminished chemotactic support [22] and impaired VCAM-1 expression [38] and our recent data indicating these same cells, when treated rhTGF- $\beta 1$, have impaired support of pro-B cell adhesion and proliferation (Fig 8 B\&C).

Our current model suggests that dose-escalated chemotherapy may initiate a ROS/MMP2 dependent activation of TGF- $\beta 1$, which may have direct influence on hematopoietic cells as well as effects on stromal cell gene expression. Further investigation of these chemotherapyinduced changes may lend insight into strategies to protect the hematopoietic microenvironment during treatment in an effect to enhance hematopoietic recovery. Of note, very distinct pathways may be initiated during the acute and chronic phases of the stress response. Consequently, conclusions regarding the effects of chemotherapy exposure must be interpreted within the appropriate context as we attempt to better understand the dynamic response of the bone marrow to chemotherapy. 


\section{ACKNOWLEDGEMENTS}

This work was supported by NIH grant R01 HL056888 (LFG) and NIEHS Training grant ES010953 (SC). The authors would like to acknowledge Dr. Michael Reiss (The Cancer Institute of New Jersey, New Brunswick, NJ), who generously provided phospho-Smad2 antibody used in experiments that preceded those shown in the current report, as well as phospho-Smad3 prior to commercial availability. 


\section{REFERENCES}

1. Gordon MY, Goldman JM, Gordon-Smith EC. Spatial and functional relationships between human hemopoietic and marrow stromal cells in vitro. Stem Cells 1983;1:429-439.

2. Harvey K, Dzierzak E. Cell-cell contact and anatomical compatibility in stromal cellmediated HSC support during development. Stem Cells 2004;22:253-258.

3. Bianco P, Riminucci M, Gronthos S, et al. Bone marrow stromal stem cells: nature, biology, and potential applications. Stem Cells 2001;19:180-192.

4. Bacigalupo A. Hematopoietic stem cell transplants after reduced intensity conditioning regimen (RI-HSCT): report of a workshop of the European group for Blood and Marrow Transplantation (EBMT). Bone Marrow Transplant 2000;25:803-805.

5. de LM, Anagnostopoulos A, Munsell $\mathrm{M}$ et al. Nonablative versus reduced-intensity conditioning regimens in the treatment of acute myeloid leukemia and high-risk myelodysplastic syndrome: dose is relevant for long-term disease control after allogeneic hematopoietic stem cell transplantation. Blood 2004;104:865-872.

6. Attisano L, Wrana JL. Signal transduction by the TGF-beta superfamily. Science 2002;296:1646-1647.

7. Derynck R, Zhang YE. Smad-dependent and Smad-independent pathways in TGF-beta family signalling. Nature 2003;425:577-584.

8. Leask A, Abraham DJ. TGF-beta signaling and the fibrotic response. FASEB J 2004;18:816827. 
9. Schnaper HW, Hayashida T, Poncelet AC. It's a Smad world: regulation of TGF-beta signaling in the kidney. J Am Soc Nephrol 2002;13:1126-1128.

10. Kanzler S, Lohse AW, Keil A et al. TGF-beta1 in liver fibrosis: an inducible transgenic mouse model to study liver fibrogenesis. Am J Physiol 1999;276:G1059-G1068.

11. Daniels CE, Wilkes MC, Edens M et al. Imatinib mesylate inhibits the profibrogenic activity of TGF-beta and prevents bleomycin-mediated lung fibrosis. J Clin Invest 2004;114:13081316.

12. Fortunel N, Hatzfeld J, Kisselev $\mathrm{S}$ et al. Release from quiescence of primitive human hematopoietic stem/progenitor cells by blocking their cell-surface TGF-beta type II receptor in a short-term in vitro assay. Stem Cells 2000;18:102-111.

13. Kim SJ, Letterio J. Transforming growth factor-beta signaling in normal and malignant hematopoiesis. Leukemia 2003;17:1731-1737.

14. Gleizes PE, Munger JS, Nunes I et al. TGF-beta latency: biological significance and mechanisms of activation. Stem Cells 1997;15:190-197.

15. Chu TM, Kawinski E. Plasmin, substilisin-like endoproteases, tissue plasminogen activator, and urokinase plasminogen activator are involved in activation of latent TGF-beta 1 in human seminal plasma. Biochem Biophys Res Commun 1998;253:128-134.

16. Mitchell EJ, O'Connor-McCourt MD. A transforming growth factor beta (TGF-beta) receptor from human placenta exhibits a greater affinity for TGF-beta 2 than for TGF-beta 1. Biochemistry 1991;30:4350-4356. 
17. Yevdokimova N, Wahab NA, Mason RM. Thrombospondin-1 is the key activator of TGFbeta1 in human mesangial cells exposed to high glucose. J Am Soc Nephrol 2001;12:703712.

18. Blakytny R, Ludlow A, Martin GE et al. Latent TGF-betal activation by platelets. J Cell Physiol 2004;199:67-76.

19. Annes JP, Chen Y, Munger JS, Rifkin DB. Integrin alphaVbeta6-mediated activation of latent TGF-beta requires the latent TGF-beta binding protein-1. J Cell Biol 2004;165:723734.

20. Shi Y, Massague J. Mechanisms of TGF-beta signaling from cell membrane to the nucleus. Cell 2003;113:685-700.

21. Roecklein BA, Torok-Storb B. Functionally distinct human marrow stromal cell lines immortalized by transduction with the human papilloma virus E6/E7 genes. Blood 1995;85:997-1005.

22. Gibson LF, Fortney J, Landreth KS et al. Disruption of bone marrow stromal cell function by etoposide. Biol Blood Marrow Transplant 1997;3:122-132.

23. Corry DB, Kiss A, Song LZ et al. Overlapping and independent contributions of MMP2 and MMP9 to lung allergic inflammatory cell egression through decreased CC chemokines. FASEB J 2004;18:995-997.

24. Gibson LF, Piktel D, Landreth KS. Insulin-like growth factor-1 potentiates expansion of interleukin-7-dependent pro-B cells. Blood 1993;82:3005-3011. 
25. Hande KR. The importance of drug scheduling in cancer chemotherapy: etoposide as an example. Stem Cells 1996;14:18-24.

26. Wang L, Fortney JE, Gibson LF. Stromal cell protection of B-lineage acute lymphoblastic leukemic cells during chemotherapy requires active Akt. Leuk.Res. 2004;28:733-742.

27. Wang L, Chen L, Benincosa J, Fortney J, Gibson LF. VEGF-induced phosphorylation of Bcl-2 influences B lineage leukemic cell response to apoptotic stimuli. Leukemia 2005; 19:344-353.

28. Fischer OM, Giordano S, Comoglio PM, Ullrich A. Reactive oxygen species mediate Met receptor transactivation by $\mathrm{G}$ protein-coupled receptors and the epidermal growth factor receptor in human carcinoma cells. J Biol Chem 2004;279:28970-28978.

29. Thomas ED, Sr. Stem cell transplantation: past, present and future. Stem Cells 1994;12:539544.

30. Clift RA, Appelbaum FR, Thomas ED. Treatment of chronic myeloid leukemia by marrow transplantation. Blood 1993;82:1954-1956.

31. Imrie K, Dicke KA, Keating A. Autologous bone marrow transplantation for acute myeloid leukemia. Stem Cells 1996;14:69-78.

32. Gorin NC. Autologous stem cell transplantation in acute lymphocytic leukemia. Stem Cells 2002;20:3-10. 
33. Socie G, Salooja N, Cohen A et al. Nonmalignant late effects after allogeneic stem cell transplantation. Blood 2003;101:3373-3385.

34. Pedersen-Bjergaard J, Andersen MK, Christiansen DH. Therapy-related acute myeloid leukemia and myelodysplasia after high-dose chemotherapy and autologous stem cell transplantation. Blood 2000;95:3273-3279.

35. Guillaume T, Rubinstein DB, Symann M. Immune reconstitution and immunotherapy after autologous hematopoietic stem cell transplantation. Blood 1998;92:1471-1490.

36. Thiele J, Kvasnicka HM, Beelen DW et al. Megakaryopoiesis and myelofibrosis in chronic myeloid leukemia after allogeneic bone marrow transplantation: an immunohistochemical study of 127 patients. Mod Pathol 2001;14:129-138.

37. Thiele J, Kvasnicka HM, Beelen DW et al. Relevance and dynamics of myelofibrosis regarding hematopoietic reconstitution after allogeneic bone marrow transplantation in chronic myelogenous leukemia--a single center experience on 160 patients. Bone Marrow Transplant 2000;26:275-281.

38. Hall BM, Fortney JE, Gibson LF. Alteration of nuclear factor-kappaB (NF-kappaB) expression in bone marrow stromal cells treated with etoposide. Biochem Pharmacol 2001;61:1243-1252.

39. Sontag E. Protein phosphatase 2A: the Trojan Horse of cellular signaling. Cell Signal 2001;13:7-16. 
40. Yu Q, Stamenkovic I. Cell surface-localized matrix metalloproteinase-9 proteolytically activates TGF-beta and promotes tumor invasion and angiogenesis. Genes Dev. 2000;14:163-176.

41. Maeda S, Dean DD, Gomez R, Schwartz Z, Boyan BD. The first stage of transforming growth factor beta1 activation is release of the large latent complex from the extracellular matrix of growth plate chondrocytes by matrix vesicle stromelysin-1 (MMP-3). Calcif.Tissue Int. 2002;70:54-65.

42. Goodsell DS. The molecular perspective: matrix metalloproteinase 2. Stem Cells 2000;18:73-75.

43. Kunugi S, Fukuda Y, Ishizaki M, Yamanaka N. Role of MMP-2 in alveolar epithelial cell repair after bleomycin administration in rabbits. Lab Invest 2001;81:1309-1318.

44. Miralles F, Battelino T, Czernichow P, Scharfmann R. TGF-beta plays a key role in morphogenesis of the pancreatic islets of Langerhans by controlling the activity of the matrix metalloproteinase MMP-2. J Cell Biol 1998;143:827-836.

45. Stawowy P, Margeta C, Kallisch H et al. Regulation of matrix metalloproteinase MT1MMP/MMP-2 in cardiac fibroblasts by TGF-beta1 involves furin-convertase. Cardiovasc Res 2004;63:87-97.

46. Kim ES, Kim MS, Moon A. TGF-beta-induced upregulation of MMP-2 and MMP-9 depends on p38 MAPK, but not ERK signaling in MCF10A human breast epithelial cells. Int J Oncol 2004;25:1375-1382. 
47. Kim HS, Shang T, Chen Z, Pflugfelder SC, Li DQ. TGF-betal stimulates production of gelatinase (MMP-9), collagenases (MMP-1, -13) and stromelysins (MMP-3, -10, -11) by human corneal epithelial cells. Exp Eye Res 2004;79:263-274.

48. Sauer H, Wartenberg M, Hescheler J. Reactive oxygen species as intracellular messengers during cell growth and differentiation. Cell Physiol Biochem 2001;11:173-186.

49. Thannickal VJ, Fanburg BL. Reactive oxygen species in cell signaling. Am J Physiol Lung Cell Mol Physiol 2000;279:L1005-L1028.

50. Pociask DA, Sime PJ, Brody AR. Asbestos-derived reactive oxygen species activate TGFbeta1. Lab Invest 2004;84:1013-1023.

51. Rajagopalan S, Meng XP, Ramasamy S, Harrison DG, Galis ZS. Reactive oxygen species produced by macrophage-derived foam cells regulate the activity of vascular matrix metalloproteinases in vitro. Implications for atherosclerotic plaque stability. J Clin Invest 1996;98:2572-2579.

52. Deem TL, Cook-Mills JM. Vascular cell adhesion molecule 1 (VCAM-1) activation of endothelial cell matrix metalloproteinases: role of reactive oxygen species. Blood 2004;104:2385-2393.

53. Furukawa F, Matsuzaki K, Mori $\mathrm{S}$ et al. p38 MAPK mediates fibrogenic signal through Smad3 phosphorylation in rat myofibroblasts. Hepatology 2003;38:879-889.

54. Leivonen SK, Chantry A, Hakkinen L, Han J, Kahari VM. Smad3 mediates transforming growth factor-beta-induced collagenase-3 (matrix metalloproteinase-13) expression in 
human gingival fibroblasts. Evidence for cross-talk between Smad3 and p38 signaling pathways. J Biol Chem. 2002;277:46338-46346.

55. Mori S, Matsuzaki K, Yoshida K et al. TGF-beta and HGF transmit the signals through JNK-dependent Smad2/3 phosphorylation at the linker regions. Oncogene 2004;23:74167429.

56. Wright N, de Lera TL, Garcia-Moruja C et al. Transforming growth factor-betal downregulates expression of chemokine stromal cell-derived factor-1: functional consequences in cell migration and adhesion. Blood 2003;102:1978-1984.

57. Dittel BN, McCarthy JB, Wayner EA, LeBien TW. Regulation of human B-cell precursor adhesion to bone marrow stromal cells by cytokines that exert opposing effects on the expression of vascular cell adhesion molecule-1 (VCAM-1). Blood 1993;81:2272-2282. 


\section{FIGURE LEGENDS}

Figure 1. Chemotherapy activates Smad3 through phosphorylation at serines 433/435 in human bone marrow derived stromal cells. Western blot analyses of HS-27A stromal cells treated with (A) $100 \mu \mathrm{M}$ etoposide for the indicated time points, (B) various concentrations of etoposide for 1 hour, or (C) 3ng/mL TGF- $\beta 1,100 \mu \mathrm{M}$ etoposide, $200 \mu \mathrm{g} / \mathrm{mL}$ melphalan, $20 \mu \mathrm{g} / \mathrm{mL}$ vincristine, $100 \mu \mathrm{g} / \mathrm{mL}$ daunorubicin, $100 \mu \mathrm{M}$ doxorubicin, $100 \mu \mathrm{g} / \mathrm{mL}$ 4-hydroperoxylcyclophosphamide or $100 \mu \mathrm{g} / \mathrm{mL}$ Ara-C for 1 hour. Membranes were probed with anti-phospho-Smad3 (P-Smad3, ser433/435) then stripped and re-probed with total Smad3 (T-Smad3) specific antibodies.

Figure 2. Chemotherapy-induced Smad3 phosphorylation is mediated by TGF- $\beta 1$. (A) Quantitative analysis of the release of active and total TGF- $\beta 1$ from HS-27A stromal cell supernatants exposed to etoposide at $0-100 \mu \mathrm{M}$ for 1 hour (upper graph) or at $100 \mu \mathrm{M}$ for $0-6$ hours (lower graph). Bars marked with an $(*)$ or $(\#)$ indicate significant differences as compared to untreated controls $(P<0.05)$. (B) Immunoprecipitation of human TGF- $\beta 1$ from HS-27A and P148 supernatants following exposure of stromal cells to the indicated concentrations of etoposide for 1 hour. Supernatants were immunoprecipitated with anti-TGF- $\beta 1$ and run under reducing conditions. Western blots were probed with anti-TGF- $\beta 1$ antibody. Recombinant human TGF- $\beta 1$ served as the molecular size control. (C) Immunoprecipitation of TGF- $\beta 1$ from HS-27A cell supernatants pre-incubated with $3 \mu \mathrm{g}$ of anti-TGF- $\beta 1$, anti-LAP/TGF- $\beta 1$, or antiLTBP-1/TGF- $\beta 1$ antibodies followed by exposure to $100 \mu \mathrm{M}$ etoposide for 1 hour. Samples were 
run under both reducing and non-reducing conditions and Western blots probed with anti-human TGF- $\beta 1$ antibody.

Figure 3. Disruption of the availability of TGF- $\beta 1$ blocks the signal transduction initiated by chemotherapy. (A) Western blot analysis of HS-27A stromal cells treated with $100 \mu \mathrm{M}$ etoposide, $200 \mu \mathrm{g} / \mathrm{mL}$ melphalan or $100 \mu \mathrm{g} / \mathrm{mL} 4-\mathrm{HC}$ for 1 hour. (B) ELISA of released total TGF- $\beta 1$ from HS-27A and P148 stromal cells transfected with the indicated concentrations of TGF- $\beta 1$ knockdown siRNA or control dsRNA for 48 hours followed by exposure to $100 \mu \mathrm{M}$ etoposide for 1 hour (upper panel). Bars marked with an $(*)$ or (\#) indicated significant differences as compared to control dsRNA transfections $(P<0.05)$. Western blot analysis of Smad-3 phosphorylation using the same TGF- $\beta 1$ siRNA transfection cell lysates is shown in the lower panel.

Figure 4. Chemotherapy-induced MMP-2 activity is required for activation of latent TGF-1. (A) Gelatin zymography analysis of supernatants from S-10 stromal cells treated with $100 \mu \mathrm{M}$ etoposide for 0-6 hours. (B) Western blot analysis of HS-27A and Ped604 stromal cells treated with $1 \mu \mathrm{M}$ MMP-2 inhibitor OA-Hy for 30 minutes prior to exposure to $100 \mu \mathrm{M}$ etoposide for 1 hour. (C) Western blot analysis of murine C57BL/6 MMP-2 knockout stromal cells (MMP-2-/-, KO) or wild-type stromal cells (MMP-2 $2^{+/+}$, WT) treated with $100 \mu \mathrm{M}$ etoposide, $200 \mu \mathrm{g} / \mathrm{mL}$ melphalan or $100 \mu \mathrm{g} / \mathrm{mL} 4-\mathrm{HC}$ for 1 hour. (D) Western blot analysis of MMP-2 ${ }^{+/+}$and MMP-2/- stromal cells treated with $100 \mu \mathrm{M}$ etoposide in the presence or absence of $250 \mathrm{ng} / \mathrm{mL}$ recombinant human active MMP-2 for 1 hour. Untreated controls were not exposed to either recombinant MMP-2 or etoposide. (E) Gelatinolytic analysis of supernatants and cell lysates from S-10 parental, vector or MMP-2 transfected S-10 stromal cells treated with $100 \mu \mathrm{M}$ 
etoposide for 1 hour and Western blot analysis of Smad3 phosphorylation and NPT II expression using the same transfection samples.

Figure 5. Activation of latent MMP-2 by chemotherapy requires the generation of reactive oxygen species (ROS). (A) Flow cytometric analysis of intracellular ROS in HS-27A stromal cells treated with $100 \mu \mathrm{M}$ etoposide for $0-4$ hour (upper panel) or HS-27A stromal cells treated with the indicated chemotherapeutic agents identical to those shown in Fig 1C for 1 hour (lower panel). Untreated control stromal cells in the lower panel are indicated by the solid histogram. Ara-C treated stromal cell ROS overlays the untreated control histogram. (B) Western blot analysis of HS-27A or P148 stromal cells pretreated with $20 \mathrm{mM} \mathrm{N}$-acetyl cysteine (NAC) overnight prior to exposure to $100 \mu \mathrm{M}$ etoposide for 1 hour. (C) Western blot analysis of HS-27A stromal cells treated with recombinant pro-MMP-2 that was activated in vitro. Cells were exposed to 0 to $500 \mathrm{ng} / \mathrm{ml}$ activated MMP-2 for 1 hour. (D) Western blot analysis of MMP-2 $2^{+/+}$ and MMP-2-/- stromal cells treated with $10 \mu \mathrm{M} \mathrm{H}_{2} \mathrm{O}_{2}$ in the presence or absence of $250 \mathrm{ng} / \mathrm{mL}$ pro-MMP-2 for 1 hour.

Figure 6. P38, but not Erk1/2 or JNK kinase, is involved in mediating etoposide-induced Smad3 phosphorylation. (A) Western blot analysis of HS-27A stromal cells treated with TGF- $\beta 1$ or the same chemotherapeutic agents shown in Figs 1C and Fig5A (lower panel). (B) Western blot analysis of HS-27 stromal cells pretreated with vehicle, $10 \mu \mathrm{M}$ Erk1/2 kinase inhibitor U0126, $20 \mu \mathrm{M}$ p38 kinase inhibitor SB220025 or $5 \mu \mathrm{M}$ JNK/SAPK inhibitor SP600125 followed by etoposide exposure for 1 hour. Blot was stripped and re-probed with antibodies specific for the proteins indicated. 
Figure 7. Etoposide treatment results in phosphorylation and subsequent nuclear localization of Smad3 protein in human stromal cells. Double-channel confocal microscopy analysis of HS-27A stromal cells treated with $100 \mu \mathrm{M}$ etoposide for up to 6 hours. Cells were double-stained with $5 \mu \mathrm{g} / 100 \mu \mathrm{L}$ PI (Rhodamine, red signal) and $3 \mu \mathrm{g} / 100 \mu \mathrm{L}$ of anti-phospho-Smad3 antibody followed by staining with FITC-conjugated anti-rabbit IgG secondary antibody (green signal). Panels on the right represent merged images of cytosolic and nuclear phospho-smad3 staining. Original magnifications 200X.

Figure 8. Recombinant TGF- $\beta 1$ activates Smad3 and impairs stromal cells support of pro-B cell adhesion and proliferation. (A) Western blot analysis of Smad3 phosphorylation of HS-27A stromal cells treated with $3 \mathrm{ng} / \mathrm{mL}$ rhTGF- $\beta 1$ for the indication time points or the indicated concentrations of rhTGF- $\beta 1$ for 24 hours. (B) Adhesion of C1.92 pro-B cells labeled with PKH26 and co-cultured on P156 and S-10 stromal cells pretreated with the indicated concentrations of rhTGF- $\beta 1$ for 72 hour. Bars marked with an $(*)$ or (\#) indicate significant differences as compared to untreated controls $(P<0.05)$. (C) ${ }^{3} \mathrm{H}$-thymidine incorporation of $\mathrm{C} 1.92$ pro-B cells co-cultured on P156 and S-10 stromal cells pretreated with the indicated concentrations of rhTGF- $\beta 1$ for 72 hour. Bars marked with an $(*)$ or (\#) indicate significant differences as compared to untreated controls $(P<0.05)$.

Figure 9. Proposed model for activation of the TGF- $\beta 1 / \mathrm{p} 38 / \mathrm{Smad} 3$ signaling cascade in bone marrow stromal cells during chemotherapy. Following chemotherapy, stromal cell mitochondria generate intracellular ROS, which translocates into the extracellular matrix and oxidizes pro- 
MMP-2 complexes. Active MMP-2 subsequently cleaves and releases TGF- $\beta 1$ from LTBP, allowing TGF- $\beta 1$ to bind to its receptor, and initiates phosphorylation of stromal cell p38 kinase. P38 mediates phosphorylation of Smad3 protein, which can subsequently dimerize with Smad4 and translocates into the nuclei to regulate a diverse set of target genes that may influence stromal cell support of hematopoietic cell development. 
Figure 1. Chemotherapy activates Smad3 through phosphorylation at serines 433/435 in human bone marrow derived stromal cells.
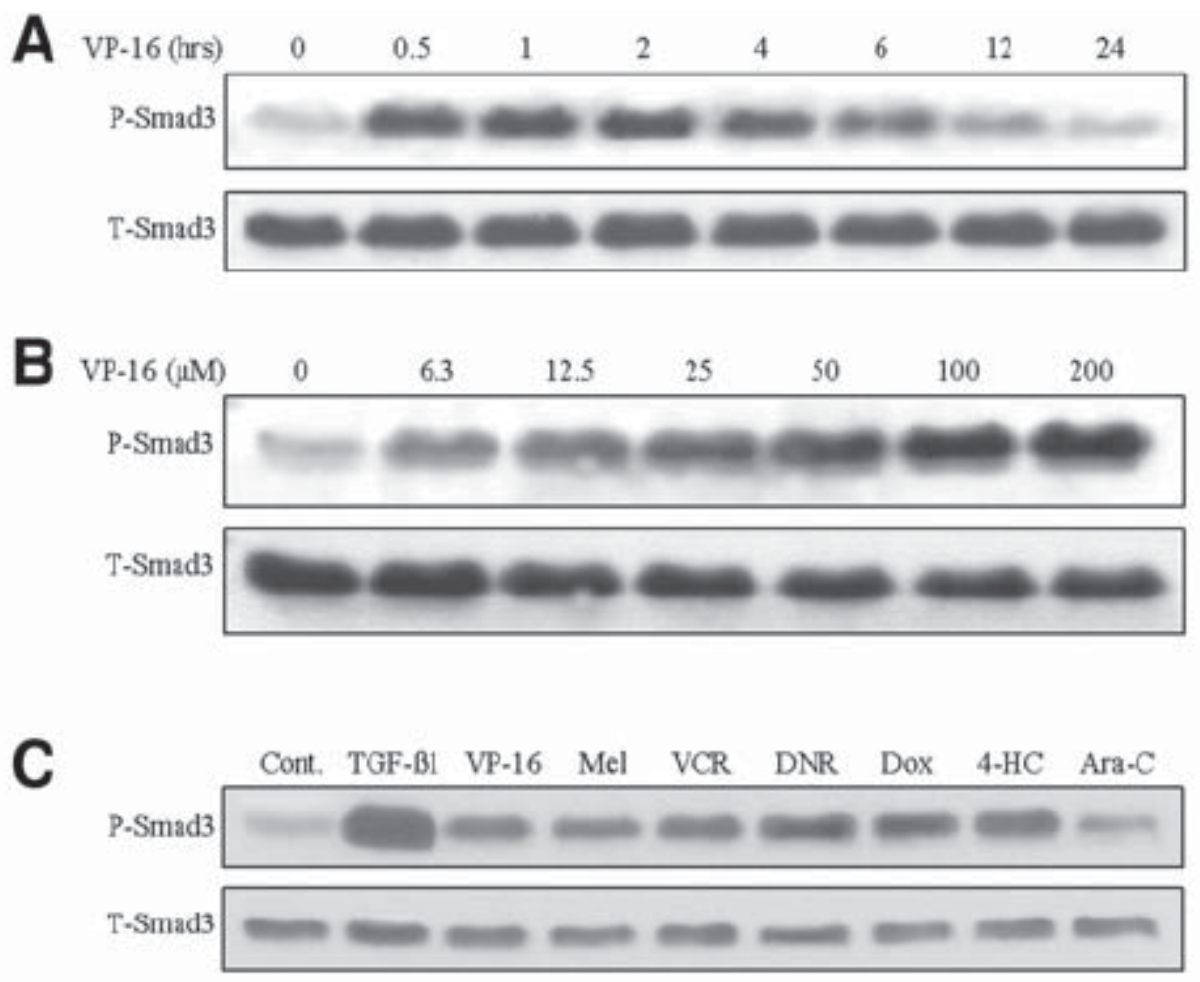
Figure 2. Chemotherapy-induced Smad3 phosphorylation is mediated by TGF- $\beta 1$.
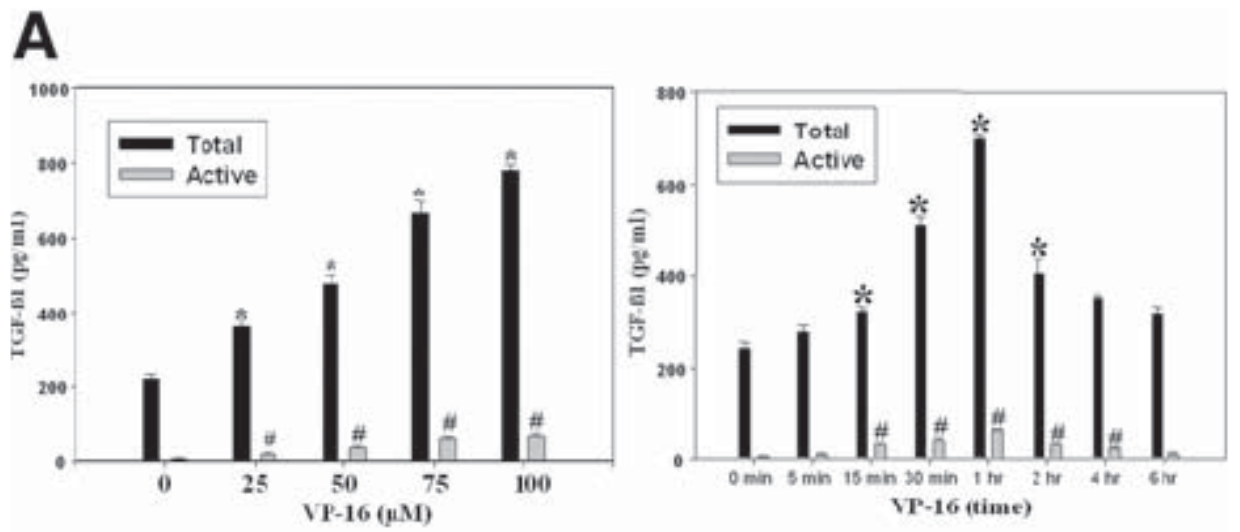

B

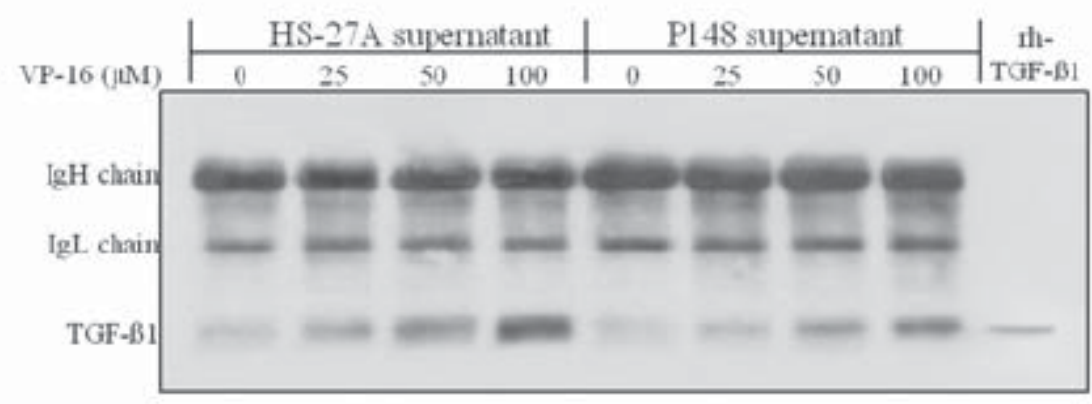

C

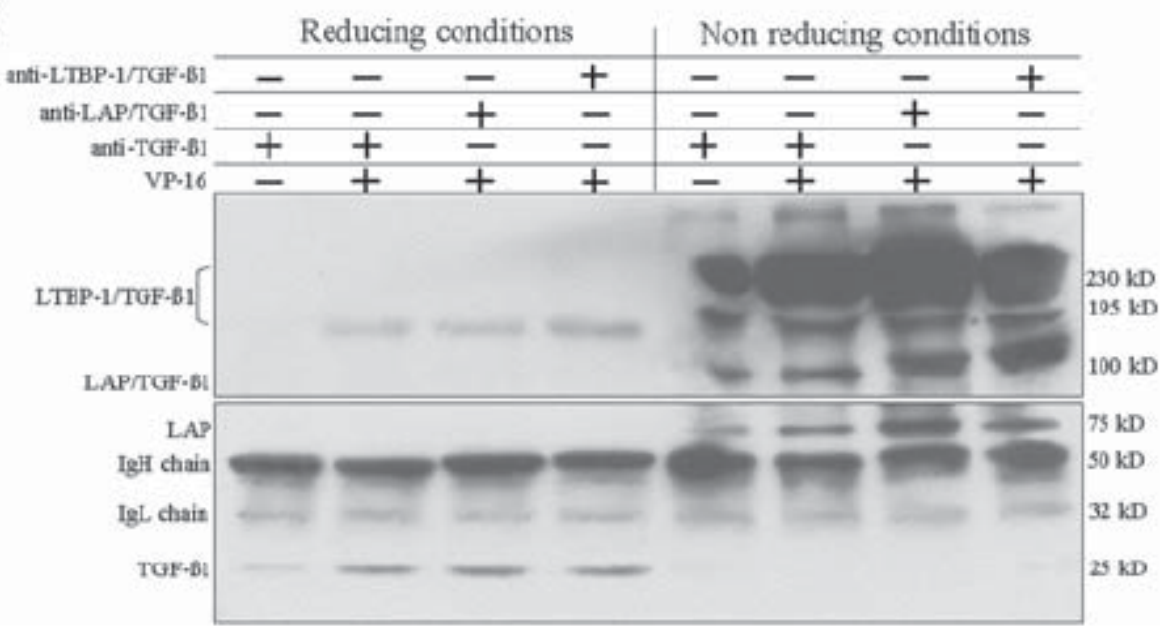


Figure 3. Disruption of the availability of TGF- $\beta 1$ blocks the signal transduction initiated by chemotherapy.
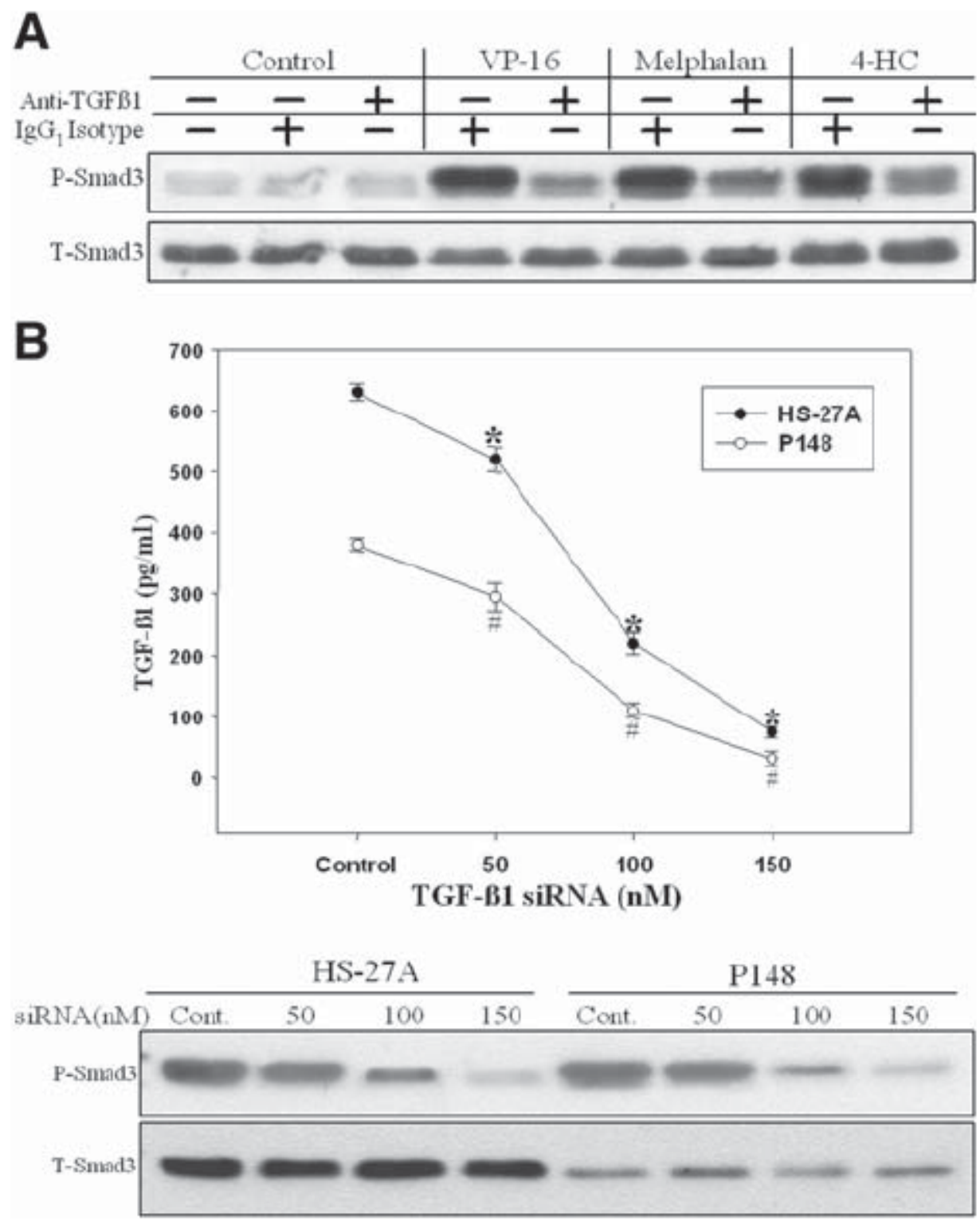
Figure 4. Chemotherapy-induced MMP-2 activity is required for activation of latent TGF-1.
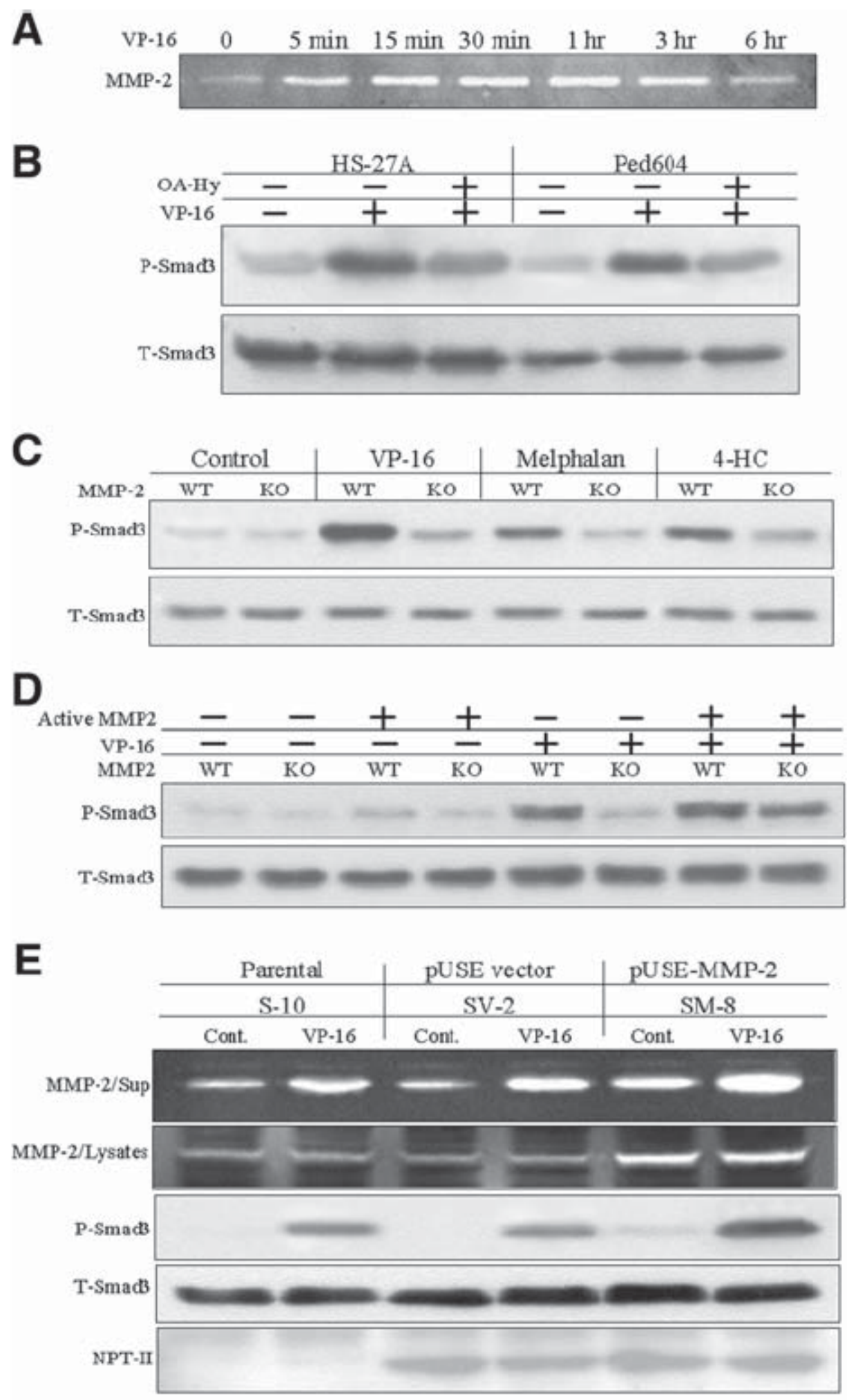
Figure 5. Activation of latent MMP-2 by chemotherapy requires the generation of reactive oxygen species (ROS).
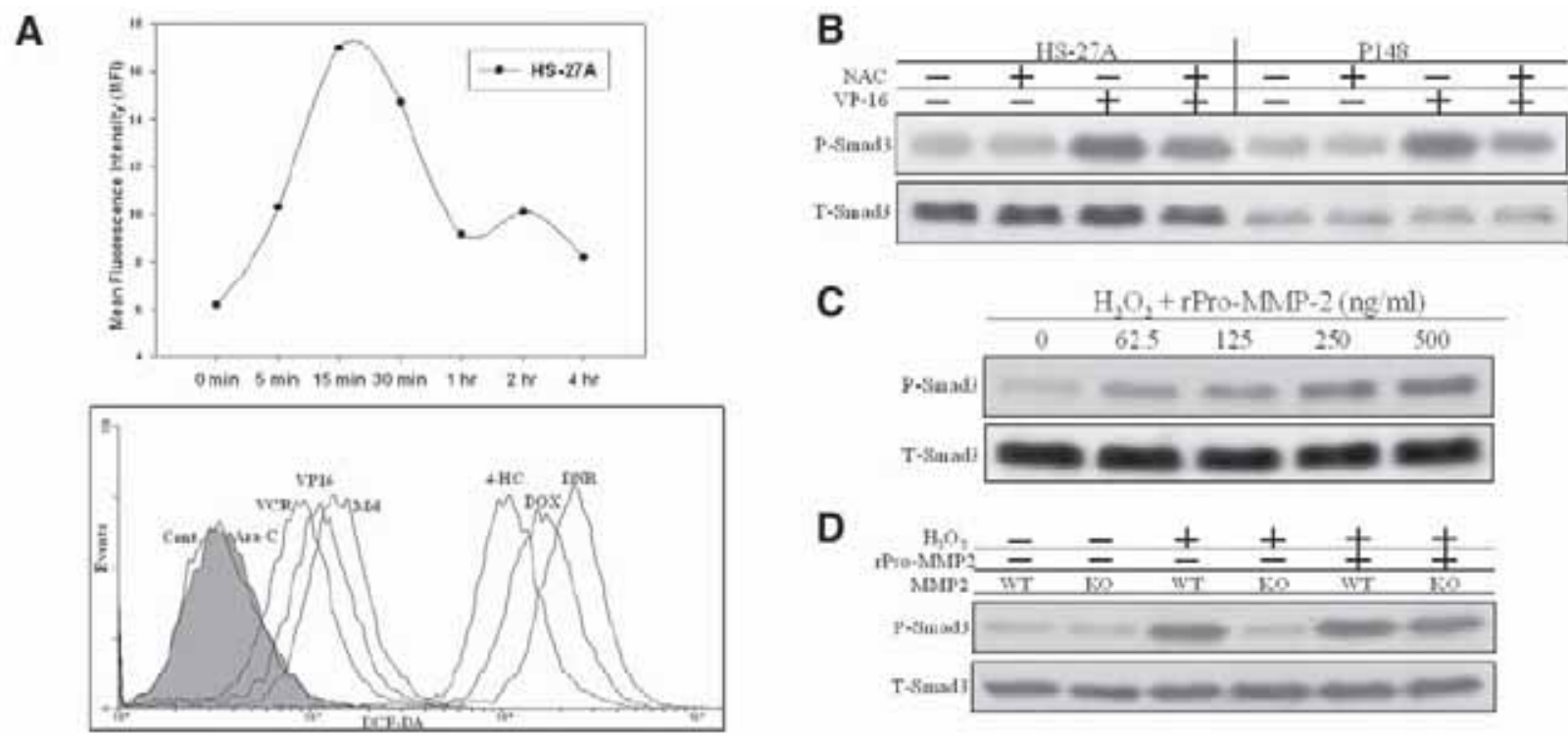
Figure 6. P38, but not Erk1/2 or JNK kinase, is involved in mediating etoposide-induced Smad3 phosphorylation.

A

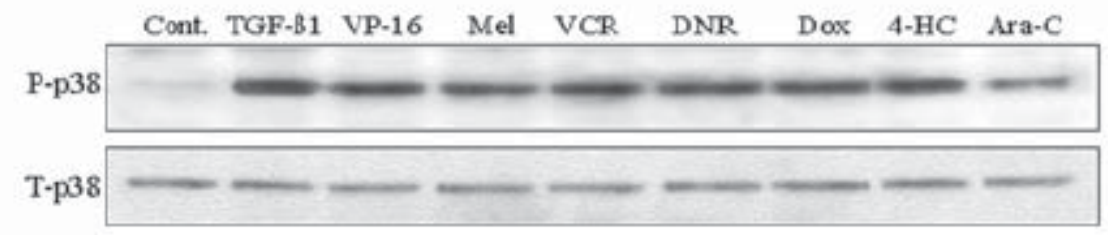

B

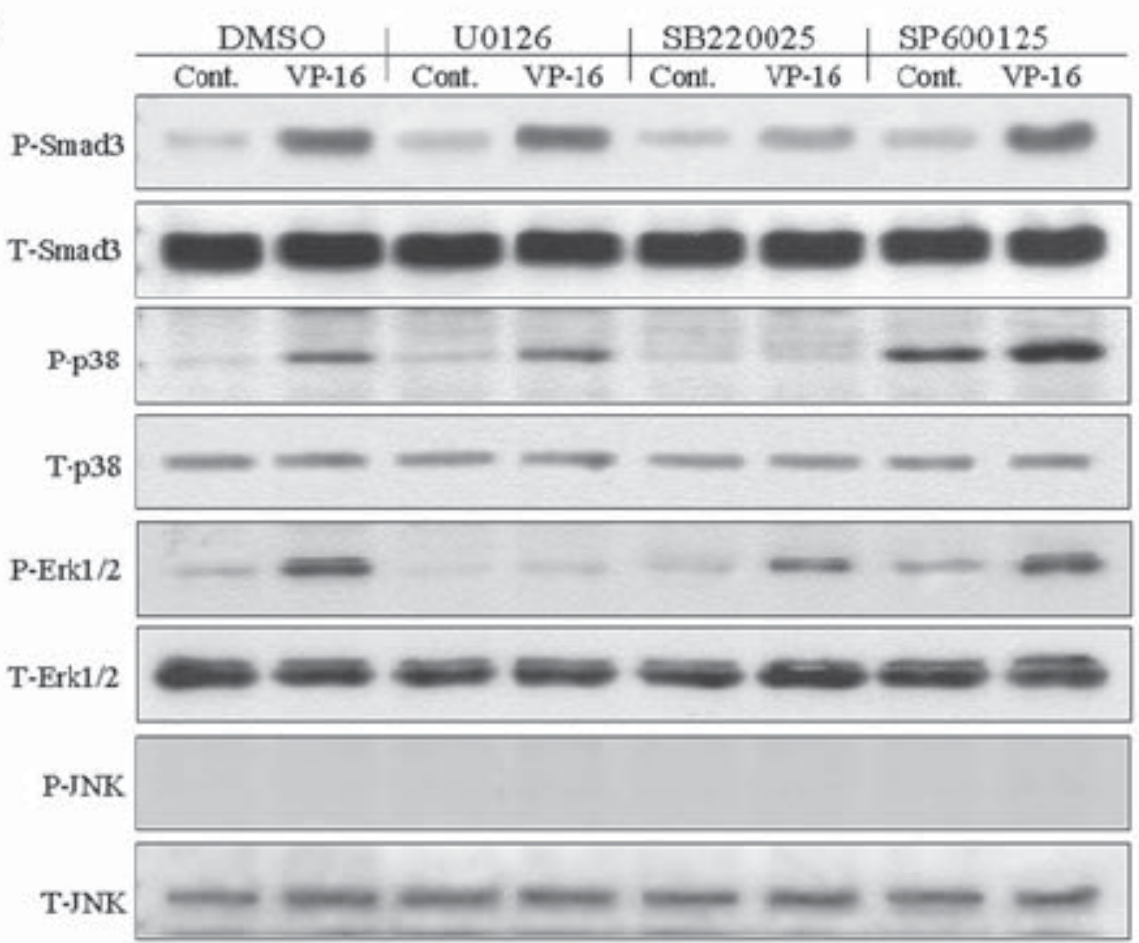


Figure 7. Etoposide treatment results in phosphorylation and subsequent nuclear localization of Smad3 protein in human stromal cells.
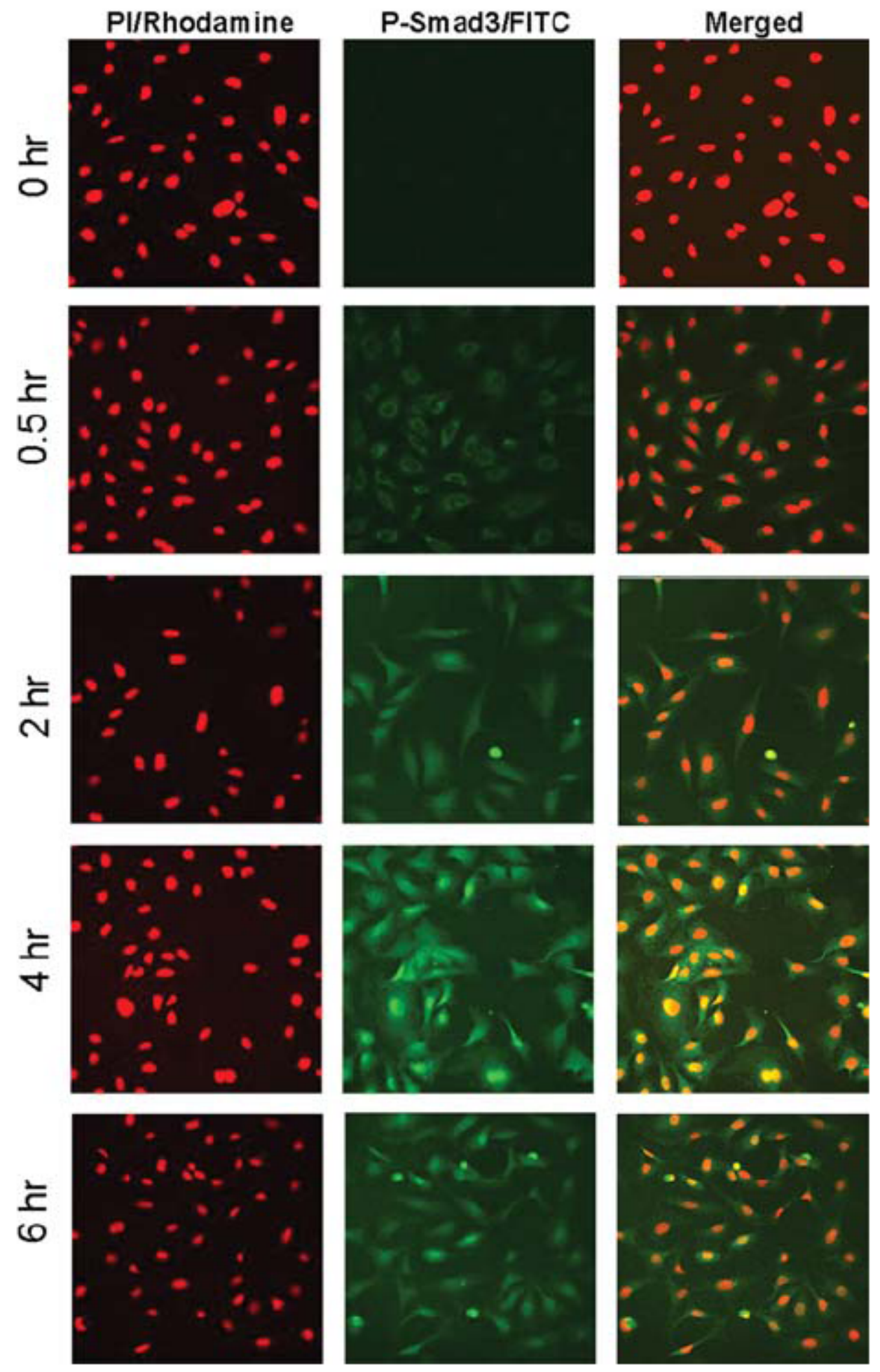
Figure 8. Recombinant TGF- $\beta 1$ activates Smad3 and impairs stromal cells support of pro-B cell adhesion and proliferation.
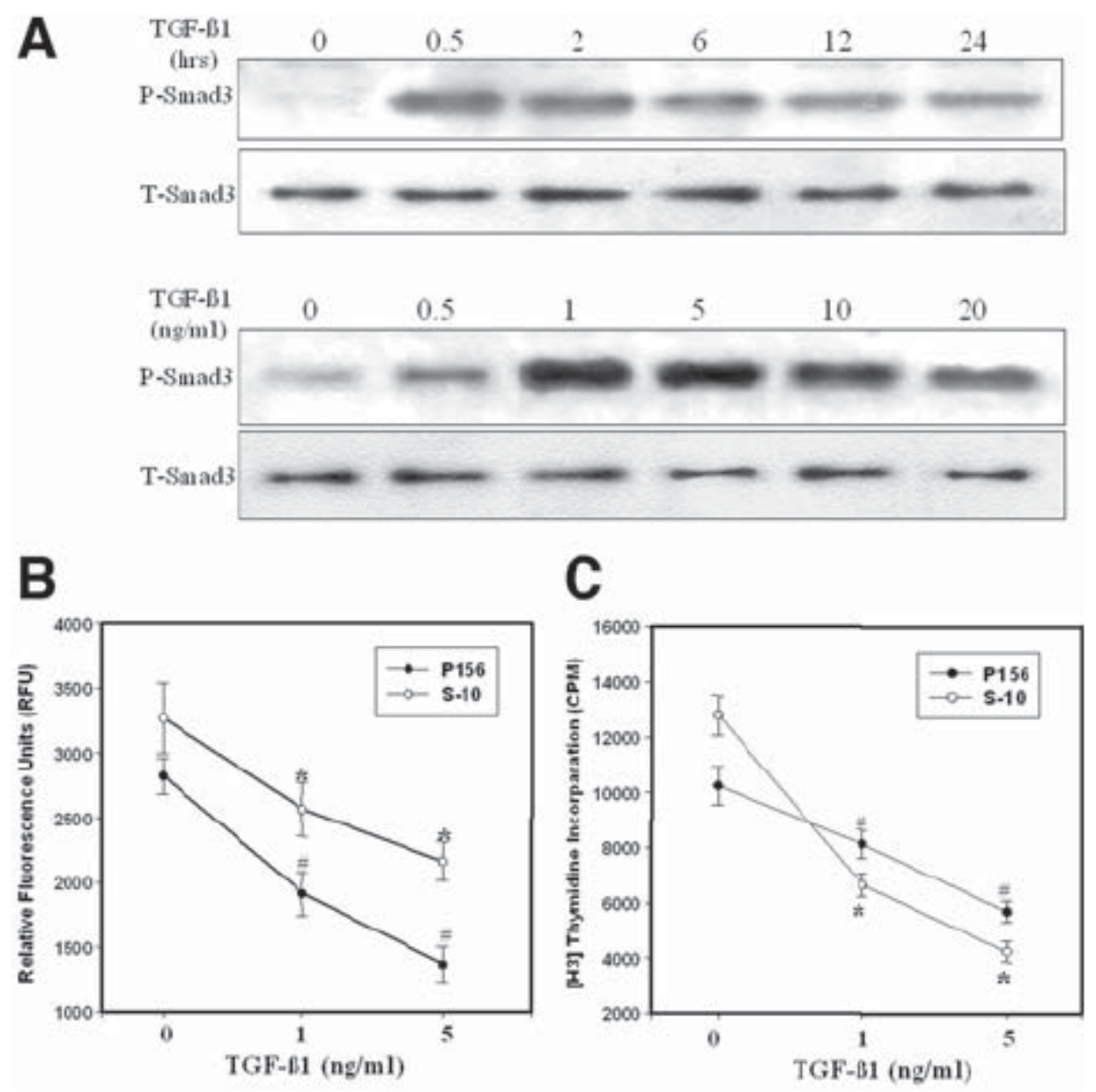
Figure 9. Proposed model for activation of the TGF- $\beta 1 / \mathrm{p} 38 / \mathrm{Smad} 3$ signaling cascade in bone marrow stromal cells during chemotherapy.

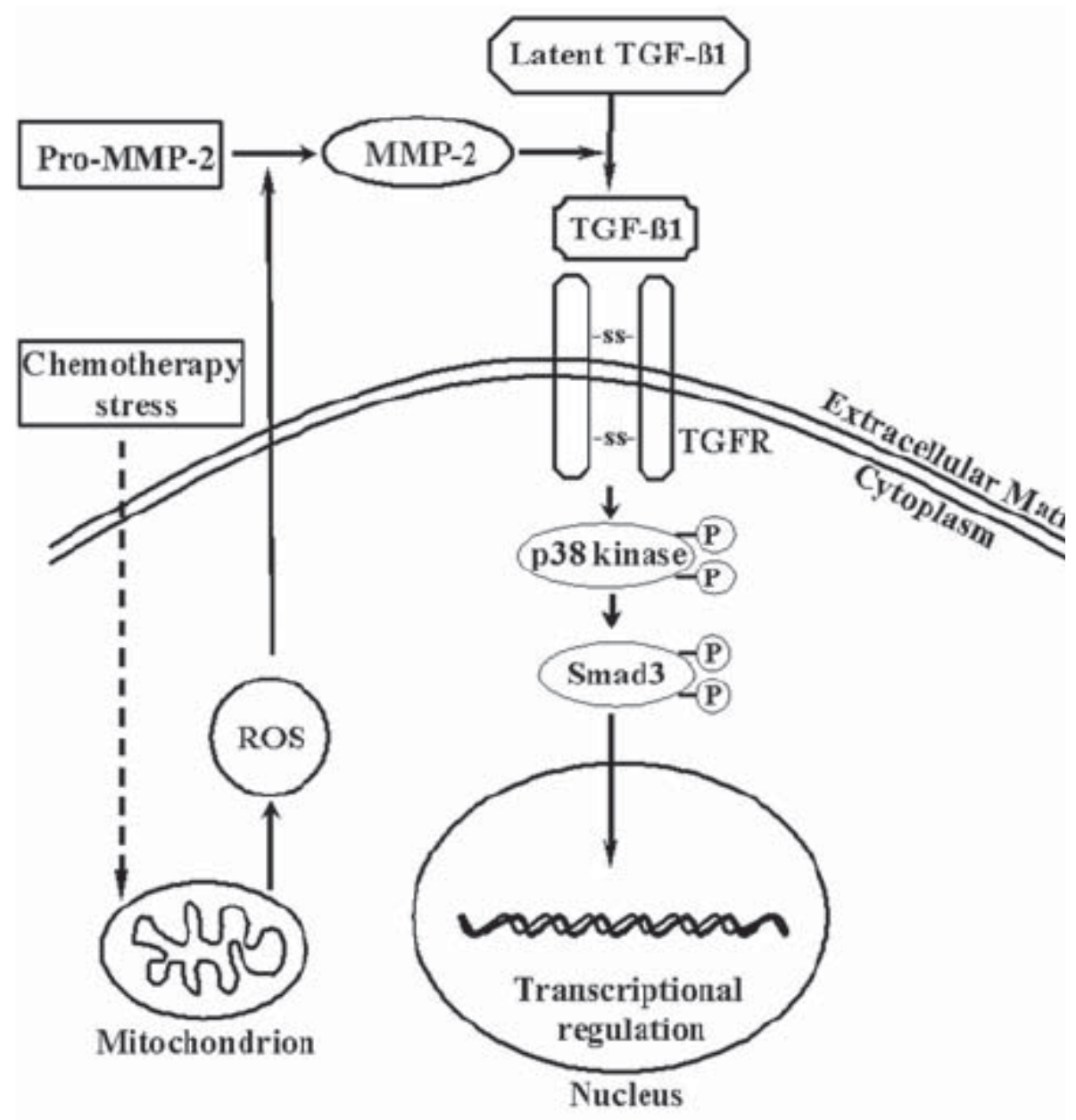




\section{CHAPTER IV}

Etoposide Disrupts Activity of Translational Regulatory Proteins in Bone Marrow Stromal

\section{Cells}

\section{Suzanne D. Clutter ${ }^{1}$, James E. Fortney ${ }^{2}$, and Laura F. Gibson ${ }^{1,2,3}$}

From the ${ }^{1}$ Department of Microbiology and Immunology, ${ }^{2}$ Department of Pediatrics, and ${ }^{3}$ Blood and Marrow Transplant and Hematologic Malignancy Program, Mary Babb Randolph Cancer Center, West Virginia University, Morgantown, WV, USA 


\begin{abstract}
Bone marrow stromal cell function is a critical influence on hematopoietic reconstitution following progenitor or stem cell transplantation. Stromal cells support hematopoietic cell migration, survival, and proliferation. We have previously reported that stromal cell MMP-2 is necessary for optimal support of pro-B cell chemotaxis through its regulation of SDF-1 release. Following exposure to the topoisomerase II inhibitor, etoposide, stromal cell MMP-2 protein expression is reduced. This reduction is not correlated with diminished mRNA expression, increased intracellular accumulation, or altered stability of MMP-2 protein. Based on these earlier observations, the current study investigated the mechanism by which VP-16 may alter translation of MMP-2 in bone marrow stromal cells. Rapid dephosphorylation of 4EBP-1, $\mathrm{P}^{\mathrm{S} 6 \mathrm{~K}}$ and S6 following VP-16 exposure was observed, consistent with blunted translational efficiency. We also observed an immediate increase in serine/threonine phosphatase activity in stromal cells exposed to VP-16, suggesting this may be one mechanism by which the activity of 4EBP-1 and P70 ${ }^{\mathrm{S} 6 \mathrm{~K}}$, which require phosphorylation for optimal activity, is reduced. Chemical inhibitors and siRNA specific for the catalytic subunit of PP2A did not block the protein phosphatase activity associated with dephosphorylation of 4EBP-1 and $\mathrm{P} 70^{\mathrm{S} 6 \mathrm{~K}}$ in $\mathrm{VP}-16$ treated stromal cells. These observations are consistent with disrupted regulation of MMP-2 translation in stromal cells exposed to VP-16. In addition, these data suggest that one mechanism by which VP-16 may alter stromal cells of the bone marrow microenvironment is through disrupted translation of proteins.
\end{abstract}




\section{INTRODUCTION}

Prior to bone marrow transplantation, myelosuppression or bone marrow ablation is often achieved by exposure to high doses of chemotherapeutic agents. Hematopoietic reconstitution following transplantation is supported, in part, by bone marrow stromal cells. We and others have shown that chemotherapy can blunt stromal cell support of hematopoietic cell proliferation and survival through disruption of proteins that contribute to this process, including, VCAM-1, IGF-1 and SDF-1 (1-5). Inefficient hematopoietic reconstitution may result, in part, from alteration of the bone marrow microenvironment's function by chemotherapy.

We have previously reported that following VP-16 exposure, stromal cell matrix metalloproteinase-2 (MMP-2) protein is reduced (6). This is functionally significant because MMP-2 releases heparin-sulfated proteoglycan bound SDF-1 present on stromal cell surfaces into the extra-cellular matrix (7-10). Subsequently, a chemotactic gradient is established that supports migration of CXCR4 positive hematopoietic cells. This SDF-1 gradient is necessary for hematopoitic progenitor cell recruitment to, and retention within, the bone marrow following transplantation $(11 ; 12)$. In an in vitro model, establishment of the chemotactic gradient was restored by addition of recombinant MMP-2 to VP-16 exposed stromal cells. MMP-2 ${ }^{-/}$bone marrow stromal cell support of chemotaxis of CXCR4 positive cells was also restored by recombinant MMP-2 (6). Based on the role of MMP-2 in regulating SDF-1 availability in the bone marrow microenvironment, it is important to better understand the mechanism by which MMP-2 protein is diminished in stromal cells exposed to VP-16. This study is focused on regulation of translation due to our earlier observations that diminished stromal cell MMP-2 
protein in VP-16 treated stromal cells was not due to reduced mRNA expression, protein stability, or altered secretion (6).

MMP-2 mRNA contains both a high degree of secondary structure and a 5' tract of pyrimidines (5'TOP). These characteristics are consistent with regulation of expression at the level of translation (13). One rate-limiting step in regulation of translation of mRNAs with a high degree of secondary structure is binding of eIF4E to the ribosomal cap. The inhibitor of eIF4E, 4EBP-1, when dephosphorylated, binds to eIF4E preventing interaction with the ribosome, resulting in translational repression (14). Phosphorylated 4EBP-1 interacts less efficiently with eIF4E allowing it to bind to the ribosome with other members of the $40 \mathrm{~S}$ preinitiation complex, eIF4A and eIF4G. Subsequently, translation is initiated (15). Exposure of Swiss $3 \mathrm{~T} 3$ fibroblasts or MCF-7 breast cancer cells to VP-16 has previously been reported to diminish 4EBP-1 phosphorylation and increase binding to eIF4E (16;17), resulting in inhibition of translation of specific mRNAs, including MMP-2.

Another translational regulatory protein, $\mathrm{P} 70^{\mathrm{S} 6 \mathrm{~K}}$, phosphorylates and activates ribosomal protein S6, which binds to the 40 S ribosome and initiates translation of proteins containing a 5'TOP (18;19). VP-16 exposure of 3T3 fibroblasts has been reported by others to decrease $\mathrm{P} 70^{\mathrm{S} 6 \mathrm{~K}}$ activity (16). Therefore, we investigated $\mathrm{P} 70^{\mathrm{S} 6 \mathrm{~K}}$ and $\mathrm{S} 6$ ribosomal protein activity in stromal cells exposed to VP-16. Following VP-16 exposure, we observed diminished phosphorylation of 4EBP-1, $\mathrm{P} 70^{\mathrm{S} 6 \mathrm{~K}}$, and $\mathrm{S} 6$ proteins. Theses observations are consistent with disruption of translation.

As a potential influence on phosphorylation status of $4 \mathrm{EBP}-1$ and $\mathrm{P} 70^{\mathrm{S} 6 \mathrm{~K}}$, phosphatase activity in VP-16 treated bone marrow stromal cells was evaluated. The serine/threonine protein phosphatase, PP2A has been shown to regulate both $4 \mathrm{EBP}-1$ and $\mathrm{P} 70^{\mathrm{S} 6 \mathrm{~K}}$ activity through 
interaction with mTOR $(20 ; 21)$. mTOR sequesters PP2A rendering the phosphatase inactive. Upon release from mTOR, PP2A dephosphorylates serine and threonine residues present on both 4EBP-1 and $\mathrm{P} 70^{\mathrm{S} 6 \mathrm{~K}}$ which are required for translational activation. Inhibition of mTOR by rapamycin in bone marrow stromal cells results in diminished MMP-2 protein. Also, an increase in serine/threonine phosphatase activity was detected in stromal cells exposed to VP-16. However, our data suggest that diminished phosphorylation of 4EBP-1 and P70 ${ }^{\mathrm{S} 6 \mathrm{~K}}$ in VP-16 treated stromal cells was not due to increased PP2A activity.

While this study was prompted by the earlier observation of reduced MMP-2 protein expressed by VP-16 treated stromal cells, the broader goal was to determine if specific translational regulatory proteins are influenced by commonly used chemotherapy. Our data suggest that alteration of translational regulation following drug-induced stress may be one mechanism by which chemotherapy alters the hematopoietic support capacity of the bone marrow microenvironment. Understanding the details of signaling pathways initiated by chemotherapy, distinct from those that drive apoptosis in actively dividing cells, will improve our ability to modulate damage in cells that would ideally be spared from treatment-induced damage. 


\section{MATERIALS AND METHODS}

\section{Cell lines and culture conditions}

P156 and SMD1 stromal cell cultures were initiated from human bone marrow from consenting donors, with approval by the West Virginia University Institutional Review Board, as previously described (1). All primary bone marrow stromal cell cultures were initiated from donors with no previous chemotherapy exposure. Bone marrow stromal cells were maintained in a-MEM supplemented with 10\% fetal bovine serum (Hyclone, Logan, UT), 1\% L-glutamine (GIBCO, Grand Island, NY), 1\% Penicillin/Streptomycin (Sigma, St. Louis, MO), and 0.1\% 2beta-mercapthanol (Sigma, St. Louis, MO). The cloned murine bone marrow stromal cell line S10 was provided by Dr. Kenneth Dorshkind (University of California Los, Angeles). Characterization and maintenance of S10 has been previously described in detail (22).

\section{Chemotherapy and other chemical agents}

Chemotherapy: Etoposide (VP-16, Bristol Laboratories, Princeton, NJ) was stored at $-20^{\circ} \mathrm{C}$ at a concentration of $33.98 \mathrm{mM}$ and diluted in $\alpha$-Modification of Eagles Medium ( $\alpha$-MEM, Gibco, Grand Island, NY) to the indicated concentrations prior to use.

The FRAP/mTOR inhibitor, rapamycin, and the MAP kinase inhibitor, PD98059, were purchased from Cell Signaling Technology (Beverly, MA). The PP2A inhibitor okadiac acid (OA) and $\lambda$-phosphatase were purchased from Sigma (St. Louis, MO).

Confluent bone marrow stromal cells were pre-treated with 10nM OA for 1 hour prior to the addition of VP-16 to cultures as indicated. Stromal cell lysates were incubated with the indicated concentrations of $\lambda$-phosphatase for 30 minutes at $30^{\circ} \mathrm{C}$ in $1 \mathrm{x} \lambda$ protein phosphatase 
buffer (50mM Tris-HCl, pH 7.5, 0.1mM Na 2 EDTA, 5mM dithiothreitol, and 0.01\% BRIJ35) and $2 \mathrm{mM} \mathrm{MnCl} 2$ and subjected to SDS-PAGE to determine if the mobility of 4EBP-1 correlates with phosphorylation.

\section{Antibodies and Western blot analysis}

Rabbit polyclonal anti-4EBP-1, anti-phospho-S6 (Ser235/236), anti-S6, anti-phospho$\mathrm{P}^{\mathrm{S} 6 \mathrm{~K}}$ (Thr389), anti-P70 ${ }^{\mathrm{S} 6 \mathrm{~K}}$, and mouse monoclonal anti-nonmethylated PP2A/c (4B7) were purchased from Cell Signaling Technology (Beverly, MA). Mouse monoclonal anti-MMP-2 antibody was purchased from Calbiochem (San Diego, CA), mouse monoclonal anti-GAPDH from Research Diagnostics Inc., (Flanders, NJ) and polyclonal anti-rabbit $\beta$-actin antibody was purchased from Santa Cruz Technologies (Santa Cruz, CA).

Confluent stromal cells were treated with $25-100 \mu \mathrm{M}$ VP-16 for 1 hour or $100 \mu \mathrm{M}$ VP-16 for 10-180 minutes. Following treatment, stromal cells were lysed in complete cell lysis buffer (CCLB) (50mM Tris-HCl, pH 7.4, 150mM NaCl, 1\% Triton-X-100, 0.25\% Na-deoxycholate, $1 \mathrm{mM}$ EDTA, and $1 \mathrm{mM} \mathrm{NaF}, 1 \mathrm{mM}$ dithiothreitol (DTT), $1 \mathrm{mM}$ phenylmethylsulphonylfluoride (PMSF), $1 \mathrm{mM}$ activated $\mathrm{Na}_{3} \mathrm{VO}_{4}, 1 \mu \mathrm{g} / \mathrm{mL}$ aprotinin, $1 \mu \mathrm{g} / \mathrm{mL}$ leupeptin, and $1 \mu \mathrm{g} / \mathrm{mL}$ pepstatin) on ice for 15 minutes. Following centrifugation at 14,000 rpm for 15 minutes, supernatants were collected and protein concentration was determined using the bicinchoninic acid (BCA) protein assay (Pierce, Rockford, IL). Proteins were resolved on SDS-PAGE gels and transferred to nitrocellulose membranes. Membranes were blocked in TBS $/ 5 \%$ nonfat dry milk/0.1\% Tween20 at room temperature for 1 hour, probed with the indicated primary antibodies, and washed in TBS/0.1\% Tween-20. Following incubation with horseradish peroxidase-conjugated secondary 
antibodies, signal was visualized with enhanced chemiluminescence reagents (Amersham, Pharmacia Biotech, Piscataway, NJ).

\section{Serine/Threonine Protein Phosphatase Activity Assay}

Stromal cells were exposed to the indicated concentrations of VP-16 for 30-180 minutes or the indicated concentrations of rapamycin for 1 hour and cells were lysed in low detergent PP2A Buffer $(0.25 \%$ Nonidet-P 40, 50mM Tris, $\mathrm{pH} 7.4,1 \mathrm{mM}$ PMSF, $10 \mu \mathrm{g} / \mathrm{mL}$ leupeptin, $10 \mu \mathrm{g} / \mathrm{mL}$ aprotinin). $1 \mu \mathrm{g}$ of protein was incubated with $37.5 \mu \mathrm{g}$ phosphopeptide in reaction buffer (50mM imidazole, $\mathrm{pH} 7.2,0.2 \%$ EGTA, $0.02 \%$ 2-ME, and 0.1\% BSA) for 30 minutes at $30^{\circ} \mathrm{C}$ as recommended by the manufacturer. Following incubation, an equal volume of molybdate dye was added and samples were read on a plate reader at 590nM (Biotek Instruments, Inc., Winoski, VT) and analyzed by the $\mathrm{KC}$ junior software.

\section{$P P 2 A / c$ siRNA}

For transient murine PP2A/c small interfering RNA (siRNA) transfection, Lipofectamine 2000 (Invitrogen, Carlsbad, CA) and 100nM nontargeting double-stranded RNA control or PP2A/c knockdown siRNA (Dharmacon, Lafayette, CO) were diluted and combined. S10 were cultured overnight and transfected with $100 \mathrm{nM}$ control or PP2A/c siRNA for 24 hours. Seventytwo hours following transfection, S10 was exposed to $100 \mu \mathrm{M}$ VP-16 for 1 hour. Stromal cell lysates were collected for western blot analyses.

\section{Statistical Analysis}


Stastical analysis was performed using Student's t-test to detect differences among means (SigmaStat Version 9.0 software, SPSS Inc., Chicago, IL). All statistical analyses represent treated samples compared to control levels. Statistically significant differences are indicated by an asterisk. 


\section{RESULTS}

VP-16 disrupts activity of translational regulatory proteins, $S 6, \mathrm{P}^{\mathrm{S} 6 \mathrm{~K}}$, and $4 E B P-1$

Both murine S10 (Fig. 1A) and human bone marrow stromal cells (Figure 1B) display rapid dephosphorylation of 4EBP-1 protein following VP-16 exposure. To confirm that increased mobility of 4EBP-1 correlates with diminished phosphorylation, S10 cell lysates incubated with increasing amounts of lambda phosphatase have three distinct forms of 4EBP-1 labeled $\alpha, \beta$, and $\gamma$, with $\beta$ representing the protein with the highest level of phosphorylation and $\gamma$ representing unphosphorylated 4EBP-1 (Fig. 1C). Phosphorylation of 4EBP-1 is diminished in a concentration dependent manner in both S10 (Fig. 1D) and SMD1 stromal cells (Fig. 1E) exposed to VP-16.

We next evaluated the phosphorylation status of S6 and $\mathrm{P} 70^{\mathrm{S} 6 \mathrm{~K}}$, as an indication of activity. S10 and SMD1 stromal cells exposed to VP-16 have diminished phosphorylation of S6 ribosomal protein that is time and concentration dependent (Figs. 2A-D). Total S6 protein, normalized to $\beta$-actin, was not influenced by identical treatment. VP-16 treated S10 and P156 stromal cells also had decreased phosphorylation of $\mathrm{P} 70^{\mathrm{S} 6 \mathrm{~K}}$ as compared to total $\mathrm{P} 70^{\mathrm{S} 6 \mathrm{~K}}$ and GAPDH which was time and concentration dependent (Figs. 3A-D).

\section{mTOR activity is required for optimal phosphorylation of $4 E B P-1$ and $\mathrm{P}^{\mathrm{S} 6 \mathrm{~K}}$ -}

Based on the observation that VP-16 exposure diminished the phosphorylation of $\mathrm{P} 70^{\mathrm{S} 6 \mathrm{~K}}$, S6, and 4EBP-1 proteins, we next investigated potential upstream regulators that may converge on these targets. Following exposure to rapamycin for 1 hour, SMD1 and S10 stromal cells were evaluated for phosphorylation of $\mathrm{P} 70^{\mathrm{S} 6 \mathrm{~K}}$ and $4 \mathrm{EBP}-1 . \quad \mathrm{P} 70^{\mathrm{S} 6 \mathrm{~K}}$ phosphorylation is abrogated 
following $10 \mu \mathrm{M}$ rapamycin exposure (Fig. 4A), while 4EBP-1 phosphorylation is reduced (Fig. 4B).

\section{Serine/Threonine protein phosphatase activity is rapidly increased following VP-16 exposure}

To determine if VP-16 exposure results in increased phosphatase activity, we evaluated the activity of serine/threonine phosphatases in S10 and SMD1 stromal cells following exposure to VP-16. An increase in serine/threonine phosphatase activity, after 5 minutes of VP-16 exposure, occurred in S10 (Fig. 5A) and SMD1 stromal cells (Fig. 5D). A concentration dependent increase in serine/threonine activity in stromal cells exposed to increasing concentrations of VP-16 was also observed (data not shown). To determine if the serine/threonine phosphatase PP2A is specifically responsible for dephosphorylation of 4EBP-1 and $\mathrm{P} 70^{\mathrm{S} 6 \mathrm{~K}}$ in S10 and SMD1 stromal cells we utilized the PP2A inhibitor okadiac acid (OA) and siRNA specific for the catalytic site of PP2A. Inhibition of PP2A with OA did not blunt the dephosphorylation of 4EBP-1 (Fig. 5B) or P70 ${ }^{\mathrm{S} 6 \mathrm{~K}}$ (Fig. 5C) in stromal cells exposed to VP-16. In addition, inhibition of PP2A expression by siRNA did not block chemotherapy induced dephosphorylation of 4EBP-1 (Fig. 5E) or P70 ${ }^{\mathrm{S} 6 \mathrm{~K}}$ (Fig. 5F).

\section{Stromal cells exposed to rapamycin display diminished MMP-2 protein and increased serine/threonine activity}

To determine whether rapamycin effects on $\mathrm{P} 70^{\mathrm{S} 6 \mathrm{~K}}$ and 4EBP-1 resulted in a downstream effect of reduced MMP-2 protein expression, stromal cells were exposed to either rapamycin, or VP-16 for comparison. Following 6 hours of treatment with either $100 \mu \mathrm{M}$ VP-16, or 10-500nM rapamycin, S10 (Fig. 6A) and SMD1 (Fig. 6B) display diminished MMP-2 protein 
expression by western blot. Additionally we found elevated serine/threonine phosphatase activity following exposure to 10 and $100 \mathrm{nM}$ rapamycin in S10 (Fig. 6C) and P156 (Fig. 6D) stromal cells. 


\section{DISCUSSION}

Bone marrow stromal cells have been demonstrated by several groups to be vulnerable to chemotherapy (1-5), without a loss of viability (1). We and others have identified disruption of several stromal cell proteins which directly correlate with support of hematopoietc cells. One example is diminished MMP-2 protein produced by VP-16 treated stromal cells, coincident with loss of optimal chemotactic support of CXCR4+ hematopoietic cells (6). In the current study we investigated potential mechanisms that may underlie diminished MMP-2 protein expression by evaluating factors which regulate translation.

Translation of proteins in which the RNA contains a high degree of secondary structure is regulated, in part, by 4EBP-1. When phosphorylated, 4EBP-1 cannot bind to, and inhibit, the mRNA cap binding protein eIF4E (14). Following VP-16 exposure, phosphorylation of 4EBP-1 in bone marrow stromal cells is diminished (Fig. 1) which correlates with its ability to inhibit eIF4E, and subsequently translation. In addition to examining phosphorylation of 4EBP-1 by western blot analysis, confocal microscopy was performed to evaluate the cellular distribution of 4EBP-1 and eIF4E in stromal cells exposed to VP-16. In the presence of VP-16, eIF4E and 4EBP-1 demonstrate co-localization in stromal cells, while in untreated stromal cells 4EBP-1 and eIF4E co-localization is less pronounced (data not shown). These data demonstrate that activity of proteins that influence translation are altered in stromal cells exposed to VP-16 as reflected by changes in phosphorylation status and suggested by cellular localization.

In addition to regulation by 4EBP-1, MMP-2 also contains a 5'TOP. RNA that contains a 5'TOP is specifically regulated by $\mathrm{P} 70^{\mathrm{S} 6 \mathrm{~K}}$ and $\mathrm{S} 6$ ribosomal proteins. Both $4 \mathrm{EBP}-1$ and $\mathrm{P} 70^{\mathrm{S} 6 \mathrm{~K}}$ phosphorylation was diminished in stromal cells exposed to VP-16 (Figs. 2 and 3). Both of these 
factors are regulated by mTOR. mTOR has previously been shown to sequester the serine/threonine phosphatase PP2A (21). Binding of PP2A to mTOR renders it inactive and unable to dephosphorylate substrates, including 4EBP-1 and P70 ${ }^{\mathrm{S} 6 \mathrm{~K}}$ (21). Stromal cells exposed to VP-16 display increased serine/threonine phosphatase activity. However, we were unable to identify the specific phosphatase (Fig. 5). Studies that are beyond the scope of the current one will determine the identity of the serine/threonine phosphatase activated in response to VP-16 exposure. Preliminary data utilizing the phosphatase inhibitors OA and fostriecin indicate PP1 is not responsible for dephosphorylation of 4EBP-1 or $\mathrm{P} 70^{\mathrm{S} 6 \mathrm{~K}}$ in VP-16 treated stromal cells (data not shown). Other potential candidates include PP2B or calcineurin which is expressed in all mammalian cells and, PP5, which is also ubiquitously expressed and displays similar structure to PP2A (23).

In addition to increased phosphatase activity following VP-16 exposure, we also investigated altered kinase activity in stromal cells exposed to VP-16 as a potential influence of activity of translational regulatory proteins. MAPK proteins have been reported to phosphorylate and activate 4EBP-1 (24), while the specific kinase for $\mathrm{P} 70^{\mathrm{S} 6 \mathrm{~K}}$ phosphorylation is PDK1 (25). In the current study, the activity, determined by phosphorylation status, of JNK, p38, ERK, or PDK1 was not altered by VP-16 (data not shown). These data collectively suggest that phosphatase activity, in contrast to kinase activity, may be the predominant mediator of the immediate response of bone marrow stromal cells to VP-16 induced stress.

Translation of other stromal proteins that may be influenced by VP-16 include those known to contain 5'TOPs such as ribosomal proteins and elongation factor 1 alpha and $2(26 ; 27)$. Identification of additional 5'TOP containing mRNAs expressed by stromal cells will lend 
further insight into the pathways by which chemotherapy may alter the bone marrow microenvironment.

To specifically evaluate the influence of inhibition of the upstream regulatory factor mTOR, in the absence of the diverse effects of VP-16, we exposed stromal cells to rapamycin. Following exposure to rapamycin, stromal cells display increased serine/threonine phosphatase activity, diminished $\mathrm{P} 70^{\mathrm{S} 6 \mathrm{~K}}$ and 4EBP-1 phosphorylation, and reduced MMP-2 protein expression. These rapamycin-induced effects mirror those of VP-16 treatment. Stromal cell Akt activity was not altered following VP-16 exposure (data not shown), suggesting VP-16 affects a downstream target.

Our data suggest that stromal cells exposed to VP-16 display diminished translation of MMP-2 protein, in part, due to altered activity of the translational regulatory proteins 4EBP-1, $\mathrm{S} 6$, and $\mathrm{P} 70^{\mathrm{S} 6 \mathrm{~K}}$. Understanding the mechanism that underlies disrupted synthesis of stromal cell MMP-2 may serve as a model in which we can investigate chemotherapy induced alterations of stromal cell function in the bone marrow microenvironment. Of note, these data represent chemotherapy induced alterations of stromal cells exposed only to VP-16. While VP-16 was the chemotherapeutic agent most extensively evaluated, translational regulation in stromal cells exposed to the chemotherapeutic agents melphalan and 4HC was also investigated. Melphalantreated stromal cells display diminished phosphorylation of translational regulatory proteins 4EBP-1 and $\mathrm{P} 70^{\mathrm{S} 6 \mathrm{~K}}$, while exposure to $4 \mathrm{HC}$ does not induce alterations in these translational regulatory proteins. These observations suggest that chemotherapeutic agents with distinct modes of action may have specific effects on translation of proteins that subsequently determines their effect on the functional integrity of the cell. 


\section{REFERENCES}

1. Gibson, L. F., Fortney, J., Landreth, K. S., Piktel, D., Ericson, S. G., and Lynch, J. P. (1997) Biol. Blood Marrow Transplant. 3, 122-132

2. Dittel, B. N. and LeBien, T. W. (1995) Blood 86, 2833-2841

3. Gibson, L. F., Piktel, D., and Landreth, K. S. (1993) Blood 82, 3005-3011

4. Hall, B., Fortney, J., and Gibson, L. (2003) Analytical Pharmacology 4, 21-29

5. del, C. C., Lopez, N., Caballero, D., Fernandez, E., Brufau, A., Vazquez, L., Mateos, V., Gutierrez, N., and San Miguel, J. F. (1999) Bone Marrow Transplant. 23, 901-905

6. Clutter, S. D., Fortney, J., and Gibson, L. F. (2005) Exp. Hematol. 33, 1192-1200

7. Gallagher, J. T., Spooncer, E., and Dexter, T. M. (1983) J. Cell Sci. 63, 155-171

8. Drzeniek, Z., Siebertz, B., Stocker, G., Just, U., Ostertag, W., Greiling, H., and Haubeck, H. D. (1997) Biochem. J. 327 ( Pt 2), 473-480

9. Roberts, R., Gallagher, J., Spooncer, E., Allen, T. D., Bloomfield, F., and Dexter, T. M. (1988) Nature 332, 376-378

10. Morris, A. J., Turnbull, J. E., Riley, G. P., Gordon, M. Y., and Gallagher, J. T. (1991) J. Cell Sci. 99 ( Pt 1), 149-156

11. Jo, D. Y., Rafii, S., Hamada, T., and Moore, M. A. (2000) J. Clin. Invest 105, 101-111 
12. D'Apuzzo, M., Rolink, A., Loetscher, M., Hoxie, J. A., Clark-Lewis, I., Melchers, F., Baggiolini, M., and Moser, B. (1997) Eur. J. Immunol. 27, 1788-1793

13. Bradley, J. M., Kelley, M. J., Rose, A., and Acott, T. S. (2003) Invest Ophthalmol. Vis. Sci. 44, 5174-5181

14. Pause, A., Belsham, G. J., Gingras, A. C., Donze, O., Lin, T. A., Lawrence, J. C., Jr., and Sonenberg, N. (1994) Nature 371, 762-767

15. Morino, S., Imataka, H., Svitkin, Y. V., Pestova, T. V., and Sonenberg, N. (2000) Mol. Cell Biol. 20, 468-477

16. Tee, A. R. and Proud, C. G. (2000) Oncogene 19, 3021-3031

17. Jeffrey, I. W., Bushell, M., Tilleray, V. J., Morley, S., and Clemens, M. J. (2002) Cancer Res. 62, 2272-2280

18. Jefferies, H. B., Fumagalli, S., Dennis, P. B., Reinhard, C., Pearson, R. B., and Thomas, G. (1997) EMBO J. 16, 3693-3704

19. Jefferies, H. B., Reinhard, C., Kozma, S. C., and Thomas, G. (1994) Proc. Natl. Acad. Sci. U. S. A 91, 4441-4445

20. Lin, T. A. and Lawrence, J. C., Jr. (1997) Diabetologia 40 Suppl 2, S18-S24

21. Peterson, R. T., Desai, B. N., Hardwick, J. S., and Schreiber, S. L. (1999) Proc. Natl. Acad. Sci. U. S. A 96, 4438-4442

22. Collins, L. S. and Dorshkind, K. (1987) J. Immunol. 138, 1082-1087 
23. Herzig, S. and Neumann, J. (2000) Physiol Rev. 80, 173-210

24. Lin, T. A., Kong, X., Haystead, T. A., Pause, A., Belsham, G., Sonenberg, N., and Lawrence, J. C., Jr. (1994) Science 266, 653-656

25. Pullen, N., Dennis, P. B., Andjelkovic, M., Dufner, A., Kozma, S. C., Hemmings, B. A., and Thomas, G. (1998) Science 279, 707-710

26. Meyuhas, O. (2000) Eur. J. Biochem. 267, 6321-6330

27. Avni, D., Biberman, Y., and Meyuhas, O. (1997) Nucleic Acids Res. 25, 995-1001 


\section{ACKNOWLEDGEMENTS}

This work was supported, in part, by NIH ROI HL056888 (LFG) and NRSA Institutional

Training Grant in Environmental Science ES010953 (SDC). 


\section{FIGURE LEGENDS}

Figure 1. Stromal cell 4EBP-1 phosphorylation is diminished following VP-16 exposure. $A$, S10 and $B$, SMD1 primary human stromal cells were exposed to $100 \mu \mathrm{M}$ VP-16 for $5-180$ minutes and subjected to western blot analysis for 4EBP-1 phosphorylation and GAPDH evaluation. Arrows pointing to $\alpha, \beta$, and $\gamma$ forms of protein indicate phosphorylated 4EBP-1, moderately phosphorylated 4EBP-1, and unphosphorylated 4EBP-1, respecively. $C$, S10 stromal cell lysates were treated with up to $1000 \mathrm{U}$ of $\lambda$-phosphatase for 30 minutes and subjected to western blot for analysis of 4EBP-1 mobility and GAPDH. D, S10 and E, P156 primary human stromal cells were evaluated for phosphorylation of 4EBP-1 and GAPDH following exposure to 25$100 \mu \mathrm{M}$ VP-16 for 1 hour. Data are representative of three independent experiments.

Figure 2. Phosphorylation of stromal cell S6 protein is diminished following VP-16 exposure. $A$ and $B, \mathrm{~S} 10$ or $C$ and $D, \mathrm{SMD} 1$ stromal cells were exposed to $100 \mu \mathrm{M}$ VP-16 for $10-180$ minutes or 25-100 $\mu \mathrm{M}$ VP-16 for 1 hour. Following exposure, cell lysates were subjected to western blot for analysis of phosphorylated S6 (P-S6), total S6 (T-S6), and $\beta$-actin protein as a lane loading control. Representative data from three independent experiments are shown.

Figure 3. Phosphorylated $\mathrm{P} 70^{\mathrm{S} 6 \mathrm{~K}}$ is diminished in stromal cells following VP-16 exposure. $A$ and $B, \mathrm{~S} 10$ and $C$ and $D, \mathrm{SMD} 1$ primary human stromal cells were exposed to either $100 \mu \mathrm{M} \mathrm{VP}-16$ for 10-180 minutes or $25-100 \mu \mathrm{M}$ for 1 hour. Following exposure, cell lysates were collected and subjected to western blot analysis for phosphorylated $\mathrm{P} 70^{\mathrm{S} 6 \mathrm{~K}}\left(\mathrm{P}-\mathrm{P} 70^{\mathrm{S} 6 \mathrm{~K}}\right)$, total $\mathrm{P} 70^{\mathrm{S} 6 \mathrm{~K}}\left(\mathrm{~T}-\mathrm{P} 70^{\mathrm{S} 6 \mathrm{~K}}\right)$, 
and GAPDH. The antibody used in these experiments recognizes both phosphorylated $\mathrm{P} 70^{\mathrm{S} 6 \mathrm{~K}}$ and $\mathrm{P} 85^{\mathrm{S} 6 \mathrm{~K}}\left(\mathrm{P}-\mathrm{P} 85^{\mathrm{S} 6 \mathrm{~K}}\right)$.

Figure 4. mTOR activity is required for phosphorylation of $\mathrm{P} 70^{\mathrm{S} 6 \mathrm{~K}}$ and 4EBP-1 in stromal cells. S10 stromal cells were exposed to either $100 \mu \mathrm{M}$ VP-16 or $1.0-250 \mathrm{nM}$ concentrations of rapamycin for 1 hour. Following exposure, cell lysates were collected and subjected to western blot for analysis of $A, \mathrm{P} 70^{\mathrm{S} 6 \mathrm{~K}}$ and GAPDH or $B, 4 \mathrm{EBP}-1$ and GAPDH. Data are representative of three independent experiments.

Figure 5. Serine/threonine phosphatase activity is rapidly increased in stromal cells exposed to VP-16. $A$, S10 or $D$, SMD1 stromal cells were treated with $100 \mu \mathrm{M}$ VP-16 for 10-180 minutes. Following exposure, stromal cells were lysed, and analyzed for phosphatase activity by a serine/threonine phosphatase specific activity assay. All samples were evaluated in triplicate. An* indicates a significant increase in phosphatase activity. $B$ and $C, \mathrm{~S} 10$ stromal cells were either left untreated or pre-treated with $10 \mathrm{nM}$ of OA for 30 minutes. Following pretreatment, stromal cells were then exposed to $100 \mu \mathrm{M}$ VP-16 for 1 hour. Cell lysates were collected and analyzed for expression of $B, 4 \mathrm{EBP}-1$ and GAPDH or $C, \mathrm{P}-\mathrm{P} 70^{\mathrm{S} 6 \mathrm{~K}}$ and GAPDH. $E$ and $F, \mathrm{~S} 10$ stromal cells were either untreated or transfected with 100nM control or siRNA specific for the catalytic unit of murine PP2A (PP2A/c) for 24 hours. 72 hours after transfection, S10 stromal cells were collected and $E$, PP2A/c, 4EBP-1, and GAPDH protein levels or $F$, PP2A/c, P70 ${ }^{\mathrm{S} 6 \mathrm{~K}}$, and GAPDH were analyzed by western blot. Data are representative of three independent experiments. 
Figure 6. Stromal cells exposed to rapamycin have diminished MMP-2 protein expression and increased serine/threonine phosphatase activity. $A$, S10 or $B$, SMD1 stromal cells were exposed to $10-500 \mathrm{nM}$ rapamycin or $100 \mu \mathrm{M}$ VP-16 for 6 hours. Following treatment, stromal cells were collected and evaluated for expression of MMP-2 and GAPDH by western blot. Data are representative of three independent experiments. $C, \mathrm{~S} 10$ stromal cells and $D, \mathrm{P} 156$ were exposed to $100 \mu \mathrm{M}$ VP-16 for 1 hour. Following treatment serine/threonine phosphatase activity was evaluated as pmol of phosphate released from S10 or P156 cells. An * indicates a significant increase in phosphate activity compared to control. 
Figure 1. Stromal cell 4EBP-1 phosphorylation is diminished following VP-16 exposure.

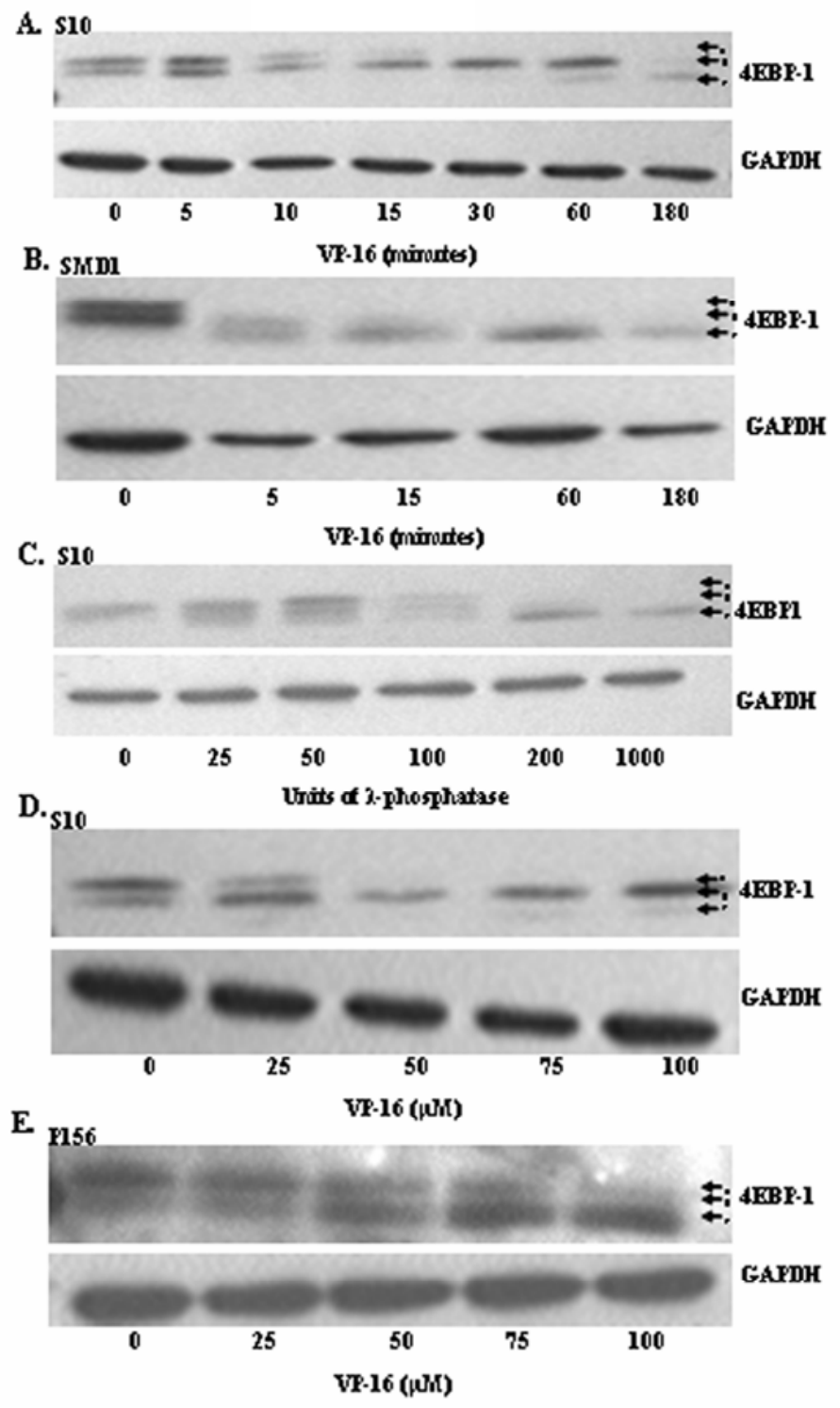


Figure 2. Phosphorylation of stromal cell S6 protein is diminished following VP-16 exposure.
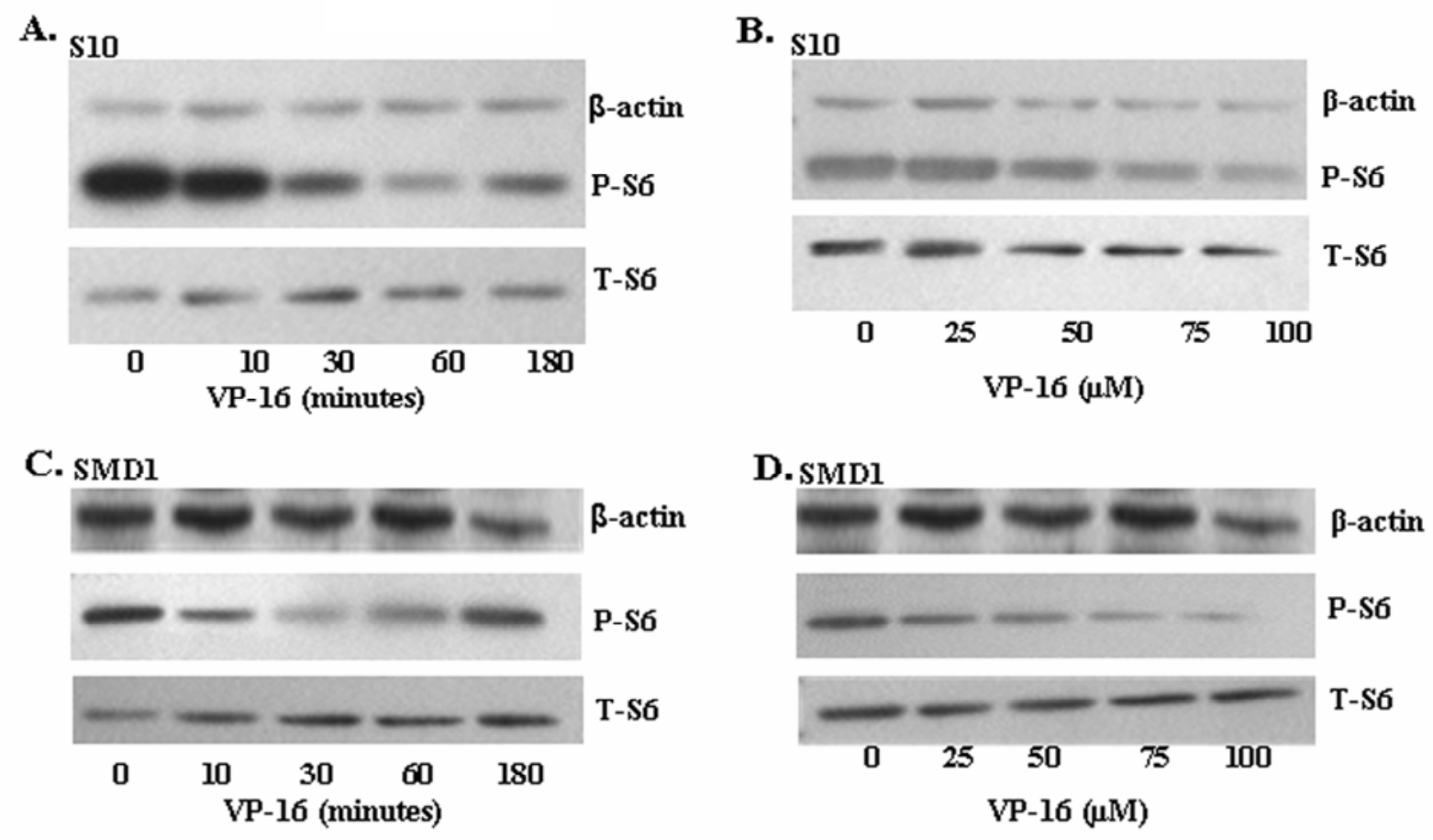
Figure 3. Phosphorylated $\mathrm{P} 70^{\mathrm{S} 6 \mathrm{~K}}$ is diminished in stromal cells following VP-16 exposure.

A.

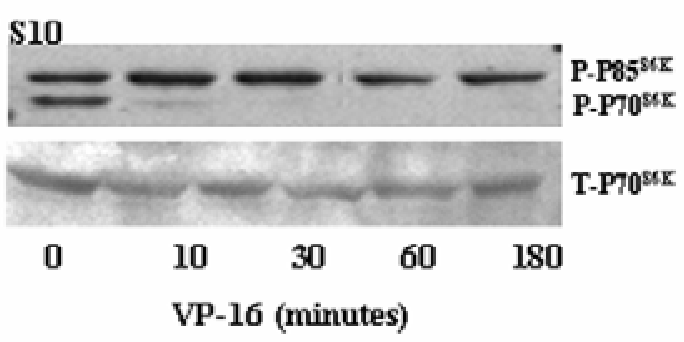

C.

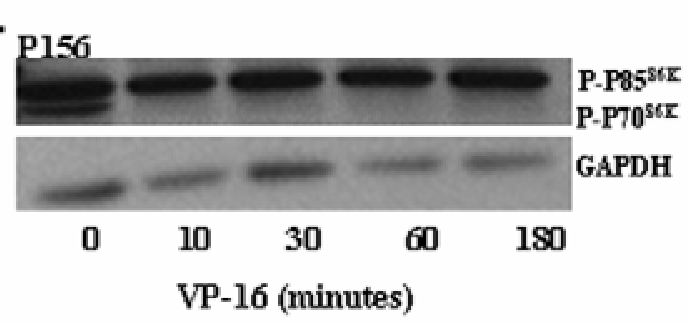

B. $\$ 10$

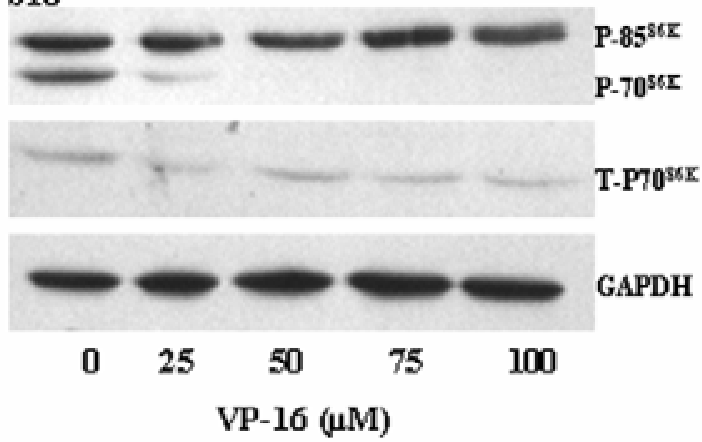

D.
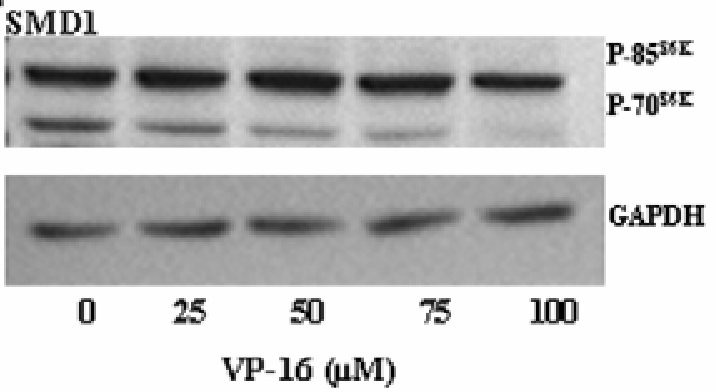
Figure 4. mTOR activity is required for phosphorylation of $\mathrm{P} 70^{\mathrm{S} 6 \mathrm{~K}}$ and $4 \mathrm{EBP}-1$ in stromal cells.

A. $\mathbf{S 1 0}$

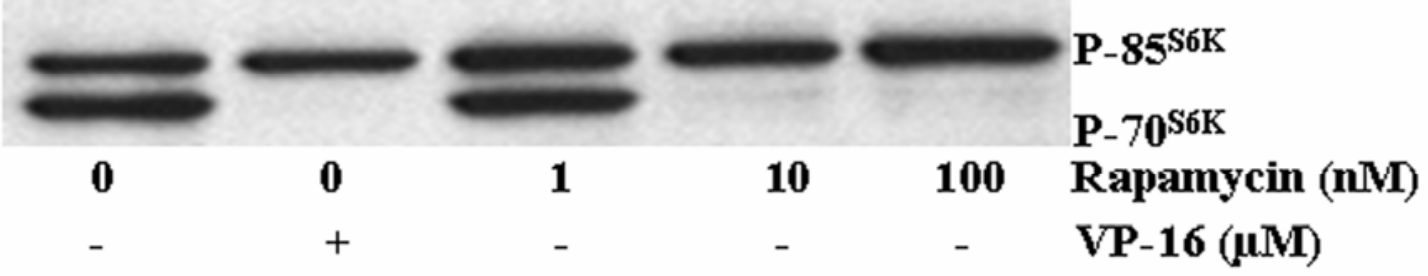

B.

S10

4EBP-1

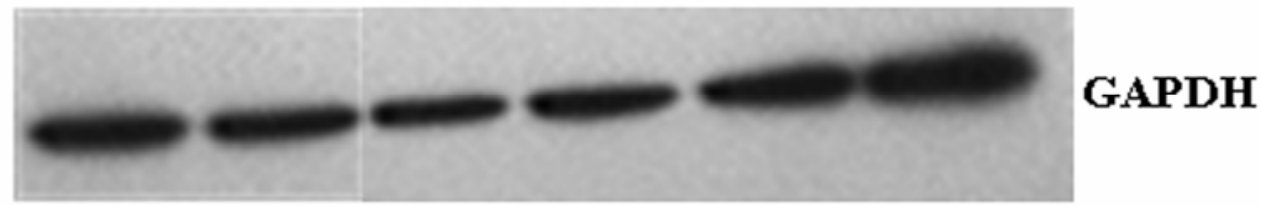

\begin{tabular}{|c|c|c|c|c|c|}
\hline $\mathbf{0}$ & $\mathbf{0}$ & 10 & 100 & 250 & Rapamycin (nM) \\
\hline+ & - & - & - & - & VP-16 $(\mu \mathrm{M})$ \\
\hline
\end{tabular}


Figure 5. Serine/threonine phosphatase activity is rapidly increased in stromal cells exposed to VP-16.

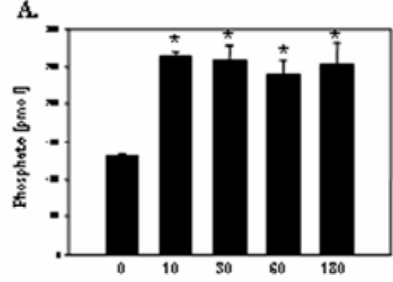

D.

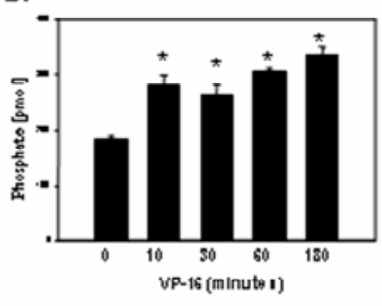

B.
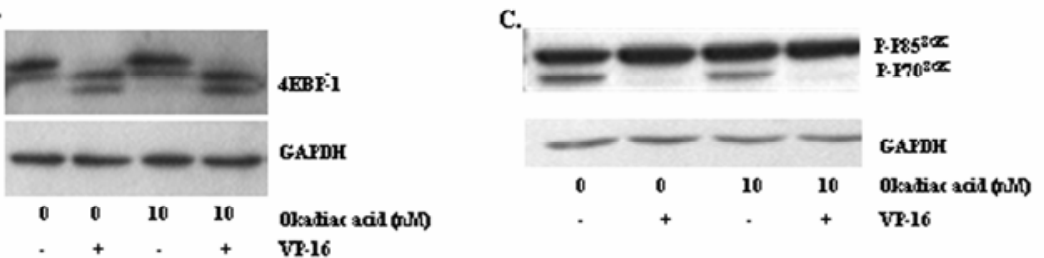

F.

E

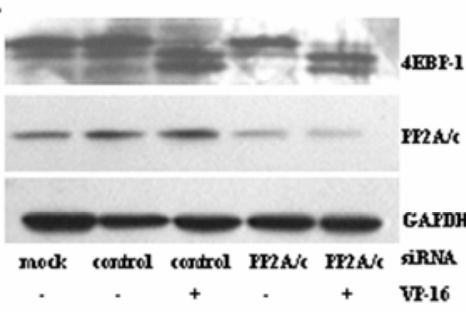

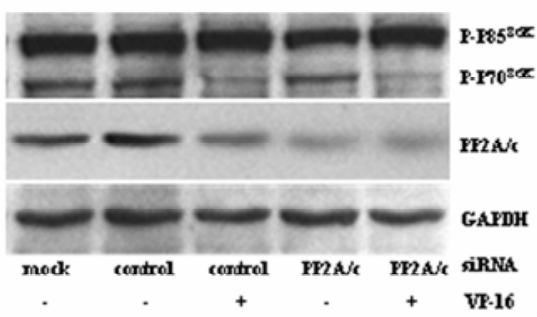


Figure 6. Stromal cells exposed to rapamycin have diminished MMP-2 protein expression and increased serine/threonine phosphatase activity.

A.

S10

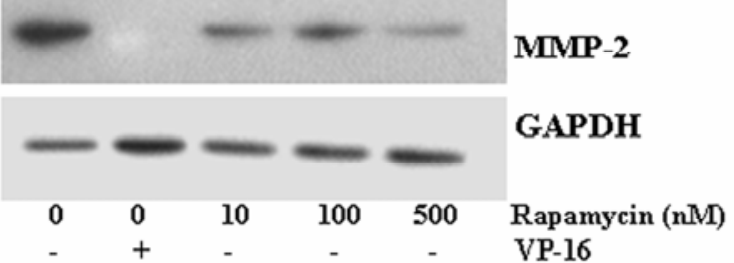

C.

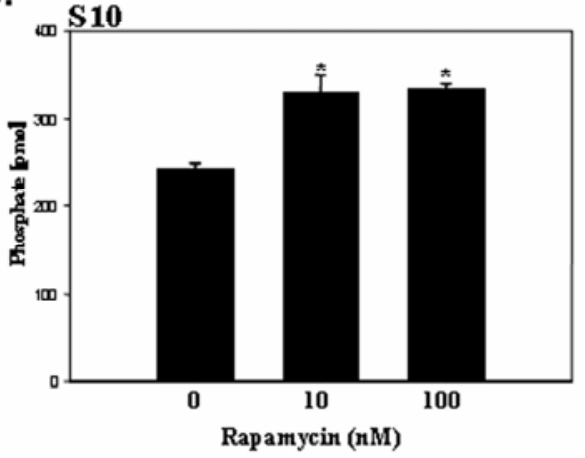

D.
B. SMD1
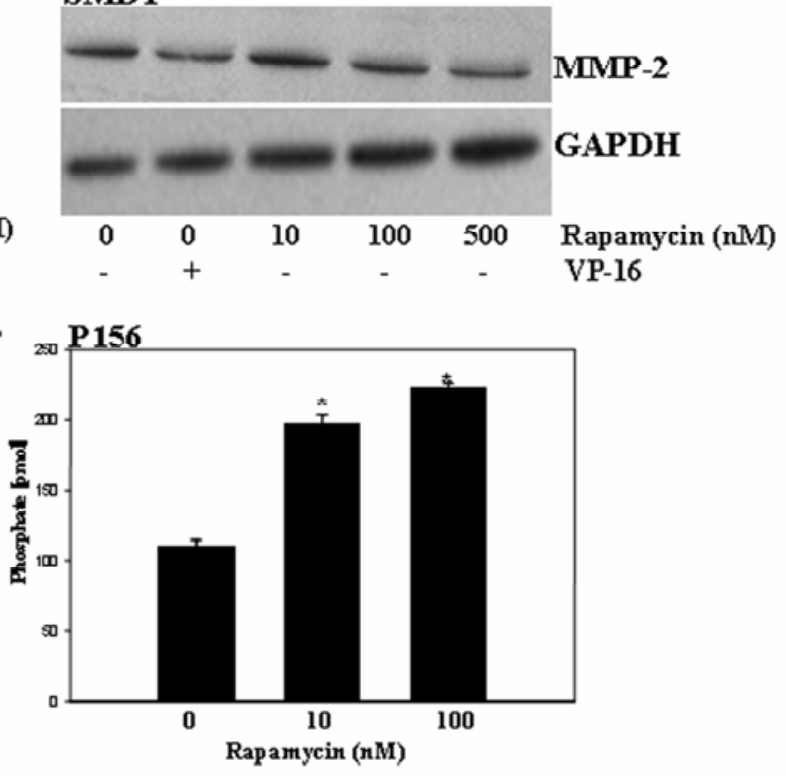


\title{
CHAPTER V
}

\author{
GENERAL DISCUSSION
}


The broad goal our studies was to understand chemotherapy-induced alterations of the bone marrow microenvironment. Specifically, we were interested in understanding mechanisms by which chemotherapy disrupts bone marrow stromal cell support of hematopoietic cell chemotaxis and survival.

To evaluate chemotherapy-induced alteration of the bone marrow microenvironment, we utilized an in vitro co-culture model which includes both primary derived human bone marrow stromal cells and pro-B cells. While stromal cells provide support to developing hematopoietic cells of all lineages $(1 ; 2)$, disruption of stromal cell support of B-lymphopoiesis was our main focus $(3 ; 3 ; 4)$. Therefore, we utilized pro-B cells to evaluate stromal cell function in the presence and absence of chemotherapy.

The major component of our in vitro model, and the focus of our research, are primary human derived bone marrow stromal cells. These cells are isolated from consenting donors who have not been exposed to chemotherapy. Stromal cells were characterized by the ability to support B-cell hematopoiesis, production of soluble SDF-1 (CXCL-12), and expression of surface VCAM-1 (5-7). Evaluation of human-derived bone marrow stromal cells is appealing because it allows for potential extrapolation of our observations to patients, and therefore, theoretically provides clinical relevance to our model of microenvironment damage. Another advantage of using primary stromal cell lines is that we were able to analyze a large number of patient derived stromal cells to determine if stromal cell response to chemotherapy was consistent. While we have found differences in the magnitudes of primary-derived stromal cell response to chemotherapy, the trend in response to chemotherapy was consistent. For example, primary derived stromal cells chronically exposed to chemotherapy display variation in the 
magnitude of MMP-2 reduction, described in Chapter II, however, in all primary cells evaluated MMP-2 production was diminished.

A main goal of this work was to determine the effects of dose-escalated chemotherapy used prior to BMT on stromal cell support of hematopoiesis. Therefore, we evaluated chemotherapeutic agents used to treat patients prior to receiving a BMT. Etoposide, or VP-16, is a topoisomerase-II inhibitor which inhibits DNA synthesis by preventing $\mathrm{S} / \mathrm{G}_{2}$ cell cycle transition (8). While VP-16 is the primary focus of many of the studies described in Chapters II, III, and IV, other chemotherapeutic agents used prior to transplantation were also evaluated. Both melphalan and cyclophosphamide are alkylating agents whose mechanism of action is to add alkyl groups to DNA molecules ultimately preventing DNA repair and RNA synthesis (9). Unlike VP-16 and melphalan, cyclophosphamide is not metabolized in vitro therefore we utilized the metabolite, 4-hydroperoxycyclophosphamide (4HC), in our in vitro stromal cell studies (10). Use of these representative chemotherapeutic agents in our in vitro stromal cell experiments enabled us to gain a better understanding of the direct effects of these agents on stromal cell function.

It is well documented that chemotherapy, including the agents utilized in these studies, initiates apoptosis in actively dividing cells (11-14). However, confluent, stromal cells exposed to chemotherapy do not initiate apoptosis or undergo necrosis. Studies by Gibson et al. demonstrated that non-dividing stromal cells exposed to chemotherapy do not initiate apoptosis, confirmed by DNA laddering experiments and propidium iodide staining (15). Furthermore, chemotherapy can be removed from stromal cell cultures following treatment, and the stromal cells will proliferate when re-plated at a sub-confluence (unpublished observations). For these 
reasons we feel confident that the functional alterations of stromal cells exposed to chemotherapy are not the result of initiation of stromal cell apoptosis.

Establishment of hematopoiesis and recovery of immune function is imperative following a BMT. It has been documented that full immune system recovery of patients following ablative chemotherapy and BMT is approximately one year (16). Bone marrow stromal cell function, measured by CFU-F, in these patients is also disrupted for at least one year (17). In addition to these published reports, observations of breast cancer patients receiving a preparative regimen containing VP-16 displayed delayed hematopoietic reconstitution, even in the presence of exogenous growth factors (unpublished observations). These observations prompted our investigation of the mechanisms by which chemotherapy disrupts stromal cell function as a key regulator of immune reconstitution.

To investigate disrupted stromal cell function, we evaluated proteins produced by stromal cells which have been previously shown to contribute to hematopoietic support. Gibson et al. determined that following VP-16 exposure, murine bone marrow stromal cells display diminished surface VCAM-1 protein (15). Many studies have established a role for VCAM-1 in normal hematopoietic processes including support of hematopoietic development and mobilization and engraftment of transplanted progenitors (18-21). Therefore, diminished stromal cell VCAM-1 expression provides a mechanism by which chemotherapy alters stromal cell function and may impact hematopoietic reconstitution following BMT. Following this initial observation of diminished VCAM-1 expression on murine stromal cells, primary human bone marrow stromal cell lines were also shown to display diminished VCAM-1 expression following VP-16 expression (5). In order to understand the impact of chemotherapy, specifically VP-16, on stromal cell VCAM-1 expression, transcription of VCAM-1 was evaluated in the presence of 
VP-16. Following VP-16 exposure, stromal cells display diminished VCAM-1 mRNA expression which correlated with reductions in nuclear p65, a component of the VCAM-1 transcription factor, NF-kB (5).

In addition to VCAM-1, we have also established that following VP-16 exposure, SDF-1 protein is diminished in stromal cell supernatants (6). As indicated in Chapter I, SDF-1 function is essential for hematopoiesis (22), and data presented in Chapter II determined that alterations in extra-cellular bone marrow stromal cell SDF-1 result in reduced chemotactic support (6). Chemotherapy-induced reduction of SDF-1 may contribute to disrupted hematopoietic reconstitution following BMT, due to an inefficient homing of transplanted cells to bone marrow.

One goal of my work was to identify the mechanism by which extracellular bone marrow stromal cell SDF- 1 protein was diminished following chemotherapy exposure. SDF-1 mRNA and intracellular protein expression were not reduced by chemotherapy (6). Therefore, we investigated SDF-1 release from stromal cell surfaces. MMP-2 is reported to regulate the availability and activity of proteins present in the extracellular matrix, including those involved in regulation of hematopoiesis (7;23-26). Following chemotherapy exposure, MMP-2 protein is diminished in stromal cell supernatants (27). Evidence, summarized in chapter II, suggests that MMP-2 regulates SDF-1 release from bone marrow stromal cell surfaces. Consistent with that observation, bone marrow stromal cells isolated from $\mathrm{MMP}-2^{-/}$mice did not efficiently support chemotaxis. Relevant to our model, recombinant MMP-2 was capable of restoring VP-16 induced disruption of stromal cell chemotaxis (27). These data suggest that following chronic exposure to VP-16, MMP-2 levels may represent a marker for recovery of the microenvironment in patients receiving chemotherapy treatment. 
In addition to the effects of chronic exposure to VP-16, we also evaluated the acute effects of chemotherapy exposure on stromal cell function. MMP-2 activity is increased in stromal cells exposed to VP-16 for 30 minutes and sustained for up to 6 hours. The increase in MMP-2 activity correlated with an increase in reactive oxygen species (ROS), which have been shown to cleave MMP-2's pro-domain resulted in activation of the MMP-2 molecule $(7 ; 28)$. The immediate increase in MMP-2 activity results in activation of TGF- $\beta$ through release from LAP and LTBP (7). Pre-treatment of stroma with recombinant TGF- $\beta$ resulted in diminished stromal cell support of pro-B cell proliferation and adhesion. These data correlate with other published observations implicating TGF- $\beta$ as a negative regulator of hematopoiesis (29-31). Therefore, activation of TGF- $\beta$ by MMP-2 may contribute to disrupted stromal cell support of hematopoiesis following chemotherapy exposure. Furthermore, treatment of stroma with TGF- $\beta$ resulted in alterations in stromal cell phenotype which may contribute to re-modeling of the microenvironment, in addition to the direct effects on stromal cell support of hematopoietic function.

Our next goal was to identify the mechanism by which MMP-2 protein is diminished in stromal cells chronically exposed to chemotherapy. MMP-2 mRNA, secretion, and stability were not altered following chemotherapy exposure. These observations, in conjunction with the previously published reports indicating MMP-2 mRNA contains elements which allow for translational regulation, prompted our investigation of MMP-2 translation during chemotherapy exposure. The eukaryotic initiation factor-4E (eIF-4E) serves as the rate-limiting step for regulation of mRNAs which contain a high degree of secondary structure, as MMP-2 does (32;33). Our studies provide evidence that phosphorylation of the protein which regulates eIF4E activity; 4E-binding protein-1 (4EBP-1) was diminished following VP-16 exposure. 
Inefficient translation of protein is correlated with disrupted phosphorylation of 4EBP-1 $(34 ; 35)$. In addition, we found that the phosphorylation and subsequent activity of $\mathrm{P} 70^{\mathrm{S} 6 \mathrm{~K}}$ and S6 ribosomal proteins were diminished in stromal cells exposed to VP-16. Both P70 ${ }^{\mathrm{S} 6 \mathrm{~K}}$ and S6 regulate that translation of mRNAs that contain a 5'TOP, including MMP-2 (36;37). These data suggest a novel role for VP-16 in the disruption of cellular translational regulatory components. These observations highlight the possibility that other proteins involved in hematopoietic regulation may also be translationally inhibited following chemotherapy exposure.

This study has established that chemotherapy, specifically VP-16, alters regulation of SDF-1, MMP-2, and TGF- $\beta$ proteins which directly contribute to diminished stromal cell support of hematopoiesis. In addition we have identified the mechanisms by which chemotherapy diminishes stromal cell SDF-1 availability, MMP-2 protein expression, and increased TGF- $\beta$ activation. These results identify specific alterations in stromal cell function while also providing novel mechanisms by which chemotherapy disrupts stromal cell function. Finally, the observations elucidated in this study suggest possibilities that may underlie delayed immune reconstitution following BMT.

This work has provided some insight regarding stromal cell function following chemotherapy, but has also led to many more unanswered questions. To determine the contribution of MMP-2 to hematopoietic recovery following BMT, characterization of MMP-2/mice is imperative. Initial characterization of $\mathrm{MMP}-2^{-/-}$by other investigators did not address alterations in hematopoiesis (38). We determined that MMP- $2^{-/-}$bone marrow stromal cells do support C1.92 pro-B cells in culture, in spite of diminished chemotactic support (unpublished observations). Further in vivo characterization of B-cell development will be necessary to identify any specific alterations in B-lymphopoiesis. It should also be noted that MMPs display 
overlapping functions in vivo (39), so potentially absence of MMP-2 may not impact steady-state B-lymphopoiesis. In vitro, we found that MMP-2 has direct impact on stromal cell support of pro-B cell chemotaxis, therefore the physiological role of MMP-2 may be to contribute to homing and migration of transplanted cells to the bone marrow microenvironment through regulation of chemokine gradients as well as migration of hematopoietic cells from fetal liver to the bone marrow during fetal hematopoiesis. Development of an in vivo transplant model will aid in identification of the contribution of MMP-2 to hematopoietic recovery following BMT.

In addition regulation of TGF- $\beta$ and SDF-1, MMP-2 has also been shown to impact other hematopoietic growth factors including IGF-1 (25). To fully understand the consequence of diminished MMP-2 by stromal cells chronically exposed to VP-16, it will be necessary to evaluate the impact on additional hematopoietic factors. The bone marrow stromal cells used in our studies predominately produce MMP-2. However, other cells within the marrow microenvironment express MMPs in addition to MMP-2. Bone marrow endothelial cells, a major component of the microenvironment, produce MMP-9 (40;41). Although stromal cells do not produce this specific MMP, extracellular surface-bound stromal proteins, like SDF-1, are also subject to regulation by MMPs produced by endothelial cells. Identification of the susceptibility of other cell types and proteases, including endothelial cells and MMP-9, to chemotherapy will further our understanding of protease mediated regulation of hematopoiesis.

One novel observation of these studies was the identification that chemotherapy alters stromal cell regulation of MMP-2 translation. Chapter IV summarizes evidence for the chemotherapy-induced disruption of two cell-signaling pathways previously shown to regulate protein translation. The observation that chemotherapy alters translational efficiency of specific mRNAs, provides a strategy for identification of other proteins influenced by chemotherapy 
exposure. A comprehensive analysis of mRNAs which contain a 5'TOP and/or a high degree of secondary structure has not yet been performed. Therefore, it will be important to determine if additional proteins which influence stromal cell function display these characteristics.

VP-16 was the primary chemotherapeutic agent used in these studies, however, incorporation of other chemotherapeutic agents yielded very similar effects on stromal cells. The observations reported in Chapter II regarding diminished stromal cell support of pro-B cell chemotaxis and extracellular SDF-1 following VP-16 exposure, were also consistent in stromal cells exposed to melphalan, and 4HC (unpublished observations). Additionally, discussed in Chapter III, TGF- $\beta$ activation occurred following stromal cell exposure to VP-16, melphalan, and 4HC. These data indicated that chemotherapy-induced disruption of stromal cell function by a variety of agents used clinically may alter the bone marrow microenvironment. It should also be noted that while exposure of stromal cells to these agents all resulted in diminished stromal cell MMP-2 expression, the mechanism by which they disrupt MMP-2 expression is not uniform. VP-16 and melphalan disrupt the regulation of proteins which control the translational efficiency of MMP-2, while stromal cells exposed 4HC did not display alterations in phosphorylation of 4EBP-1 or $\mathrm{P}^{\mathrm{S} 6 \mathrm{~K}}$ (unpublished observation). As such, the effects of specific drugs, or classes of drugs, will need to be carefully evaluated.

Collectively, these data contribute to our understanding of chemotherapy-induced bone marrow microenvironment damage. Specifically, this work has identified mechanisms for stromal cell SDF-1 availability, MMP-2 regulation, and TGF- $\beta$ activation following chemotherapy exposure. Our work has aided in the understanding of how the hematopoietic microenvironment responds to stress, specifically chemotherapy exposure, and subsequently, how this stress-induced damage impacts capacity to support immature B-lineage cells. This 
study improves our appreciation of stromal cells within the bone marrow microenvironment as a vulnerable population to chemotherapy commonly used in the clinical setting. As such, this work impacts how we consider the broad process of hematopoietic recovery following BMT. 


\section{Reference List}

1. Dexter, T. M., Allen, T. D., and Lajtha, L. G. (1977) J Cell Physiol 91, 335-344

2. Whitlock, C. A. and Witte, O. N. (1982) Proc. Natl. Acad. Sci. U. S. A 79, 3608-3612

3. Kurosaka, D., LeBien, T. W., and Pribyl, J. A. (1999) Exp Hematol 27, 1271-1281

4. McGinnes, K., Quesniaux, V., Hitzler, J., and Paige, C. (1991) Exp Hematol 19, 294-303

5. Hall, B. M., Fortney, J. E., and Gibson, L. F. (2001) Biochem. Pharmacol. 61, 1243-1252

6. Hall, B., Fortney, J., and Gibson, L. (2003) Analytical Pharmacology 4, 21-29

7. Wang, L., Clutter, S., Benincosa, J., Fortney, J., and Gibson, L. F. (2005) Stem Cells 23, $1122-1134$

8. Smith, P. and Soutes, S. (1994) Br J Cancer 23, 47

9. ROSS, W. C. (1953) Adv. Cancer Res. 1, 397-449

10. Takamizawa, A., Matsumoto, S., Iwata, T., Tochino, Y., Katagiri, K., and Yamaguchi, K. (1975) J Med. Chem. 18, 376-383

11. Sharkis, S. J., Santos, G. W., and Colvin, M. (1980) Blood 55, 521-523

12. Dyson, J. E., Simmons, D. M., Daniel, J., McLaughlin, J. M., Quirke, P., and Bird, C. C. (1986) Cell Tissue Kinet 19, 311-324

13. Gorczyca, W., Bigman, K., Mittelman, A., Ahmed, T., Gong, J., Melamed, M. R., and Darzynkiewicz, Z. (1993) Leukemia 7, 659-670

14. Walker, P. R., Smith, C., Youdale, T., Leblanc, J., Whitfield, J. F., and Sikorska, M. (1991) Cancer Res. 51, 1078-1085

15. Gibson, L. F., Fortney, J., Landreth, K. S., Piktel, D., Ericson, S. G., and Lynch, J. P. (1997) Biol. Blood Marrow Transplant. 3, 122-132

16. del, C. C., Lopez, N., Caballero, D., Fernandez, E., Brufau, A., Vazquez, L., Mateos, V., Gutierrez, N., and San Miguel, J. F. (1999) Bone Marrow Transplant. 23, 901-905

17. Galotto, M., Berisso, G., Delfino, L., Podesta, M., Ottaggio, L., Dallorso, S., Dufour, C., Ferrara, G. B., Abbondandolo, A., Dini, G., Bacigalupo, A., Cancedda, R., and Quarto, R. (1999) Exp Hematol 27, 1460-1466

18. Kikuta, T., Shimazaki, C., Ashihara, E., Sudo, Y., Hirai, H., Sumikuma, T., Yamagata, N., Inaba, T., Fujita, N., Kina, T., and Nakagawa, M. (2000) Exp Hematol 28, 311-317 
19. Koni, P. A., Joshi, S. K., Temann, U. A., Olson, D., Burkly, L., and Flavell, R. A. (2001) J Exp Med. 193, 741-754

20. Oostendorp, R. A., Reisbach, G., Spitzer, E., Thalmeier, K., Dienemann, H., Mergenthaler, H. G., and Dormer, P. (1995) Br J Haematol 91, 275-284

21. Simmons, P. J., Masinovsky, B., Longenecker, B. M., Berenson, R., Torok-Storb, B., and Gallatin, W. M. (1992) Blood 80, 388-395

22. Nagasawa, T., Hirota, S., Tachibana, K., Takakura, N., Nishikawa, S., Kitamura, Y., Yoshida, N., Kikutani, H., and Kishimoto, T. (1996) Nature 382, 635-638

23. McQuibban, G. A., Butler, G. S., Gong, J. H., Bendall, L., Power, C., Clark-Lewis, I., and Overall, C. M. (2001) J Biol. Chem. 276, 43503-43508

24. McQuibban, G. A., Gong, J. H., Tam, E. M., McCulloch, C. A., Clark-Lewis, I., and Overall, C. M. (2000) Science 289, 1202-1206

25. Fowlkes, J. L., Thrailkill, K. M., Serra, D. M., Suzuki, K., and Nagase, H. (1995) Prog. Growth Factor Res. 6, 255-263

26. Zuo, J., Ferguson, T. A., Hernandez, Y. J., Stetler-Stevenson, W. G., and Muir, D. (1998) J Neurosci. 18, 5203-5211

27. Clutter, S. D., Fortney, J., and Gibson, L. F. (2005) Exp Hematol 33, 1192-1200

28. Rajagopalan, S., Meng, X. P., Ramasamy, S., Harrison, D. G., and Galis, Z. S. (1996) J Clin. Invest 98, 2572-2579

29. Lee, G., Ellingsworth, L. R., Gillis, S., Wall, R., and Kincade, P. W. (1987) J Exp Med. 166, 1290-1299

30. Roberts, A. B., Anzano, M. A., Wakefield, L. M., Roche, N. S., Stern, D. F., and Sporn, M. B. (1985) Proc. Natl. Acad. Sci. U. S. A 82, 119-123

31. Sporn, M. B., Roberts, A. B., Wakefield, L. M., and Assoian, R. K. (1986) Science 233, $532-534$

32. Bradley, J. M., Kelley, M. J., Rose, A., and Acott, T. S. (2003) Invest Ophthalmol. Vis. Sci. 44, 5174-5181

33. Koromilas, A. E., Lazaris-Karatzas, A., and Sonenberg, N. (1992) EMBO J 11, 41534158

34. Pause, A., Belsham, G. J., Gingras, A. C., Donze, O., Lin, T. A., Lawrence, J. C., Jr., and Sonenberg, N. (1994) Nature 371, 762-767

35. Morino, S., Imataka, H., Svitkin, Y. V., Pestova, T. V., and Sonenberg, N. (2000) Mol. Cell Biol. 20, 468-477 
36. Jefferies, H. B., Fumagalli, S., Dennis, P. B., Reinhard, C., Pearson, R. B., and Thomas, G. (1997) EMBO J 16, 3693-3704

37. Jefferies, H. B., Reinhard, C., Kozma, S. C., and Thomas, G. (1994) Proc. Natl. Acad. Sci. U. S. A 91, 4441-4445

38. Itoh, T., Ikeda, T., Gomi, H., Nakao, S., Suzuki, T., and Itohara, S. (1997) J Biol. Chem. 272, 22389-22392

39. Sternlicht, M. D. and Werb, Z. (2001) Annu. Rev. Cell Dev. Biol. 17, 463-516

40. Vande, B., I, Asosingh, K., Allegaert, V., Leleu, X., Facon, T., Vanderkerken, K., Van, C. B., and Van, R., I (2004) Leukemia 18, 976-982

41. Janowska-Wieczorek, A., Marquez, L. A., Matsuzaki, A., Hashmi, H. R., Larratt, L. M., Boshkov, L. M., Turner, A. R., Zhang, M. C., Edwards, D. R., and Kossakowska, A. E. (1999) Br J Haematol 105, 402-411 


\section{Suzanne Davis Clutter}

\section{EDUCATION}

West Virginia Universiy, Morgantown, WV

Doctor of Philosophy, May 2006

Department of Microbiology, Immunology, and Cell Biology, School of Medicine

Advisor: Laura F. Gibson, $\mathrm{PhD}$

Dissertation Title: Chemotherapy Induced Disruption of Stromal Cell Function

West Liberty State College, West Liberty, WV

Bachelor of Science, May 2001

Major: Clinical Laboratory Science/Biotechnology

Minor: Biology

Graduated cum laude

\section{PUBLICATIONS}

S Clutter, J Fortney, L Gibson. 2005. MMP-2 Is Required for Bone Marrow Stromal Cell Support of Pro-B Cell Chemotaxis. Experimental Hematology. 33(10):1192-1200.

Wang, L, S Clutter, J Benincosa, J Fortney, and LF Gibson. 2005. Activation of TGF$\beta 1 / \mathrm{p} 38 / \mathrm{Smad} 3$ signaling in stromal cells requires ROS-mediated MMP-2 activity during bone marrow damage. Stem Cells. 23:93-102.

Hall, BM, JE Fortney, L Taylor, H Wood, L Wang, S Adams, S Davis, LF Gibson. 2004. Stromal Cells Expressing elevated VCAM-1 Enhance Survival of B Lineage Tumor Cells. Cancer Letters. 207:229-39.

\section{ABSTRACTS AND PRESENTATIONS}

Clutter, SD, J Fortney, LF Gibosn. Etoposide Disrupts Translation of MMP-2 in Stromal Cells. American Society of Cell Biology Meeting. San Francisco, CA. December 2005.

Clutter, SD, J Fortney, LF Gibson. MMP-2 Is Required for Bone Marrow Stromal Cell Support of Chemotaxis. WVU Research Day, April 2005 
Clutter, SD, J Fortney, LF Gibson. MMP-2 is Required for Pro-B cell Development. American Society of Matrix Biology $2^{\text {nd }}$ Meeting. San Diego, CA. November 2004.

Clutter, SD J Fortney, LF Gibson. The Role of MMP-2 in Pro-B Cell Development. WVU Research Day, April 2004

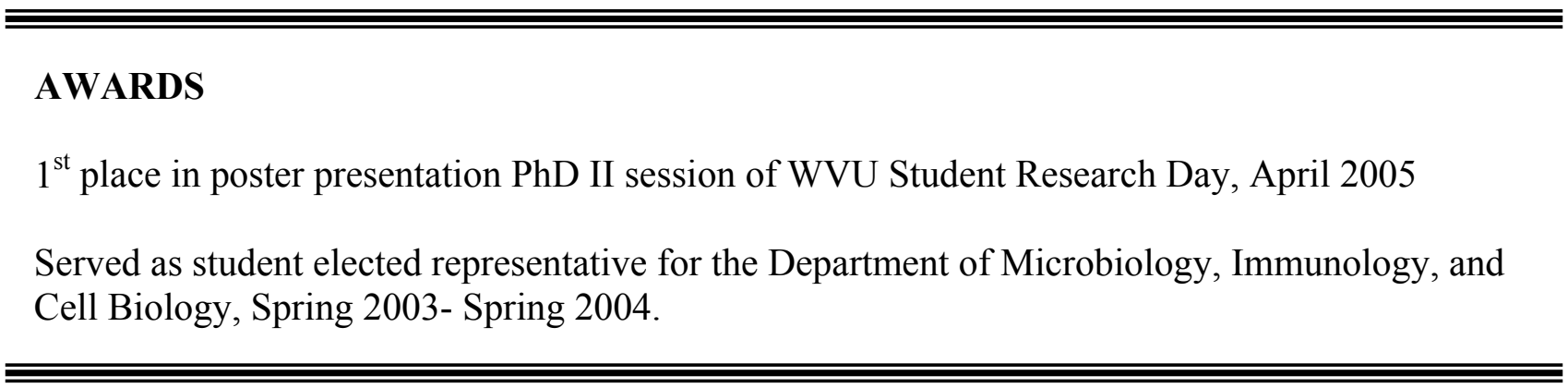

\section{TEACHING EXPERIENCE}

Graduate teaching assistant, January-May 2002. Medical Parisitology.

Graduate teaching assistant, January-May 2003. Medical Microbiology. 